\title{
Nuclear Waste Package \\ Materials Testing \\ Report: Basaltic and \\ Tuffaceous Environments
}
D. J. Bradley
D. G. Coles
F. N. Hodges
G. L. McVay
R. E. Westerman

March 1983

Prepared for the

Office of Nuclear Waste Isolation under U.S. Department of Energy

Contract DE-AC06-76RLO 1830

Pacific Northwest Laboratory

Operated for the U.S. Department of Energy

by Battelle Memorial Institute 


\title{
DISCLAIMER
}

This report was prepared as an account of work sponsored by an agency of the United States Government. Neither the United States Government nor any agency thereof, nor any of their employees, makes any warranty, express or implied, or assumes any legal liability or responsibility for the accuracy, completeness, or usefulness of any information, apparat $\lrcorner$, product, or process disclosed, or represents that its use would not infringe privately owned rights. Reference herein to any specific commercial product, process, or service by trade name, trademark, manufacturer, or otherwise, does not necessarily constitute or imply its endorsement, recommendation, or favoring by the United States Government or any agency thereof. The views and opinions of authors expressed herein do not necessarily state or re lect those of the United States Government or any agency thereof.

\author{
PACIFIC NORTHWEST LABORATORY \\ operated by \\ BATTELLE \\ for the \\ UNITED STATES DEPARTMENT OF ENERGY \\ under Contract DE-AC06-76RLC 1830

Printed in the United States of America Available from

National Technical Information Service United States Department of Commercs 5285 Pont Royal Road Springfield, Virginia 22161

NTIS Price Codes

Microfiche A01

Printed Copy

Pages

001-025

026-050

051-075

076-100

101-125

126-150

$151-175$

176-200

201-225

226-250

251-275

276-300 
PNL -4452

UC -70

NUCLEAR WASTE PACKAGE MATERIALS TESTING REPORT:

BASALTIC AND TUFFACEOUS ENVIRONMENTS
D. J. Bradley
D. G. Coles
F. N. Hodges
G. L. McVay
R. E. Westerman

March 1983

Prepared for the U.S. Department of Energy under Contract DE-AC06-76RLO 1830

Pacific Northwest Laboratory

Richland, Washington 99352 


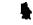

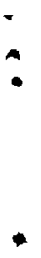




\section{SUMMARY}

The disposal of high-level nuclear wastes in underground repositories in the continental United States requires the development of a waste package that will contain radionuclides for a time period commensurate with performance criteria, which may be up to 1000 years. This report addresses materials testing in support of a waste package for a basalt (Hanford, Washington) or a tuff (Nevada Test Site) repository.

The materials investigated in this testing effort were:

- sodium and calcium bentonites and mixtures with sand or basalt as a backfill

- iron and titanium-based alloys as structural barriers

- borosilicate waste glass PNL 76-68 as a waste form.

The testing also incorporated site-specific rock media and ground waters: Reference Umtanum Entablature-1 basalt and reference basalt ground water, Bullfrog tuff and NTS J-13 well water.

The results of the testing are discussed in four major categories:

- Backfill Materials: emphasizing water migration, radionuclide migration, physical property and long-term stability studies.

- Structural Barriers: emphasizing uniform corrosion, irradiationcorrosion, and environmental-mechanical testing.

- Waste Form Release Characteristics: emphasizing ground water, sample surface area/solution volume ratio, and gamma radiolysis effects.

- Component Compatibility: emphasizing solution/rock, glass/rock, glass/structural barrier, and glass/backfill interaction tests. This area also includes sensitivity testing to determine primary parameters to be studied, and the results of "systems" tests where more than two waste package components were combined during a single test. 
The objective of the first two categories is the selection of candidate materials and development of baseline property information to evaluate material or function lifetimes. The waste form research centers on understanding the basic processes involved with waste form/solution interactions so that a release model can be derived for predicting the radioactive "source-term" arising from waste form/solution contact.

The last area, component compatibility testing, is aimed at learning how waste package materials interact with each other under repository conditions. Information gained from the first three areas is being used to understand the systems interactions revealed by testing in the fourth area. Another purpose of component compatibility testing is, as the name implies, to spot potential problems among materials as early as possible. Data from all four areas are being used to develop a model describing the behavior of the waste package as a whole, under both expected and off-normal conditions. 


\section{CONTENTS}

SUMMARY

INTRODUCTION

CONCLUSIONS.

WASTE PACKAGE MATERIALS TESTING AND EVALUATION................. 7

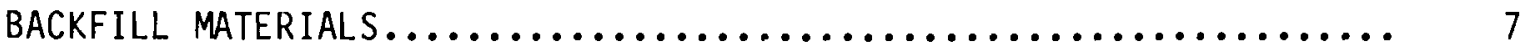

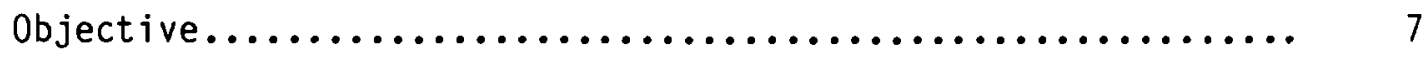

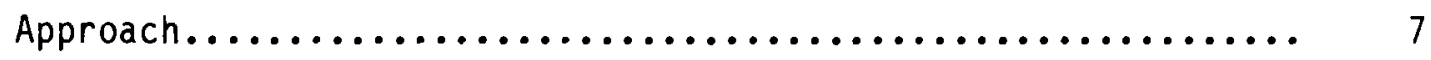

Materials..................................... 8

Results and Discussion........................ in

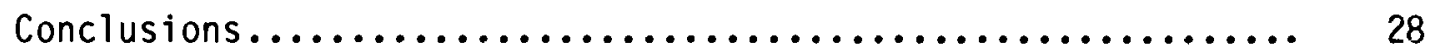

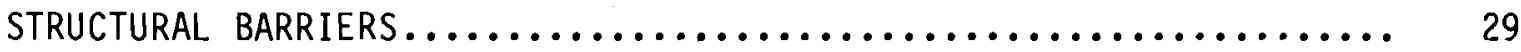

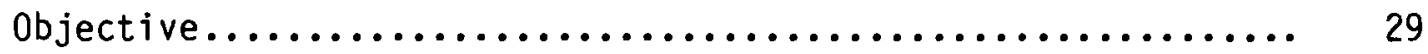

Approach................................... 29

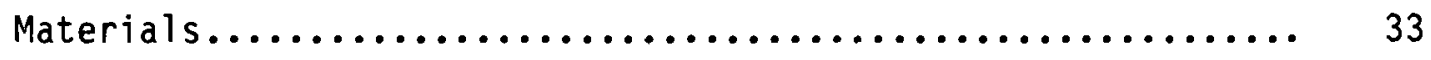

Results and Discussion............................. 35

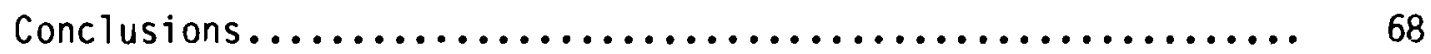

WASTE FORM RELEASE CHARACTERISTICS.................... 69

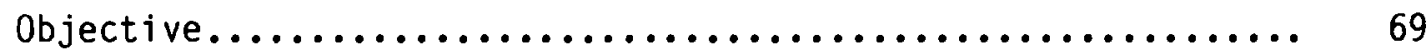

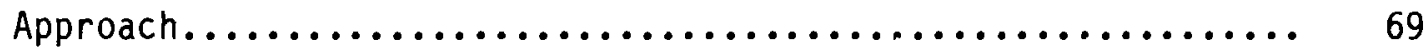

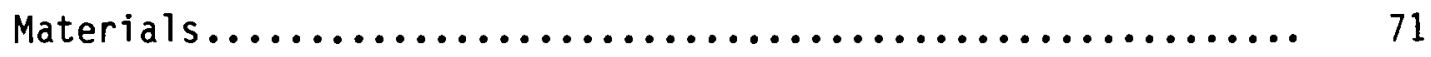

Results and Discussion......................... 71

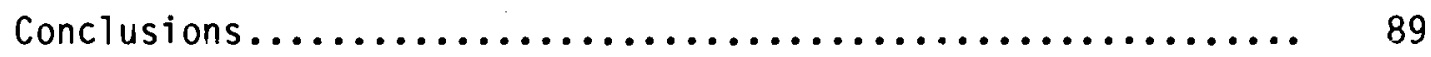

COMPONENT COMPATIBILITY........................... $9 n$

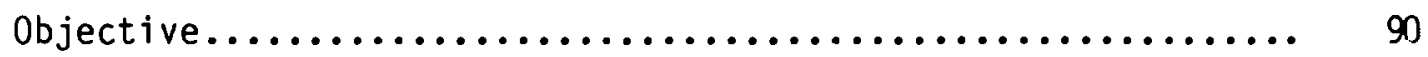


Approach.................................... 90

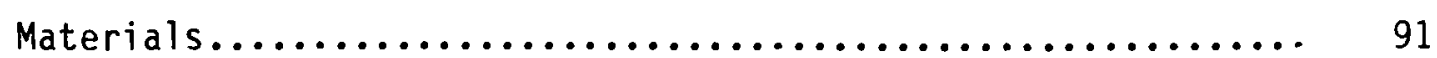

Results and Discussion......................... 92

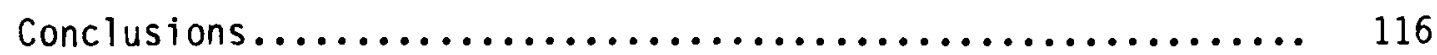

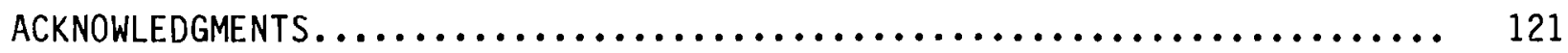

REFERENCES $\ldots \ldots \ldots \ldots \ldots \ldots \ldots \ldots \ldots \ldots \ldots \ldots \ldots \ldots \ldots \ldots \ldots \ldots \ldots \ldots \ldots$ 


\section{FIGURES}

1 Water Content As a Function of Position in Sample for Water Saturation Tests........................................ 12

2 Hydraulic Conductivity As a Function of Density for Compacted Sodium Bentonite............................... 13

3 Hydraulic Conductivity As a Function of Density for Compacted Calcium Bentonite.............................. 14

4 Hydraulic Conductivity As a Function of Density for Sodium Bentonite/Quartz Sand Mixtures...................... 16

5 Thermal Diffusivity As a Function of Temperature for

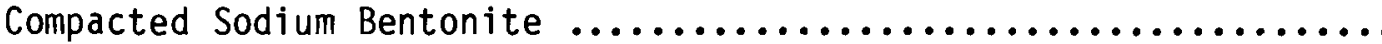

6 Density As a Function of Water Content for Sodium Bentonite at Various Pressures............................. 21

7 Density As a Function of Water Content for 75 wt\% Sodium Bentonite/25 wt\% Quartz Sand Mixture at Various Pressures......... 22

8 Density As a Function of Water Content for 50 wt\% Sodium Bentonite/50 wt\% Quartz Sand Mixture at Various Pressures.......... 23

9 Density As a Function of Water Content for Calcium Bentonite

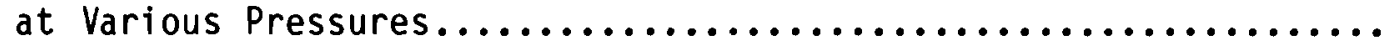

10 Clay Expansion As a Function of Heating Time for Sodium Bentonites Heated at $100^{\circ}, 200^{\circ}$, and $300^{\circ} \mathrm{C}$ under Dry Conditions.... 26

11 Clay Expansion As a Function of Time for Sodjum Bentonite

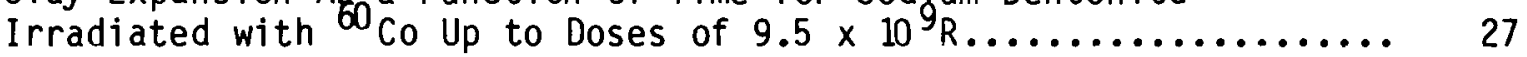

12 Schematic Diagram of Typical Refreshed Autoclave System Used in General Corrosion Study................................

13 The General Corrosion of Cast Ferrous Materials in Basalt Ground Water at $250^{\circ} \mathrm{C}$, Based on Linear Corrosion Kinetics...........

14 The General Corrosion of Cast Ferrous Materials in Basalt Ground Water at $150{ }^{\circ} \mathrm{C}$ and $250^{\circ} \mathrm{C}$ Based on Linear Corrosion Kinetics.......

15 Specimen Weight Loss As a Function of Exposure Time in

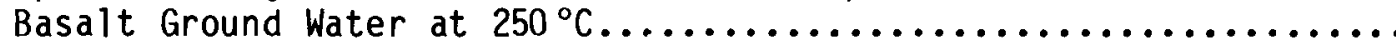

16 Specimen Weight Loss As a Function of Exposure Time in Basalt Ground Water at $250^{\circ} \mathrm{C}$ 
17 Photomicrograph of Cross Section of Corrosion Product Film on Ductile Iron Specimen After 5-Month Exposure in Basalt Ground

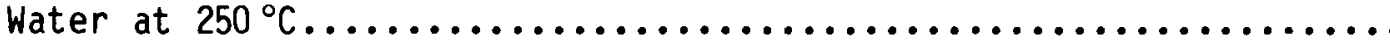

18 The General Corrosion of Cast Ferrous Materials in Tuff Ground Water at $250^{\circ} \mathrm{C}$, Compared to the Rates Found in Basalt Ground Water, Based on Linear Corrosion Kinetics......................

19 The General Corrosion of Cast Ferrous Materials in Deionized Water at $250^{\circ} \mathrm{C}$, Compared to Basalt Ground Water Based on Linear

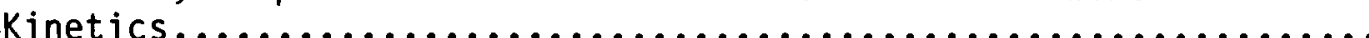

२ Schematic Diagram of Irradiation-Corrosion Test Facility..........

21 The General Corrosion of Two Cast Ferrous Materials in Basalt Ground Water at $250^{\circ} \mathrm{C}$, with and without Radiation, Based on

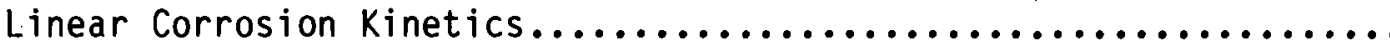

22 Sample Holder Containing Titanium Alloy Specimens for

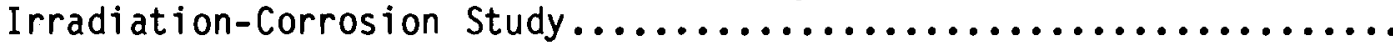

23 Variation of Local Radiation Intensity with Position of

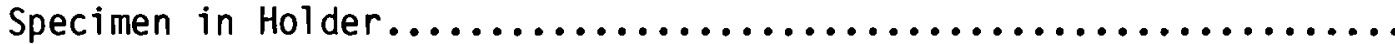

24 Effect of Sample Position on Weight Change Observed.

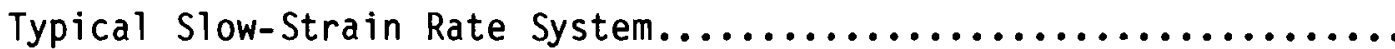

26 Fatigue Crack Growth Rate Test System......................

27 Results of Slow-Strain-Rate Testing of Titanium Grade 2, LT Orientation, in Basalt Ground water and Air at $250{ }^{\circ} \mathrm{C}$

28 Results of Slow-Strain-Rate Testing of Titanium Grade 12, TL Orientation, in Basalt Ground Water and Air at $250^{\circ} \mathrm{C} \ldots \ldots \ldots \ldots \ldots$

29 Results of Slow-Strain-Rate Testing of Titanium Grade 12, TL Orientation, in Basalt Ground Water and Air at $250^{\circ} \mathrm{C} \ldots \ldots \ldots \ldots \ldots$

30 Typical Fracture Surfaces of Titanium Grade 12 Specimens, TL Orientation, Strained to Failure at (a) $10^{-4} / \mathrm{s}$ and

(b) $2 \times 10^{-7} / \mathrm{s}$ in Basalt Ground Water at $250^{\circ} \mathrm{C} \ldots \ldots \ldots \ldots \ldots \ldots . . . .$.

31 Effect of Temperature on Ductility at Constant Strain Rate Slow-Strain-Rate Test Results, Titanium Grade 2, LT Orientation,

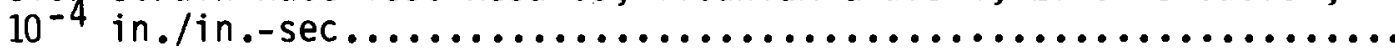

32 Fatigue Crack Growth Rates of Titanium Grade 2, LT Orientation, in High-Fluoride and Normal Basalt Ground Water at $90^{\circ} \mathrm{C} \ldots . . . . .$. 
33 Fatigue Crack Growth Rate of Titanium Grade 12, LT Urientation, in High Fluoride and Normal Basalt Ground Water at $90^{\circ} \mathrm{C} . . . . . . .$.

34 Boron and Cesium Release from PNL 76-68 Glass As a Function

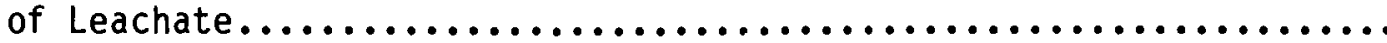

35 Release of Various Elements from PNL $76-68$ Glass at $90^{\circ} \mathrm{C}$ in Deionized water As a Function of $S A / V \ldots \ldots \ldots \ldots \ldots \ldots \ldots \ldots \ldots \ldots$

36 Concentration As a Function of Leaching Time and SA/V for Silicon Release from PNL $76-68$ Glass in $90^{\circ} \mathrm{C}$ Deionized water............. 76

37 Concentration As a Function of Leaching Time and SA/V for Sodium Release from PNL $76-68$ Glass in $90^{\circ} \mathrm{C}$ Deionized Water........

38 Concentration As a Function of Leaching Time and SA/V for Calcium Release from PNL 76-68 Glass in $90^{\circ} \mathrm{C}$ Deionized Water...... 78

39 Effect of SA/V Ratio on Elemental Depletion Depths in PNL 76-68 Glass Leached 14 Days at $90^{\circ} \mathrm{C}$ in Deionized Water.................

40 Dissolution Rate As a Function of Dose Rate for PNL 76-68 Glass

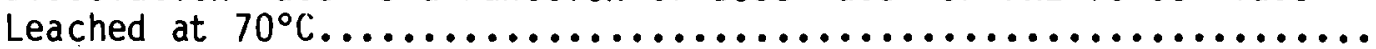

41 Silicon Dissolution Rate As a Function of Reciprocal Temperature for

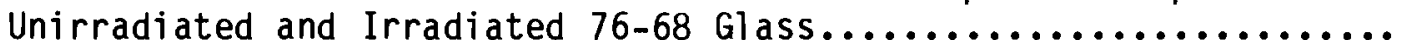

42 Boron Dissolution Rate As a Function of Reciprocal Temperature for Unirradiated and Irradiated $76-68$ Glass.....................

43 Comparison of Radiolysis Effects on Boron Removal from PNL 76-68 Glass in Deionized Water and Basalt Ground Water........

44 Comparison of Radiolysis Effects on Cesium Removal from PNL 76-68 Glass in Deionized Water and Basalt Ground Water.................

45 Concentration of Sodium and Silicon in Fluid Collected at $300^{\circ} \mathrm{C}$ and 300 Bars from Basalt Ground Water and Umtanum Basalt

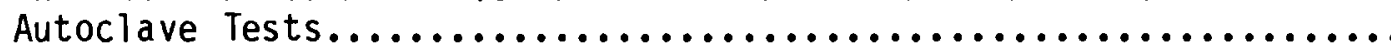

46 Solution pH As a Function of Temperature for Various Glass/Rock

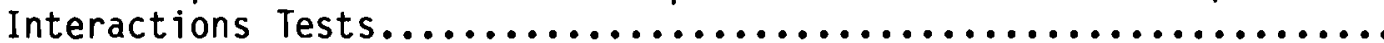

47 Evidence for Low Solubility Reaction Product Formation

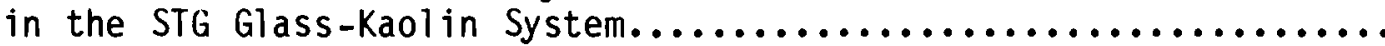

48 Thermal Gradients and Fluid Flow at Repository Conditions.........

49 Relative Intensities of Elements After Migration in Basalt

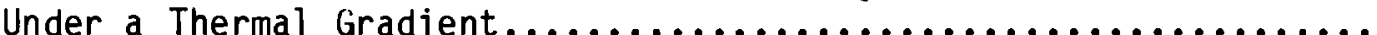


50 Leaching Characteristics of PNL 76-68 Glass: The Effect of Ground Water Composition without Iron Present and the Effect of Having Iron Present During Leaching................... 107

51 PNL 76-68 Glass Reaction Layers After 28-Day Exposures to $90^{\circ} \mathrm{C}$ Deionized Water, Basalt, and Tuff Ground Waters with and without Ductile Iron Present........................... 108

52 Time-Dependent Changes in the Silicon Concentrations of $90^{\circ} \mathrm{C}$ Basalt and Tuff Ground Waters When Exposed to Ductile Iron..........

53 Time Dependent Changes in the Calcium Concentrations of $90^{\circ} \mathrm{C}$ Basalt and Tuff Ground Waters When Exposed to Ductile Iron.........

54 The Effect of Bentonite Clay on the Time Dependent Reaction Layer Thickness of PNL 76-68 Glass in $90^{\circ} \mathrm{C}$ Deionized Water and Basalt

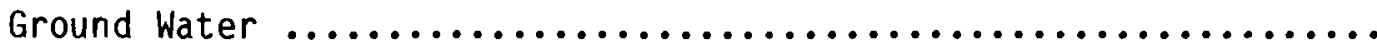

55 Changes in Solution Composition As a Function of Time from

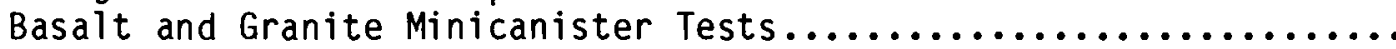

56 Element Segregation in the Reaction Layer of PNL 76-68 Glass During

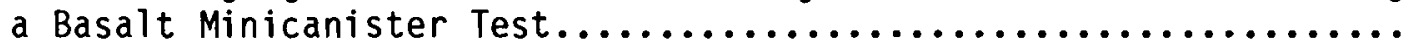


$\underline{\text { TABLES }}$

1 Composition of Basalt Ground Water.......................... 9

2 Composition of Tuff Ground Water from Well J-13,

Jackass Flats, Nevada Test Site ............................ 10

3 Batch Distribution Ratios for Candidate Backfill Materials

in Basalt Ground Water................................. 17

4 Batch Distribution Ratios for American Clay Institute

Source Clays in Basalt Ground Water....................... 18

5 Batch Sorption Distribution Ratios for Candidate Backfill

Materials in Tuff Ground Water ........................... 18

6 Preliminary Thermal Conductivities for Compacted, Air

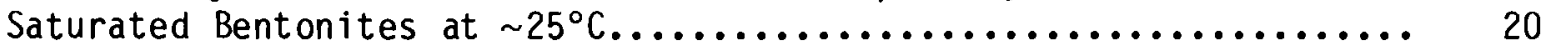

7 Permeability Values for Heat Treated and Irradiated

Na-Bentonite Samples................................. 27

8 Composition of Titanium Alloys with ASTM Nominal

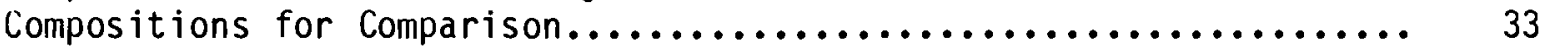

9 Composition of Iron-Base Alloys......................... 34

10 Room Temperature Mechanical Properties of Iron and

Titanium-Based Alloys................................... 34

11 Composition of Umtanum Flow Basalt.......................... 36

12 Composition Range of Welded Silicic Tuff....................... 36

13 Composition of PNL $76-68$ waste Glass........................ 71

14 Primary Radiolytic Species G Values for Gamma and 5 MeV Alpha

15 Gamma-Irradiation Effects on Silicon Leach Rate

from PNL $76-68$ Glass................................... 83

16 Effect of Gamma Radiolysis on Carbonate Waters

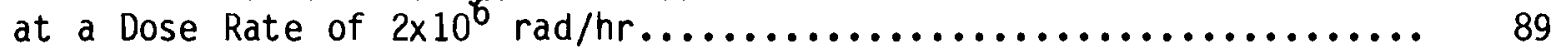

17 Solution Analyses from Basalt and Basalt Ground

Water Autoclave Tests.................................... 94

18 Basalt and Tuff Sensitivity Tests........................... 104 
INTRODUCTION

The National Waste Terminal Storage program (NWTS) of the U.S. Department of Energy is responsible for identification and exploration of three candidate geologic repository sites. Basalt deposits underlying the Hanford Site, tuff deposits on the Nevada Test Site, and a yet-to-be-determined salt site are considered the primary repository candidates. In each case, the waste form would be enclosed in a waste package incorporating one or more of the following elements: canister, overpack, and backfill.

The design of a waste package depends on the criteria which it must meet and the geochemical environment in which it is to be placed. Both the criteria and the environment must be considered in determining the components required to make up the package, the functions those components are to perform, and the materials of which the components are to be made.

Although regulatory criteria for the package have not yet been promulgated, most criteria statements center on two issues: one, a containment requirement which may extend for as much as 1,000 years; and, two, a requirement for slow release of radionuclides thereafter.

To meet these requirements, three types of package components have been considered: 1) a solid, high durability waste form which is resistant to ground water attack and limits the rate of release of radionuclides, 2) a strong corrosion-resistant structural barrier, which may be the waste form container and an additional "overpack," which functions to protect the waste form from ground water attack for some period of time, and 3) a "backfill" barrier which is expected to function primarily to limit ground water flow into the package and then, when the canister is breached, to slow radionuclide release by providing some retardation of radionuclides within the backfill and limiting outward flow.

A large number of candidate materials have been screened down to a relatively few candidates and backup materials which show promise of meeting the assigned functional requirements of package components. The information gained from testing to date has helped determine current waste package conceptual designs and materials selected for each repository type. Further materials 
testing under site specific conditions will help refine conceptual designs as well as help build the best scientifically defens ble model for predicting waste package behavior for use in the licensing process.

The geologic and geochemical conditions among the prime repository rock media are sufficiently different so that some variation in materials and component choices are dictated. For this reason the common NWTS technology program, which brought us to the current stage of waste package materials testing, will be incorporated into three separate site-specific programs starting in $F Y$ 1983. This report describes the current status and conclusions from waste package testing of the prime waste package matericils relevant to a basalt or tuff repository as funded through FY 1982 by the office of Nuclear Waste Isolation for the Department of Energy. 
CONCLUSIONS

The waste package materials testing efforts in basalt and tuff repository media have yielded several conclusions to date. Each section in this report discusses the conclusions that can be made and the research that supports them. To summarize the results from each of the sections, the following key conclusions can be drawn:

- Batch sorption studies using sodium and calcium bentonite in basalt and tuff ground waters indicate strong retardation of strontium, cesium, americium, and moderate retardation of uranium and neptunium.

- Movement of water through clay compacts takes place by two distinct mechanisms: 1) relatively rapid diffusion, and 2) much slower permeation (Darcian flow) of liquid water through the clay.

- Permeability tests indicate no significant differences between basalt and tuff ground water for sodium bentonite. Permeabilities measured for both sodium and calcium bentonites are small enough that diffusion of radionuclides, not the rate of radionuclide transport resulting from water movement, is expected to be the controlling mechanism for radionuclide release through a backfill media.

- Based on six-month corrosion data in oxic basalt ground water at 250 and $150^{\circ} \mathrm{C}$, and the assumption of linear corrosion kinetics (a conservative assumption as the corrosion rates are expected to decrease with time), it would appear that cast iron, or cast steel, can be employed as a basalt repository waste package structural barrier with a 1000-year corrosion allowance of only $\sim 1 / 2 \mathrm{in}$. However, this conclusion must be tempered by the three-month, $250^{\circ} \mathrm{C}$ basalt ground water irradiation-corrosion data, which shows a corrosion allowance requirement of $\sim 1$ in. Until the situation is better understood, a conservative approach would necessitate a 1-in. corrosion allowance. 
- Irradiation-corrosion studies of Titanium Gräde 2 and Grade 12 in $250^{\circ} \mathrm{C}$ basalt ground water show that the corrosion of either of these alloys is not significant from a waste packagle design standpoint. The corrosion of the Grade 2 alloy is affected by radiation to a much greater extent than the Grade 12 material after a three month exposure: $40 \mathrm{mil} / 1000 \mathrm{yr}$ for Titanium Grade 2 , and $2 \mathrm{mil} / 1000 \mathrm{yr}$ for Titanium Grade 12.

- The environmental enhancement of crack growth in Titanium Grade 2 and Grade 12 have not yet been positively observed in any environment to which these materials have been exposed: U-bend and bolt-loaded compact tension specimens in irradiated basalt ground water at $250^{\circ} \mathrm{C}$, tensile specimens in slow-strain-rate tests in basalt ground water to $300^{\circ} \mathrm{C}$, and compact tension specimens in normal and fluoride-enhanced basalt ground water fatigue-crack-growth-rate tests at $90^{\circ} \mathrm{C}$. It can, therefore, be concluded that these materials would be expected to show an extremely high resistance to stress corrosion cracking in a basalt repository environment.

- Ground waters alone decrease elemental release from PNL 76-68 waste glass in proportion to the amount of silicon that they contain.

- Increasing the sample surface area to soluticn volume ratio (SA/V) may be used to accelerate glass leach testing as it pertains to solution concentrations, since leaching appears to be controlled by the silicon concentration in solution.

- Inclusion of ductile iron in leach tests with deionized water, basalt, or tuff ground waters eliminates the compositional effect of the leachate, i.e., all of the leachates behave the same. The ductile iron enhances (about a factor of 5) leaching from PNL 76-68 glass by removing elements from solution through precipitate formation; some of these precipitates are colloidal in nature. 
- Inclusion of Titanium Grade 12 in PNL 76-68 glass leaching experiments in deionized water shows little or no effect on leaching, but in basalt ground water it shows enhanced leaching due to silicate precipitation on the Titanium Grade 12 surface. 


\section{WASTE PACKAGE MATERIALS TESTING AND EVALUATION}

BACKF ILL MATERIALS

Objective

The objective of backfill development work is to select, characterize, and recommend materials for use as part of a high-level nuclear waste package for use in a repository in tuff or basalt.

Approach

The technical approach followed in the backfill development effort consists of four major elements:

- Water migration studies, including permeability and saturation studies

- Radionuclide migration studies

- Physical property determinations

- Materials stability studies.

Water migration studies are important because transport in or through an aqueous phase is the only reasonable mechanism of radionuclide release from a repository. Permeability tests determine how rapidly water will move through a waste package in the long term, after saturation of the repository. Ideally this movement will be so slow that radionuclde transport is limited to diffusion through the interstitial aqueous phase. Saturation studies address the problem of how long it will take a waste package to resaturate when water reenters after the initial period of dehydration.

Radionuclide migration studies are important because sorption of radionuclides on backfill material will significantly slow (retard) their rate of migration and in many cases will significantly extend the time to release from the waste package. Batch sorption studies to determine distribution ratios (Rd) for radionuclides in ground waters onto candidate backfill materials is a useful means of screening materials for their ability to retard the migration of radionuclides out of the waste package. 
Physical property determinations are important because the physical properties of a backfill are vital to its other functions. Compressibility and mechanical strength are of importance in determining emplacement techniques and to what degree the backfill will mechanically support the containerized waste. The thermal conductivity of the backfill will, in many cases, play a major role in determining maximum temperatures and temperature profiles within the waste package.

Materials stability studies are important because the backfill must survive in a reasonably intact state long enough to carry out its major functions of controlling water movement through and radionuclide release from the waste package. Stability studies can be conveniently divided into two categories. One is tests under dry conditions to determine the upper temperature limits during the early high-temperature phase when the backfill will be dehydrated. The other is hydrothermal testing to determine the long-term stability of the backfill materials in the period after resaturation of the repository. Included in these studies were tests performed to determine the effect of gamma radiation on bentonite permeability and swelling potential.

This study did not directly address emplacernent techniques for backfills; however, we recognize the importance of this technology to the ultimate use of backfills in a repository. Our determinations on the compaction properties of bentonites are a first step toward determining the feasibility of emplacing backfill.

Materials

The two principal bentonites used in these studies were natural untreated bentonite (CS-50) and calcium bentonite (Panther Creek), both provided by the American Colloid Company. X-ray diffraction data for CS-50 bentonite indicates that it is sodium montmorillonite with 5-10 wt\% of impurities, principally feldspar and quartz. X-ray diffraction of Panther Creek bentonite indicates that it is calcium bentonite with 10-15 wt\% impurities, principally feldspar, quartz and calcite. 
The composition of the reference basalt ground water used is given in Table 1. The ground water is made up to simulate the water contained in the aquifer lying just beneath the proposed Hanford Site repository horizon (Wood 1980).

The composition of the tuff ground water used in the study is given in Table 2. This ground water was obtained directly from well J-13, Jackass Flats, Nevada Test Site. The J-13 well water composition noted in Table 2 may or may not correspond closely to the composition of the water occurring within the specific, yet-to-be-selected tuff repository location, but it is considered to be reasonably typical of the ground waters in the region. (An independent PNL analysis of the J-13 well water obtained for use in the corrosion studies was in substantial agreement with the results shown in Table 2).

TABLE 1. Composition of Basalt Ground Water (Wood 1980)

\begin{tabular}{lc} 
Chemical Species & Concentration, $\mathrm{mg} / \mathrm{L}$ \\
\cline { 2 - 2 } $\mathrm{Na}^{+}$ & 250 \\
$\mathrm{~K}^{+}$ & 1.9 \\
$\mathrm{Ca}^{+2}$ & 1.3 \\
$\mathrm{Mg}^{+2}$ & 0.40 \\
$\mathrm{CO}_{3}{ }^{-2}$ & 27 \\
$\mathrm{HCO}_{3}^{-}$ & 70 \\
$\mathrm{OH}^{-}$ & 1.4 \\
$\mathrm{H}_{3} \mathrm{SiO}_{4}^{-}$ & 103 \\
$\mathrm{Cl}^{-}$ & 148 \\
$\mathrm{SO}_{4}^{-2}$ & 108 \\
$\mathrm{~F}^{-}$ & 37 \\
$\mathrm{pH}^{-2}=9.8$ to 10 &
\end{tabular}


TABLE 2. Composition of Tuff Ground Water from Well J-13, Jackass Flats, Nevada Test Site (Wolfsberg et al. 1981, Winograd 1971) (a)

\begin{tabular}{cc} 
Constituent & Concentration \\
\hline $\mathrm{Li}$ & 1.05 \\
$\mathrm{Na}$ & 51 \\
$\mathrm{~K}$ & 4.9 \\
$\mathrm{Mg}$ & 2.1 \\
$\mathrm{Ca}$ & 14 \\
$\mathrm{Sr}$ & 0.05 \\
$\mathrm{Ba}$ & 0.003 \\
$\mathrm{Fe}$ & 0.04 \\
$\mathrm{Al}^{2}$ & 0.03 \\
$\mathrm{Si}_{2}$ & 61 \\
$\mathrm{~F}^{-}$ & 2.2 \\
$\mathrm{Cl}^{-}$ & 7.5 \\
$\mathrm{CO}_{3}^{-2}$ & 0.0 \\
$\mathrm{HCO}_{3}^{-}$ & 120 \\
$\mathrm{SO}_{4}^{-2}$ & 22 \\
$\mathrm{NO}_{3}^{-}$ & 5.6 \\
$\mathrm{PO}_{4}^{-3}$ & 0.12
\end{tabular}

(a) The $\mathrm{pH}$ of the ground water is slightly basic (7.1); Eh is mildly reducing.

Results and Discussion

Water Migration

Water migration studies can be divided into two parts: 1) study of the rate and mechanisms of the initial hydration of a backfill, and 2) study of the rate at which water will move through a saturated backfill.

Initial water saturation tests have been carried out in permeability cells with cylinders of $\mathrm{Na}$-bentonite compacted to densities of approximately $2.1 \mathrm{~g} / \mathrm{cm}^{3}$. The fluid used in all of these tests was reference basalt ground water. The clay cylinders were kept under a water pressure of $15 \mathrm{MPa}$ 
(2200 psi) for predetermined periods of time. At the end of each test the clay cylinders were sectioned into disks and the water content of each disk determined. Several initial tests (up to 28 days) were carried out with $3 \mathrm{~cm}$ samples; however, all subsequent tests have been carried out with compacted clay cylinders approximately $5 \mathrm{~cm}$ in length. The results of saturation tests with $5 \mathrm{~cm}$ clay compacts, for times between 4 hours and 42 days, are presented in Figure 1. The form of the water concentration profiles indicates that water is moving into the clay by a diffusion process. The mechanism of diffusion transport has not been determined; however, vapor diffusion or some type of surface diffusion appear the most likely candidates.

Although water diffuses rapidly into compacted bentonite, the movement of liquid water through thick clay compacts is a much slower process. Water can be forced through a thin sample rather quickly. The breakthrough of liquid water requires only 5 to 6 days for a $\mathrm{Na}$-bentonite compact $0.5 \mathrm{~cm}$ thick and only 12 to 14 days for a Na-bentonite compact approximately $1 \mathrm{~cm}$ thick. However, a Na-bentonite compact $\left(p \sim 2.2 \mathrm{~g} / \mathrm{cm}^{3}\right) 2 \mathrm{~cm}$ in thickness was kept under water pressure (15 MPa) for 373 days without breakthrough of liquid water. Furthermore, sectioning and determination of water contents atter the test indicate that the liquid water front had only moved approximately $0.5 \mathrm{~cm}$ into the sample during the course of the test. The swelling pressure developed in the $2 \mathrm{~cm}$ sample during the test was approximately $72 \mathrm{MPa}$, considerably greater than the applied water pressure. It may well be that these conditions, in relatively thick samples, will stop the migration of liquid water entirely.

Hydraulic conductivities of $\mathrm{Na}$-bentonite and $\mathrm{Ca}$-bentonite are plotted as a function of pressed density $\left(\sim 5\right.$ wt $\left.\% \mathrm{H}_{2} \mathrm{O}\right)$ in Figures 2 and 3 . These plots (which include only data from tests where the initial load cell reading was approximately $100 \mathrm{lb}$; this pressure was used to hold the apparatus together) clearly indicate the very low permeabilities of both $\mathrm{Na}$ - and Ca-bentonites and the well defined increase in hydraulic conductivity with decreasing density for both clays.

Two permeability measurements (Figures 2 and 3 ) have been carried out with tuff ground water ( $\mathrm{J}-13$ we11, Nevada Test Site). The two measurements, one for compacted $\mathrm{Na}$-bentonite and one for compacted Ca-bentonite, are 


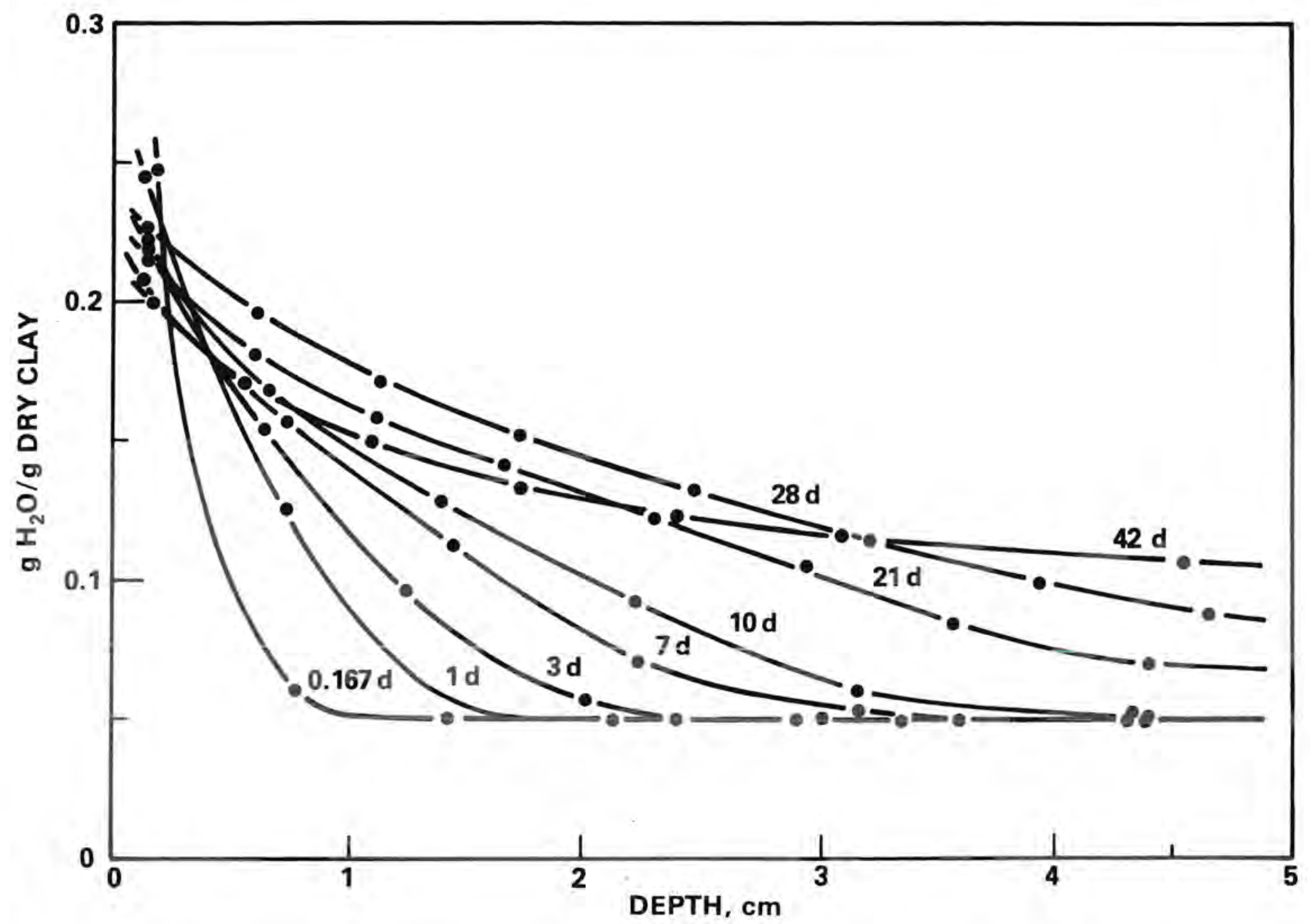

FIGURE 1. Water Content As a Function of Position in Sample for Water Saturation Tests (sample length $\cong 5 \mathrm{~cm}, \rho \cong 2.1 \mathrm{~g} / \mathrm{cm}^{3}$ ) 


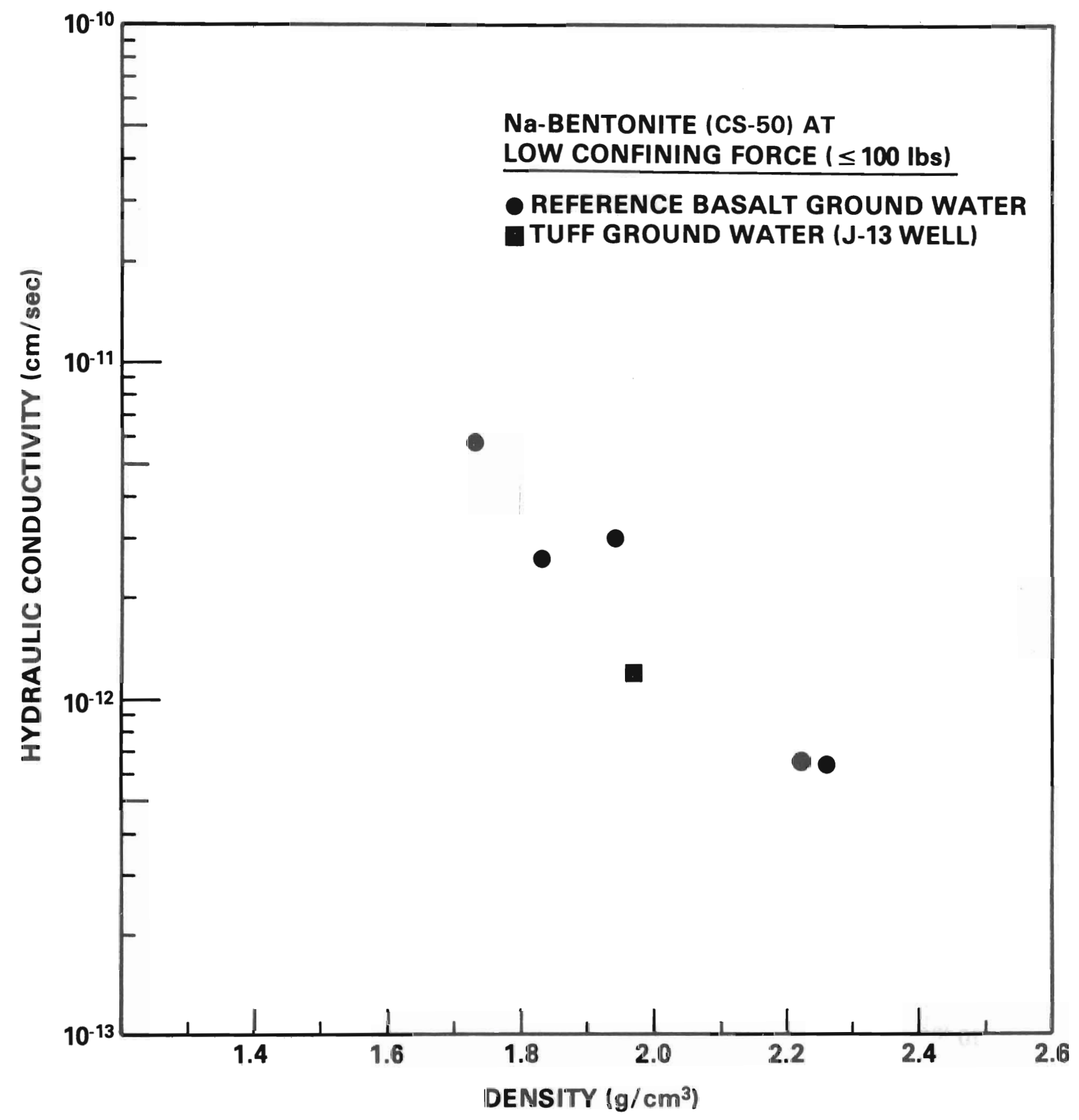

FIGURE 2. Hydraulic Conductivity As a Function of Density for Compacted Sodium Bentonite 


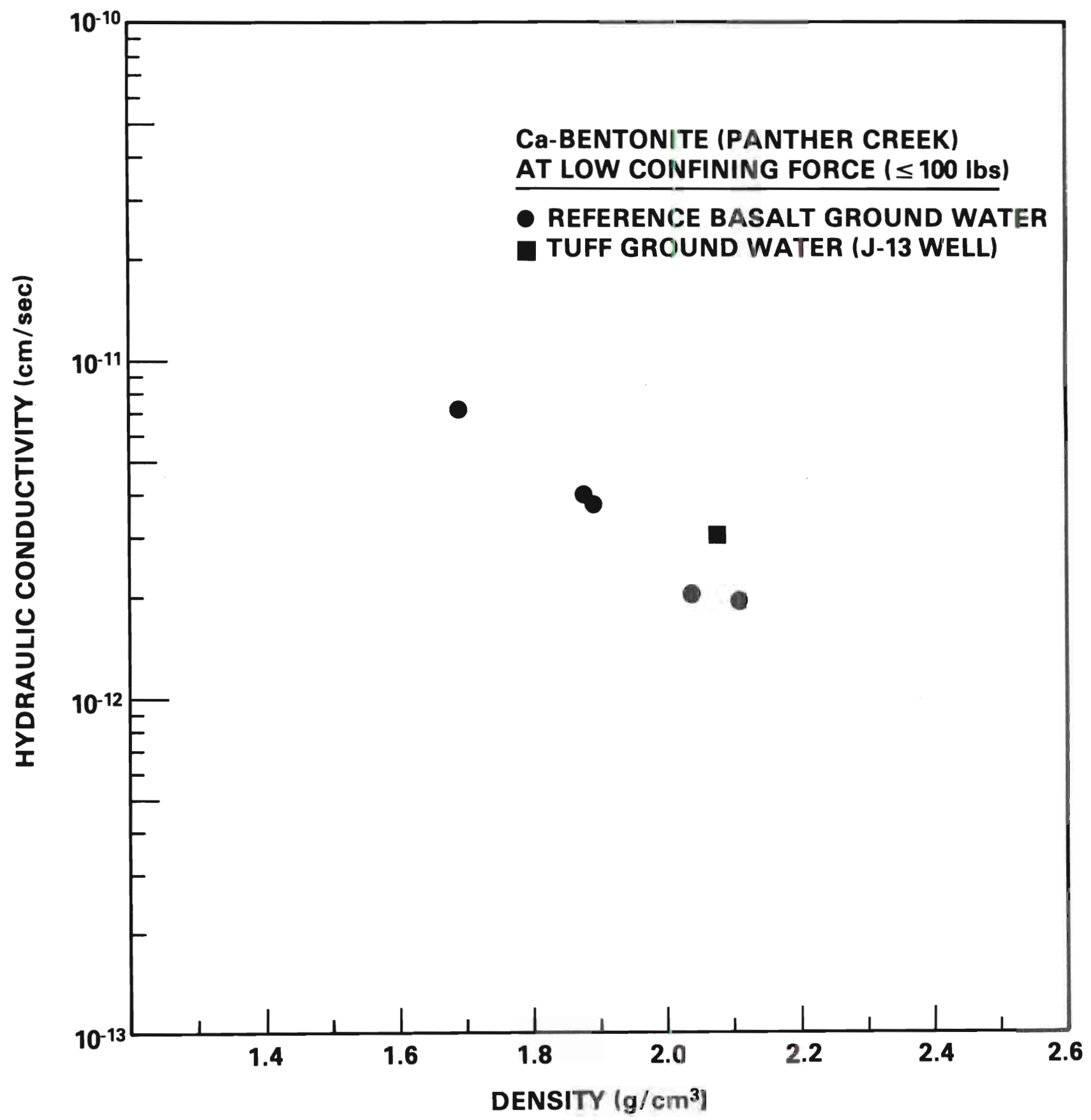

FIGURE 3. Hydraulic Conductivity As a Function of Density for Compacted Calcium Bentonite 
consistent with results obtained with reference basalt ground water and there is no apparent reason, given the similarity of the two waters, to think that results with basalt ground water will not be valid for tuff ground water.

Hydraulic conductivities of Na-bentonite/quartz sand mixtures, plotted as a function of density, are shown in Figure 4. The plot clearly shows the increase in hydraulic conductivity with increasing sand content, at constant density. This increase in hydraulic conductivity is a result of the decreasing clay density with increasing sand content $\left(\rho \sim 2.65 \mathrm{~g} / \mathrm{cm}^{3}\right)$. This density decrease does not represent a fundamental property of the sand/clay mixtures and it should be possible to decrease the hydraulic conductivities of sand/clay mixtures by increasing the bulk density. The limit on densities of sand/clay mixtures will be determined by the minimum volume into which the sand matrix can be packed.

\section{Radionuclide Migration}

Batch sorption distribution ratios $\left(R_{d}\right)$ have been determined for a number of candidate backfill materials including several bentonites and zeolites. Results of determinations for ${ }^{85} \mathrm{Sr},{ }^{99} \mathrm{Tc},{ }^{125} \mathrm{I},{ }^{137} \mathrm{Cs},{ }^{233_{\mathrm{U}}},{ }^{237} \mathrm{~Np}$, and ${ }^{241_{\mathrm{Am}}}$ in reference basalt ground water are presented in Table 3 . All of the $R_{d}$ values reported in Table 3 were determined at $25^{\circ} \mathrm{C}$ in contact with air.

Batch sorption distribution ratios $\left(R_{d}\right)$ have also been determined for the American Clay Institute "Source Clays" (Table 4) for purposes of interlaboratory comparison. These determinations have been carried out in reference basalt ground water for ${ }^{85} \mathrm{Sr},{ }^{137} \mathrm{Cs}$, and ${ }^{241} \mathrm{Am}$.

Batch sorption distribution ratios $\left(R_{d}\right)$ have been determined for ${ }^{85} \mathrm{Sr}$, ${ }^{99} \mathrm{Tc},{ }^{125} \mathrm{I},{ }^{137} \mathrm{Cs},{ }^{233} \mathrm{U},{ }^{237} \mathrm{~Np}$, and ${ }^{241} \mathrm{Am}$ on Na-bentonite, Ca-bentonite, and charcoal in tuff ground water ( $\mathrm{J}-13$ we11) from the Nevada Test Site. Results of the batch sorption determinations carried out at $25^{\circ} \mathrm{C}$ in contact with air are presented in Table 5. The results are very similar to those obtained with reference basalt ground water with the exception of the ${ }^{125}{ } R_{d}$ on $\mathrm{Na}$ - and Cabentonite. The ${ }^{125} \mathrm{I}$ Rd 1 s considerably higher in the tutt ground water than in the reference basalt ground water, possibly because of the lower $\mathrm{F}$ - and $\mathrm{Cl}^{-}$ content of the former. 


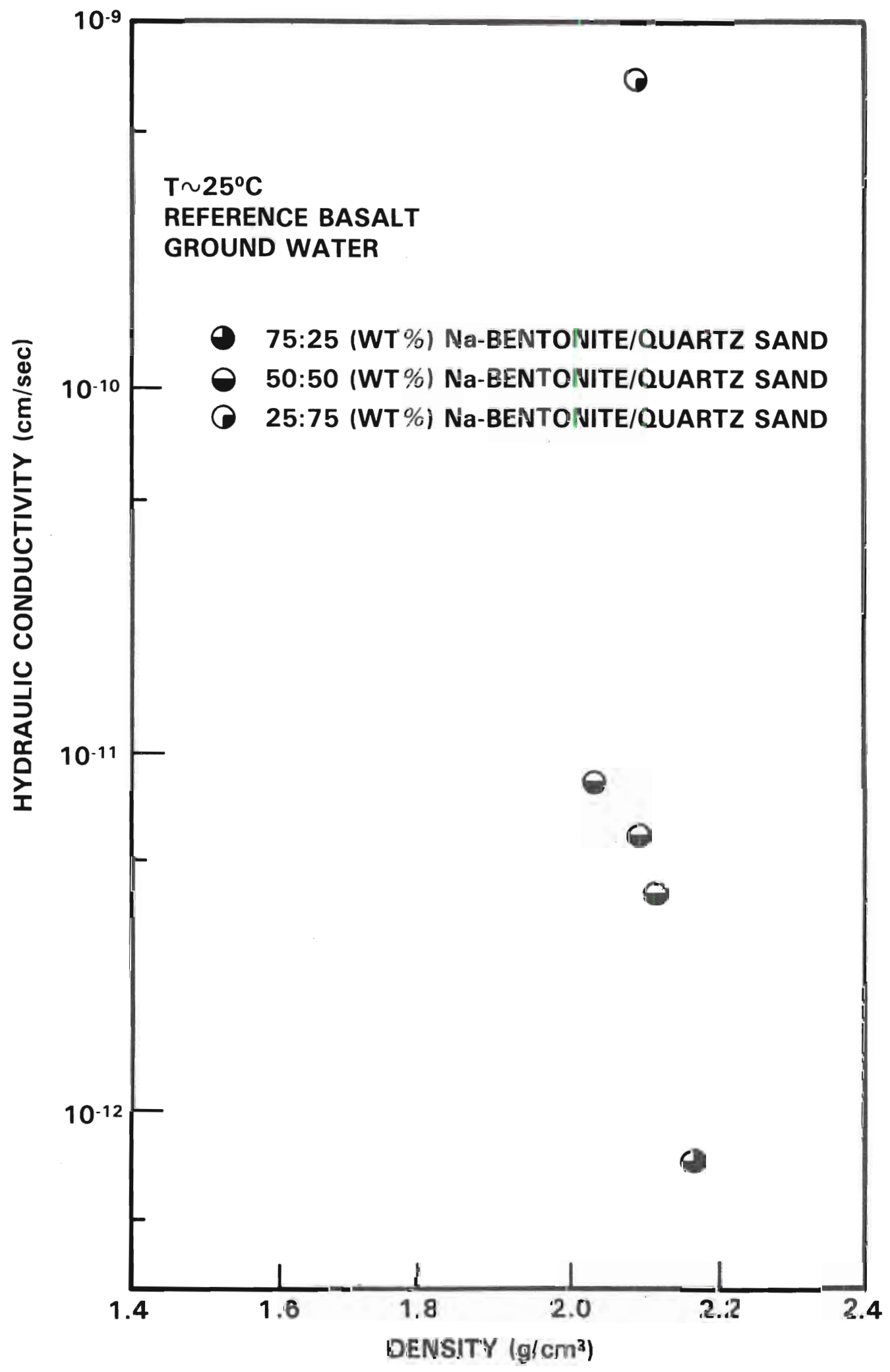

FIGURE 4. Hydraulic Conductivity As a Function of Density for Sodium Bentonite/Quartz Sand Mixtures 
TABLE 3. Batch Distribution Ratios $\left(R_{d}\right)$ for Candidate Backfill Materials in Basalt Ground Water(a)

\begin{tabular}{|c|c|c|c|c|c|c|c|}
\hline Material & ${ }^{85} \mathrm{Sr}$ & ${ }^{99} \mathrm{Tc}$ & $125_{I}$ & ${ }^{137} \mathrm{Cs}$ & $233_{U}$ & $237 \mathrm{~Np}$ & ${ }^{24} 1_{\mathrm{Am}}$ \\
\hline $\begin{array}{l}\text { Coconut } \\
\text { Charcoal }\end{array}$ & 97.9 & $1.5 \mathrm{E} 4$ & $8.3 \mathrm{E} 3$ & 8 & 290 & 583 & $1.2 \mathrm{E} 5$ \\
\hline $\begin{array}{l}\text { Iron } 320 \\
\text { (Powder) }\end{array}$ & $2.2 \mathrm{E} 4$ & 2.4 & 9 & $9.2 \mathrm{E} 3$ & 710 & $1.2 \mathrm{E} 5$ & \\
\hline $\begin{array}{l}\text { Aluminum } \\
\text { (Powder) }\end{array}$ & 139 & - & - & 33 & - & - & - \\
\hline $\begin{array}{l}\text { Na-Bentgpjte } \\
(\mathrm{CS}-50)(\mathrm{b})^{\text {te }}\end{array}$ & $6.8 \mathrm{E} 3$ & - & $1.4 \mathrm{E} 3$ & $1.0 \mathrm{E} 3$ & 8 & 29 & $1.4 \mathrm{E} 3$ \\
\hline $\begin{array}{l}\text { Na-Bentonite } \\
(\text { Saljng Seal- } \\
100)(b)\end{array}$ & $1.5 \mathrm{E} 3$ & - & 3.6 & $3.8 \mathrm{E} 3$ & 76 & - & - \\
\hline $\begin{array}{l}\text { Na-Bentonite } \\
(\text { Accofloc-350) (b) }\end{array}$ & $1.5 \mathrm{E} 3$ & - & 0.1 & 1. $1 \mathrm{E} 3$ & - & - & - \\
\hline $\begin{array}{l}\text { Ca-Bentonite } \\
\text { (Panther Creek) (b) }\end{array}$ & 865 & 1.2 & $1.5 \mathrm{E} 3$ & $1.1 \mathrm{E} 5$ & - & 78 & $9.2 \mathrm{E} 3$ \\
\hline $\begin{array}{l}\text { Faujacite } \\
(13-x \text {, Powder })(c)\end{array}$ & $6.8 \mathrm{E} 4$ & 0.8 & 1.2 & $1.8 \mathrm{E} 3$ & 194 & 18 & 35 \\
\hline $\begin{array}{l}\text { Type A } \\
(4 A \text { Powder })(d)\end{array}$ & 2.0E4 & 0.8 & 0.4 & $1.0 \mathrm{E} 3$ & - & 11 & - \\
\hline $\begin{array}{l}\text { Erionite } \\
(\text { AW-400) }(c)\end{array}$ & $2.3 \mathrm{E} 4$ & 1.2 & 0.8 & $6.7 \mathrm{E} 4$ & 7 & 13 & 92 \\
\hline $\begin{array}{l}\text { Chabazite } \\
(\text { AW-500) }(c)\end{array}$ & $2.3 E 3$ & 0.9 & 1.5 & $7.8 \mathrm{E} 4$ & 17 & 18 & 1. $3 \mathrm{E} 3$ \\
\hline $\begin{array}{l}\text { Mordenite } \\
(\text { Zeolon-900) }(d)\end{array}$ & $1.5 \mathrm{E} 4$ & 1.6 & 1.8 & 8. 3E4 & 35 & 12 & 24 \\
\hline $\begin{array}{l}\text { Pyrite } \\
\left(\mathrm{FeS}_{2}\right)\end{array}$ & 140 & - & $5.1 \mathrm{E} 3$ & 4 & - & - & - \\
\hline
\end{tabular}

(a) Tests performed for 28 days at $25^{\circ} \mathrm{C}$ under atmospheric conditions.

(b)Registered trade names of the American Colloid Co., Skokie, Illinois.

(c) Registered trade names of the Linde Molecular Sieves Division of the Union Carbide Co., New York, New York.

(d) Registered trade name of the Norton Chemical Process Products Division of Norton Co., Akron, Ohio. 
TABLE 4. Batch Distribution Ratios $\left(R_{g}\right)$ for American Clay Institute Source Clays in Basalt Ground Water (a)

\begin{tabular}{|c|c|c|c|}
\hline Material & ${ }^{85} \mathrm{Sr}$ & ${ }^{137} \mathrm{Cs}$ & $241_{A m}$ \\
\hline KGa -1 & $3.02 \mathrm{E} 2$ & 1. $28 \mathrm{E} 2$ & $9.22 \mathrm{E} 2$ \\
\hline KGa-2 & $5.24 \mathrm{E} 2$ & $1.88 \mathrm{E} 2$ & $9.0 \mathrm{E} 3$ \\
\hline$S A z-1$ & $2.0 \mathrm{E} 3$ & $2.7 \mathrm{E} 3$ & $8.15 \mathrm{E} 2$ \\
\hline STX -1 & $1.7 \mathrm{E} 3$ & $1.9 \mathrm{E} 3$ & $1.4 \mathrm{E} 3$ \\
\hline SWy -1 & $1.7 \mathrm{E} 3$ & $1.0 \mathrm{E} 3$ & 2.0E3 \\
\hline
\end{tabular}

(a) Tests performed for 28 days at $25^{\circ} \mathrm{C}$ under atmospheric conditions.

\section{Physical Property Determinations}

Thermal Conductivity Studies. Measurements of thermal diffusivity have been made for dry compacted $\mathrm{Na}$-bentonite using a transient laser thermal pulse technique. Results for a dry compact with a pressed density of $2.1 \mathrm{~g} / \mathrm{cm}^{3}$ are shown in Figure 5. The average thermal diffusivity (15 measurements) between $25^{\circ} \mathrm{C}$ and $600^{\circ} \mathrm{C}$ is $3.25 \pm 0.22 \mathrm{~cm}^{2} / \mathrm{sec}$. Assuming a reasonable range of values for heat capacity $(C p)$ of between 0.2 and $0.3 \mathrm{cal} / \mathrm{g}-{ }^{\circ} \mathrm{C}$ yields thermal conductivities in the range of 0.6 to 0.9 watt $/ \mathrm{m}^{\circ}-\mathrm{C}$. This is consistent with results obtained at Sandia National Laboratory (Moss and Molecke 1982) and is considerably higher than has been assumed in various design studies (Westinghouse 1982).

TABLE 5. Batch Sorption Distribution Ratios $\left(R_{d}\right)$ for Candidate
Backfill Materials in Tuff Ground Water $(a)$

\begin{tabular}{|c|c|c|c|c|c|c|c|}
\hline Material & ${ }^{85} \mathrm{Sr}$ & ${ }^{99} \mathrm{Tc}$ & $125_{\mathrm{I}}$ & ${ }^{137} \mathrm{Cs}$ & ${ }^{233} U$ & ${ }^{237} \mathrm{~Np}$ & ${ }^{24} 1_{A m}$ \\
\hline $\begin{array}{l}\text { Na-Bentonite } \\
(C S-50)\end{array}$ & $3.2 \mathrm{E} 2$ & 14 & 6 & $1.9 \mathrm{E} 3$ & 3 & 37 & $1.5 \mathrm{E} 3$ \\
\hline $\begin{array}{l}\text { Ca-Bentonite } \\
\text { (Panther Creek) }\end{array}$ & 665 & 0.03 & 13.1 & $6.4 \mathrm{E} 3$ & 15 & 82 & $2.7 \mathrm{E} 3$ \\
\hline Charcoal & $2.1 \mathrm{E} 3$ & $2.6 \mathrm{E} 4$ & 899 & 10 & $1.1 \mathrm{E} 3$ & 719 & $1.5 \mathrm{E} 4$ \\
\hline
\end{tabular}

(a) Tests performed for 28 days at $25^{\circ} \mathrm{C}$ under atmospheric conditions. 


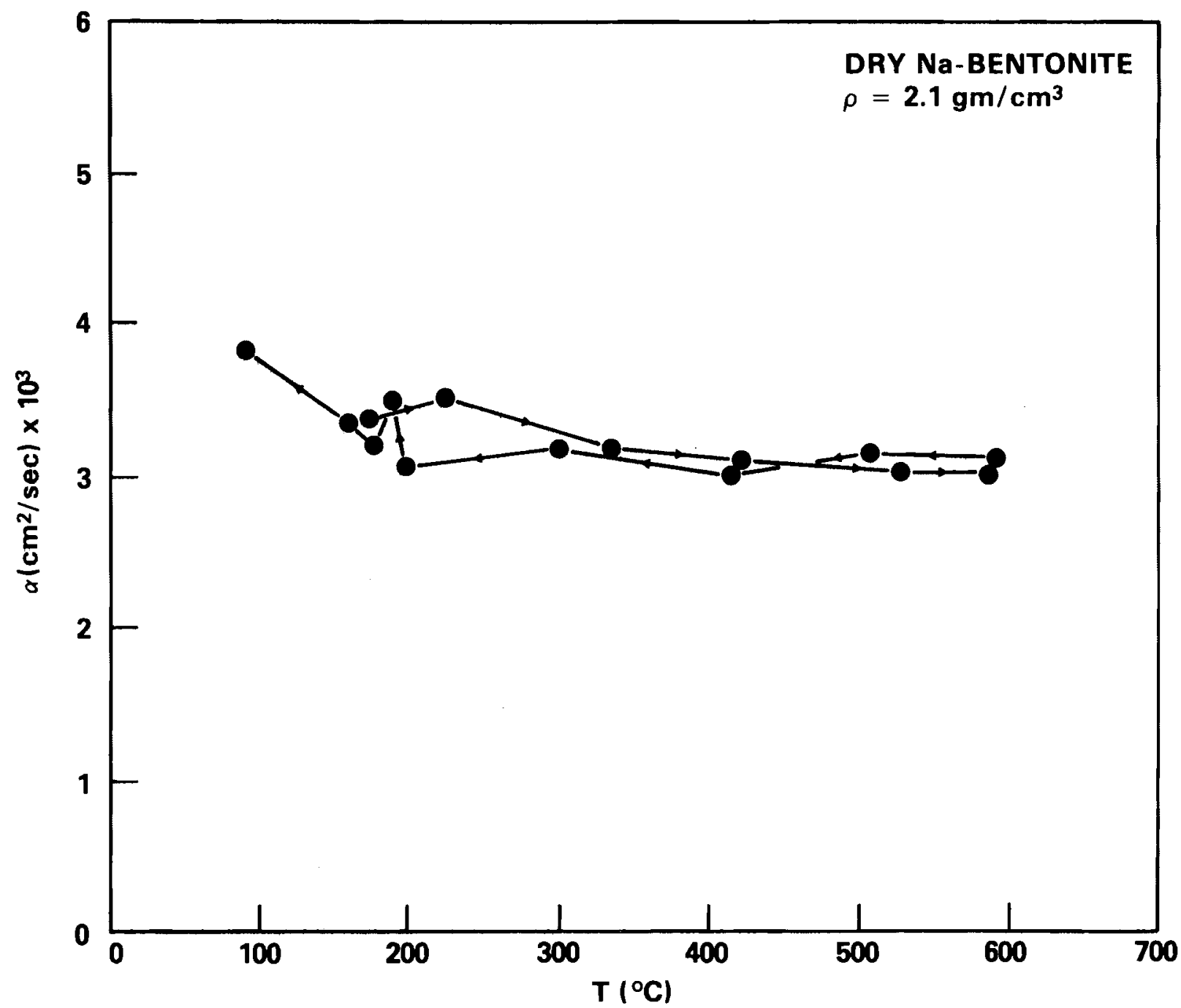

FIGURE 5. Thermal Diffusivity As a Function of Temperature for Compacted Sodium Bentonite

Preliminary measurements of thermal conductivity have been made on air saturated $\left(\sim 5\right.$ wt\% $\mathrm{H}_{2} \mathrm{O}$ ) bentonite samples confined in a modified permeability cell using a transient wire heater technique. The results of $\mathrm{Na}-$ and $\mathrm{Ca}-$ bentonite are shown in Table 6. As a point of reference, the density of bentonites loosely poured into a container ranged from 0.7 to $1.0 \mathrm{~g} / \mathrm{cm}^{3}$. 
TABLE 6. Preliminary Thermal Conductivities for Compacted, Air Saturated Bentonites at $\sim 25^{\circ} \mathrm{C}$

\begin{tabular}{|c|c|c|c|}
\hline Material & $\begin{array}{l}\text { Densityy, } \\
\mathrm{g} / \mathrm{cm}^{3}\end{array}$ & $\begin{array}{l}\text { Thermal } \\
\text { Conductivity, } w / \mathrm{m}^{\circ} \mathrm{C}\end{array}$ & $\begin{array}{c}\text { Pressing } \\
\text { Force, psi (MPa) }\end{array}$ \\
\hline $\mathrm{Na}$-Bentonite & 1.70 & 0.52 & $3,000 \quad(21)$ \\
\hline$"$ & 1.77 & 0.61 & $5,000 \quad(35)$ \\
\hline$"$ & 1.90 & 0.71 & $8,000 \quad(55)$ \\
\hline " & 2.03 & 0.76 & $13,000 \quad(90)$ \\
\hline$"$ & 2.25 & 0.96 & $20,000(138)$ \\
\hline Ca-Bentonite & 1.60 & 0.71 & $3,000 \quad(21)$ \\
\hline$"$ & 1.68 & 0.74 & $5,000 \quad(35)$ \\
\hline " & 1.91 & 0.87 & $13,000 \quad(90)$ \\
\hline$"$ & 2.13 & 1.10 & $20,000(138)$ \\
\hline
\end{tabular}

Compaction Studies

Most scenarios for the use of bentonite backfills call for the emplacement of highly compacted bentonite around the containerized waste. Therefore, the compaction properties of bentonites are important to the design of waste packages that include a bentonite backfill.

Compaction curves for bentonites and bentonite sand mixtures are shown in Figures 6 through 9. The "zero" water content in all of these diagrams is taken as the water content of a clay sample that has been heated at $110^{\circ} \mathrm{C}$ for 16 hours. Compaction curves for sodium bentonite are shown in Figure 6 . In Figure 6, clay water content is plotted against density after pressing and the curves connect densities acheived with equal pressing pressures. The definite maxima in the curves around $5 \mathrm{wt} \% \mathrm{H}_{2} \mathrm{O}$ probably represents the maximum amount of ordered interlayer water taken up by the clay, at least for these short pressing times. Figure 7 shows similar results for a mixture of $75 \% \mathrm{Na-bento-}$ nite/25\% quartz sand.

Figure 8 shows partial curves for $50 \% \mathrm{Na}$-bentonite/50\% quartz sand. The curves have been carried to the point where the mixture stopped taking up water 


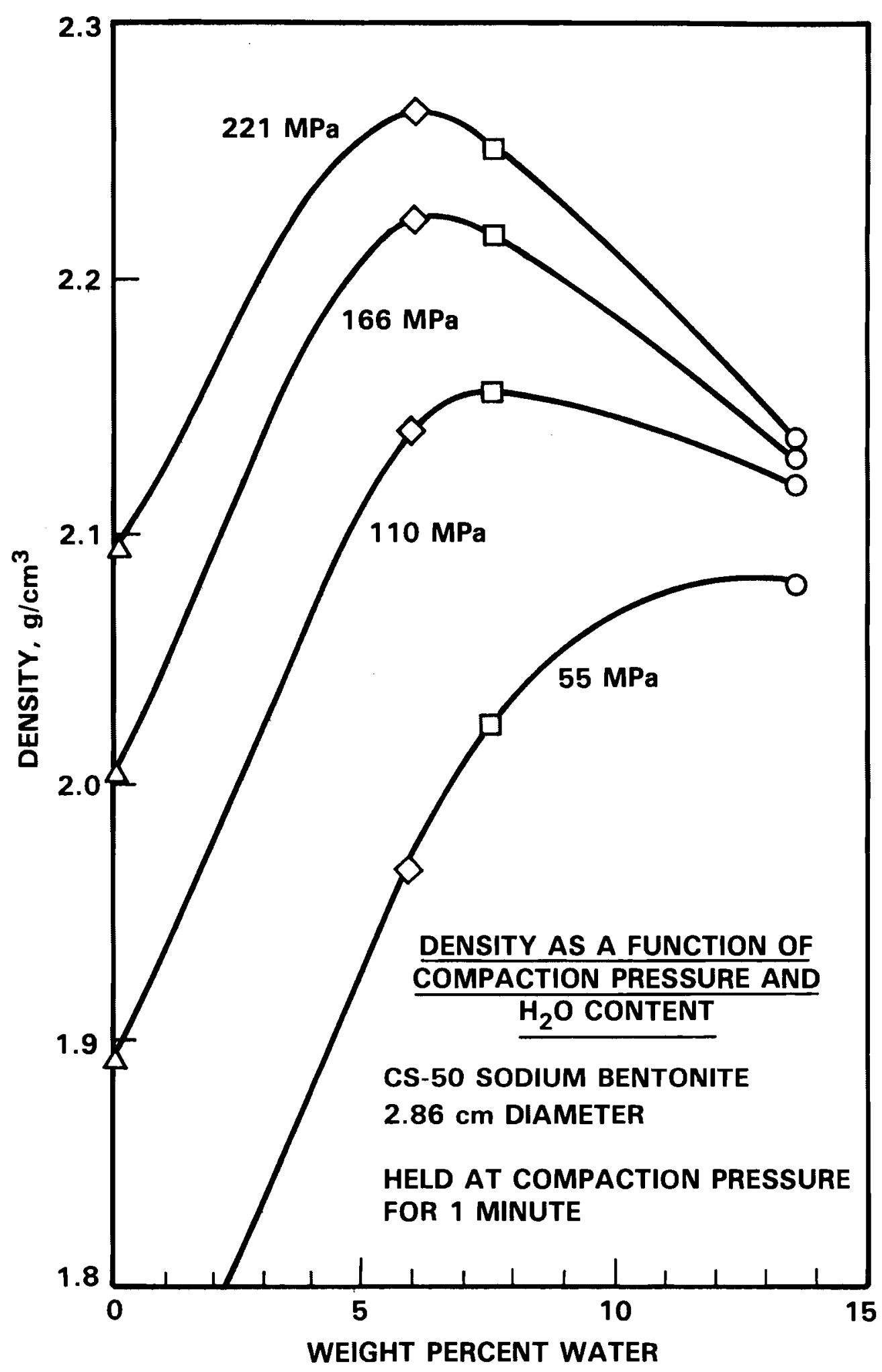

FIGURE 6. Density As a Function of Water Content for Sodium Bentonite at Various Pressures 


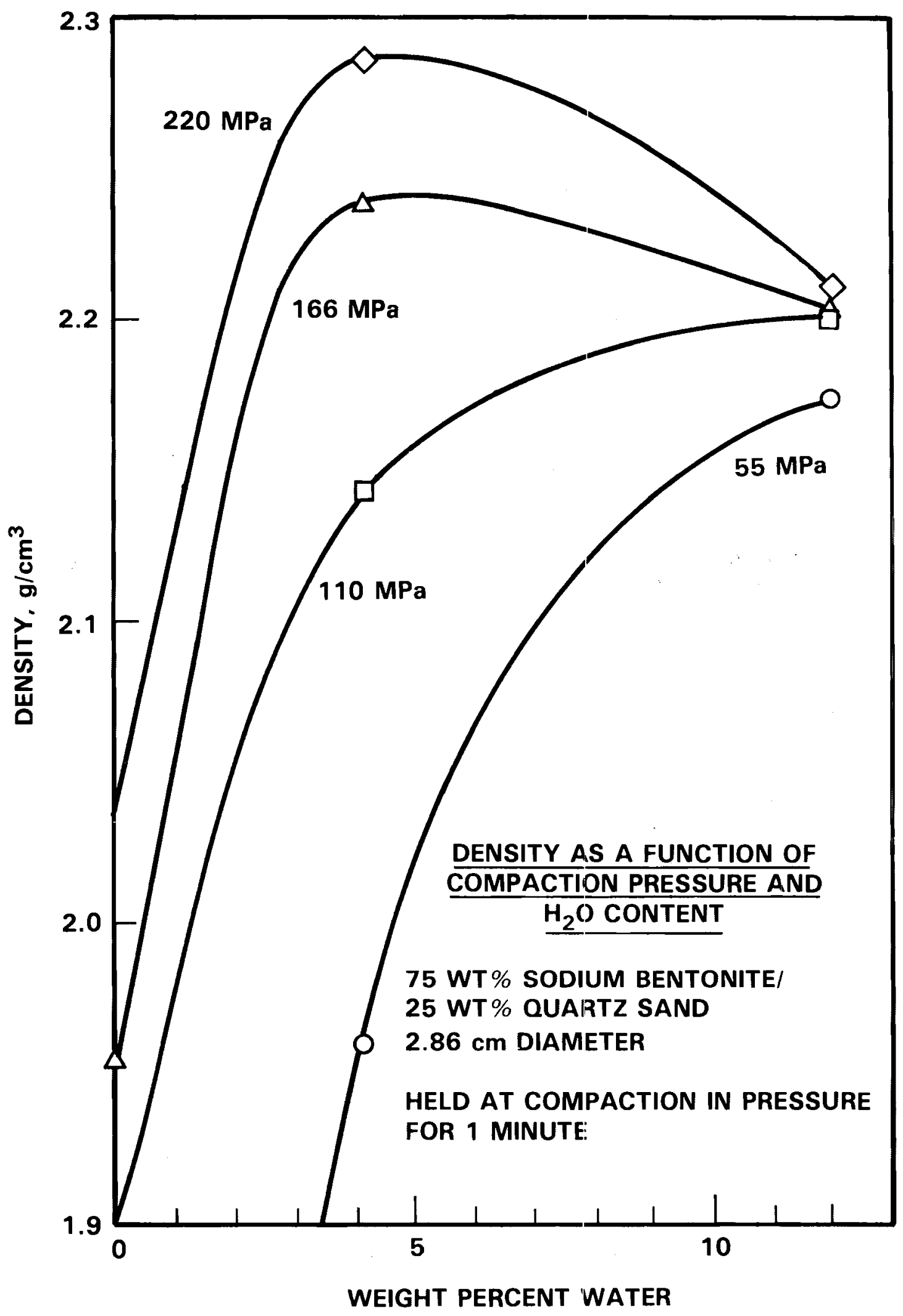

FIGURE 7. Density As a Function of Water Content for $75 \mathrm{wt} \%$ Sodium Bentonite/25 wt\% Quartz Sand Mixture at Various Pressures 


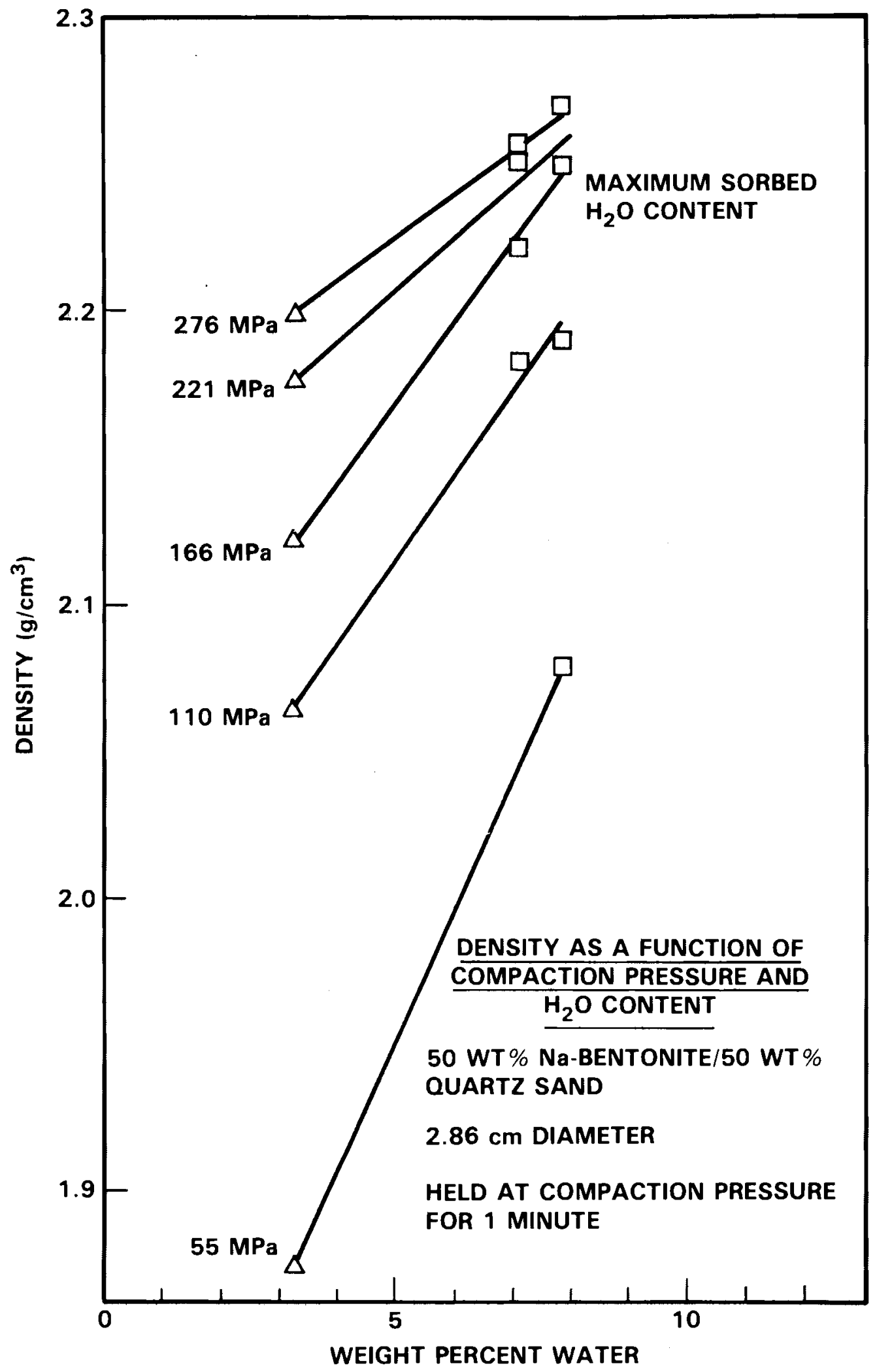

FIGURE 8. Density As a Function of Water Content for $50 \mathrm{wt} \%$ Sodium Bentonite/50 wt\% Quartz Sand Mixture at Various Pressures 


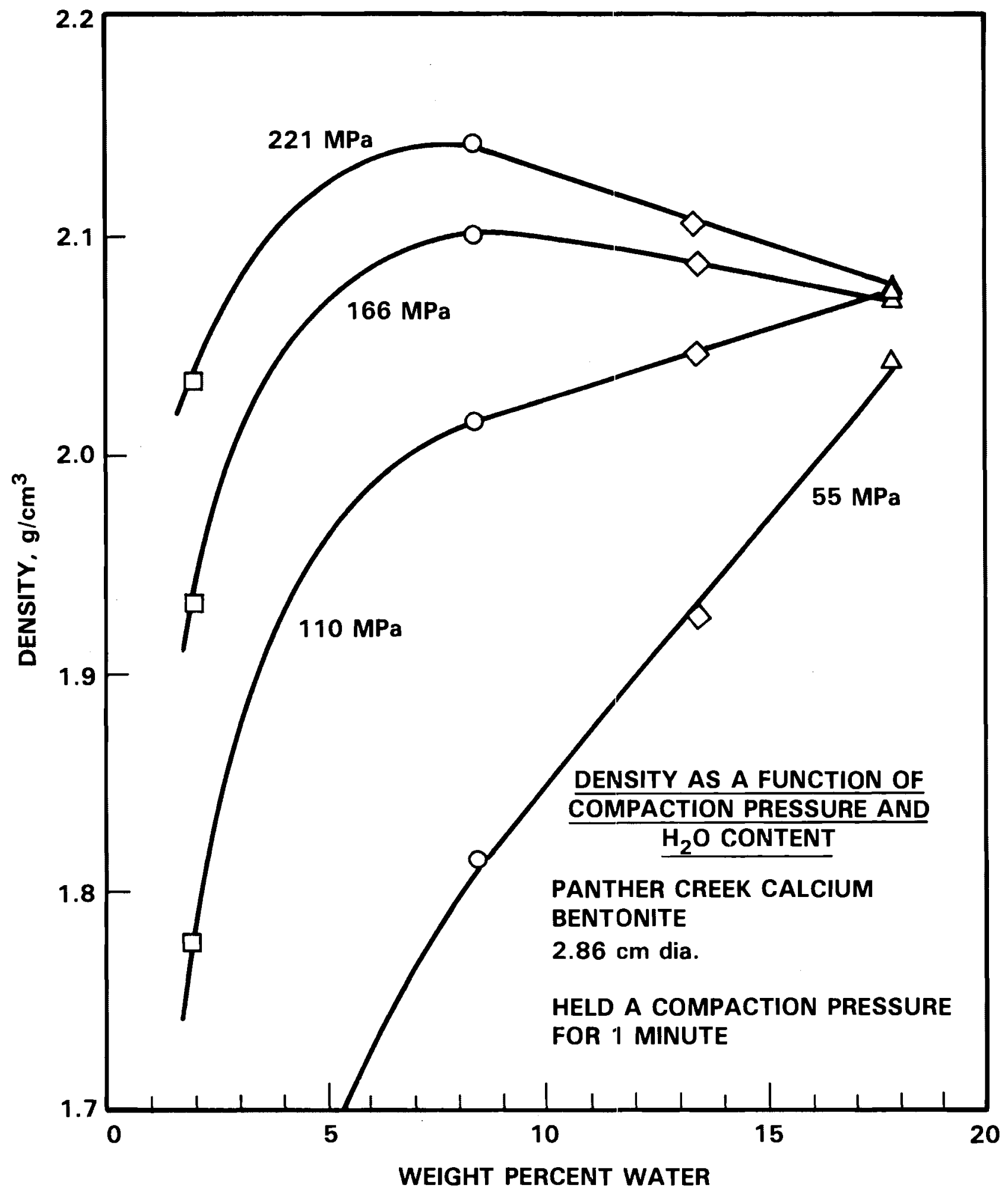

FIGURE 9. Density As a Function of Water Content for Calcium Bentonite at Various Pressures 
from saturated air. Figure 9 shows results for Ca-bentonite. The curves differ slightly in shape than those of $\mathrm{Na}$-bentonite; however, they pass through maxima in a manner similar to those of $\mathrm{Na}$-bentonite.

\section{Materials Stability Studies}

The material chosen for use in a backfill must be stable under repository conditions or must survive long enough to fulfill their design functions. A material with the best of hydraulic and sorption properties is worthless unless it survives long enough for these properties to have an impact on waste package performance.

For a repository in a silicate host rock it seems highly likely that the waste package will dehydrate during the early high temperature phase of repository life. Therefore, it is important to determine the high temperature stability of bentonites under repository conditions. As an approach to this problem, samples of $\mathrm{Na}$ - and Ca-bentonite have been heated in laboratory ovens (open to air) at $100^{\circ}, 200^{\circ}$, and $300^{\circ} \mathrm{C}$ for periods up to one year. Results for tests up to six months indicate that there is apparently a small decrease in the ability of the bentonites to swell upon intake of water, resulting in a decrease in swelling pressure and an increase in permeability. Most of the change in swelling ability took place during the first several months of heating as shown in Figure 10, which indicates the volume of 1 gram (dry) of clay after being allowed to swell freely in an excess of water. Similar results, however, with considerably more scatter can be seen in permeability tests carried out with treated samples. The scatter is due, at least in part, to the difficulty in pressing to exactly the same conditions with existing equipment. In addition, batch sorption determinations with heat treated bentonites indicate no changes in their sorption properties as a result of heating. Radiation from the waste package will be another important component of the environment in which the backfill must function. The effects of radiation have been tested by irradiating bentonites in a ${ }^{60}$ Co facility to doses up to $9.5 \times 10^{9} \mathrm{rad}$. The results of a permeability test with a Na-bentonite sample that received the maximum dose are given in Table 7 . The change in swelling potential of Na-bentonite as a result of radiation is indicated in Figure 11. It can been seen that there is a small but definite change in the ability of bentonite to swell as a result of the irradiation. 


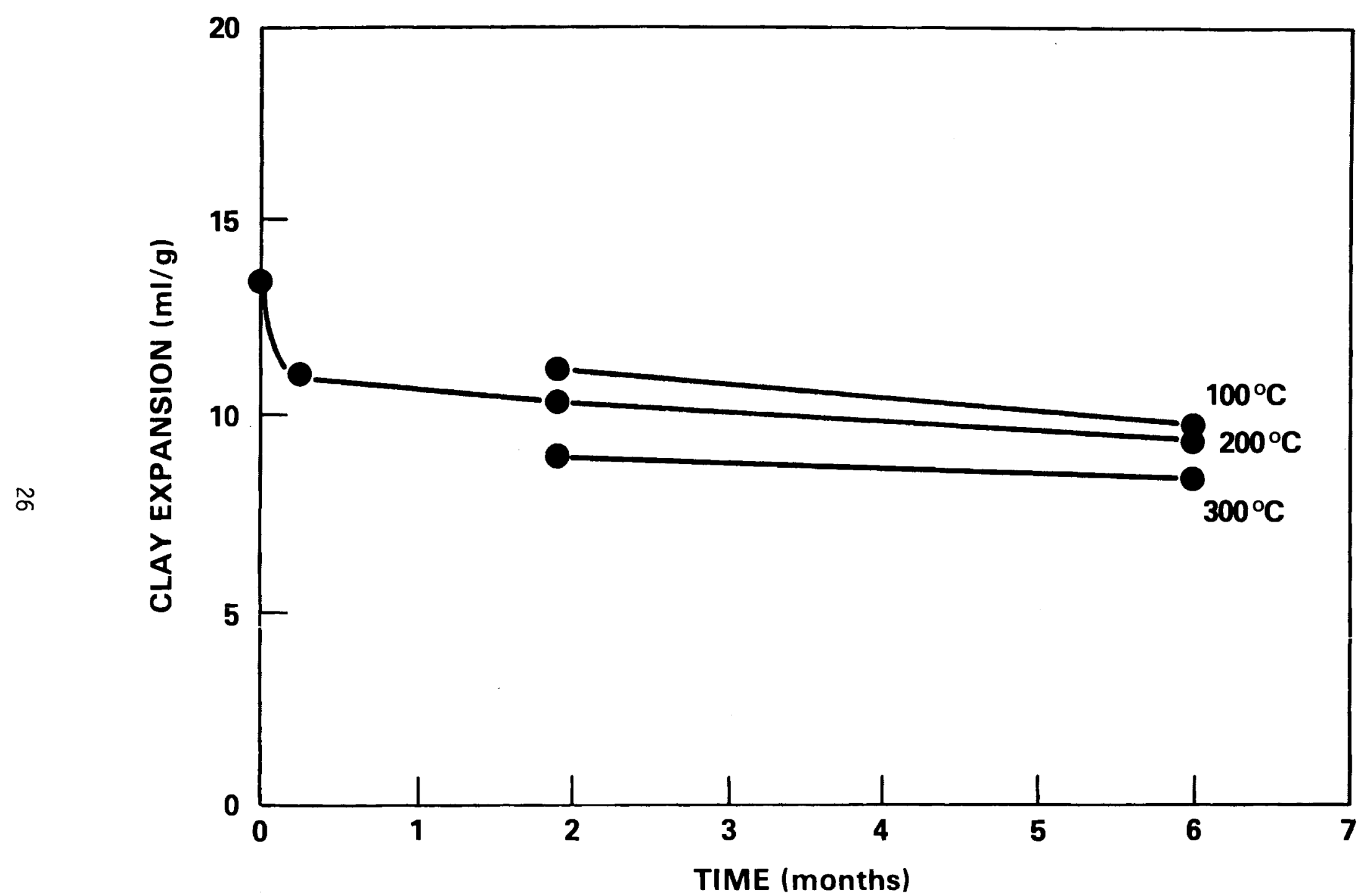

FIGURE 10. Clay Expansion As a Function of Heating Time for Sodium Bentonites Heated at $100^{\circ}, 200^{\circ}$, and $300^{\circ} \mathrm{C}$ under Dry Conditions 
TABLE 7. Permeability Values for Heat Treated and Irradiated Na-Bentonite Samples

\begin{tabular}{|c|c|c|c|}
\hline Sample & $\begin{array}{l}\text { Density } \\
\left(\mathrm{g} / \mathrm{cm}^{3}\right) \\
\end{array}$ & Treatment & $\begin{array}{l}\text { Hydraulic Conductivity } \\
(\mathrm{cm} / \mathrm{sec})\end{array}$ \\
\hline $\mathrm{Na}$-bentonite & 2.22 & None & $6.6 \times 10^{-13}$ \\
\hline$"$ & 2.12 & 6 mo. at $100^{\circ} \mathrm{C}$ & $1.2 \times 10^{-12}$ \\
\hline$"$ & 2.07 & $6 \mathrm{mo}$. at $300^{\circ} \mathrm{C}$ & $1.5 \times 10-12$ \\
\hline$"$ & 2.22 & $\begin{array}{l}9.5 \times 10^{9} \mathrm{rad}{ }^{60} \mathrm{Co} \\
(40-\text { day })\end{array}$ & $8.3 \times 10^{-13(a)}$ \\
\hline
\end{tabular}

(a) Initial confining force of 5000 ib rather than $\sim 1001 \mathrm{~b}$.

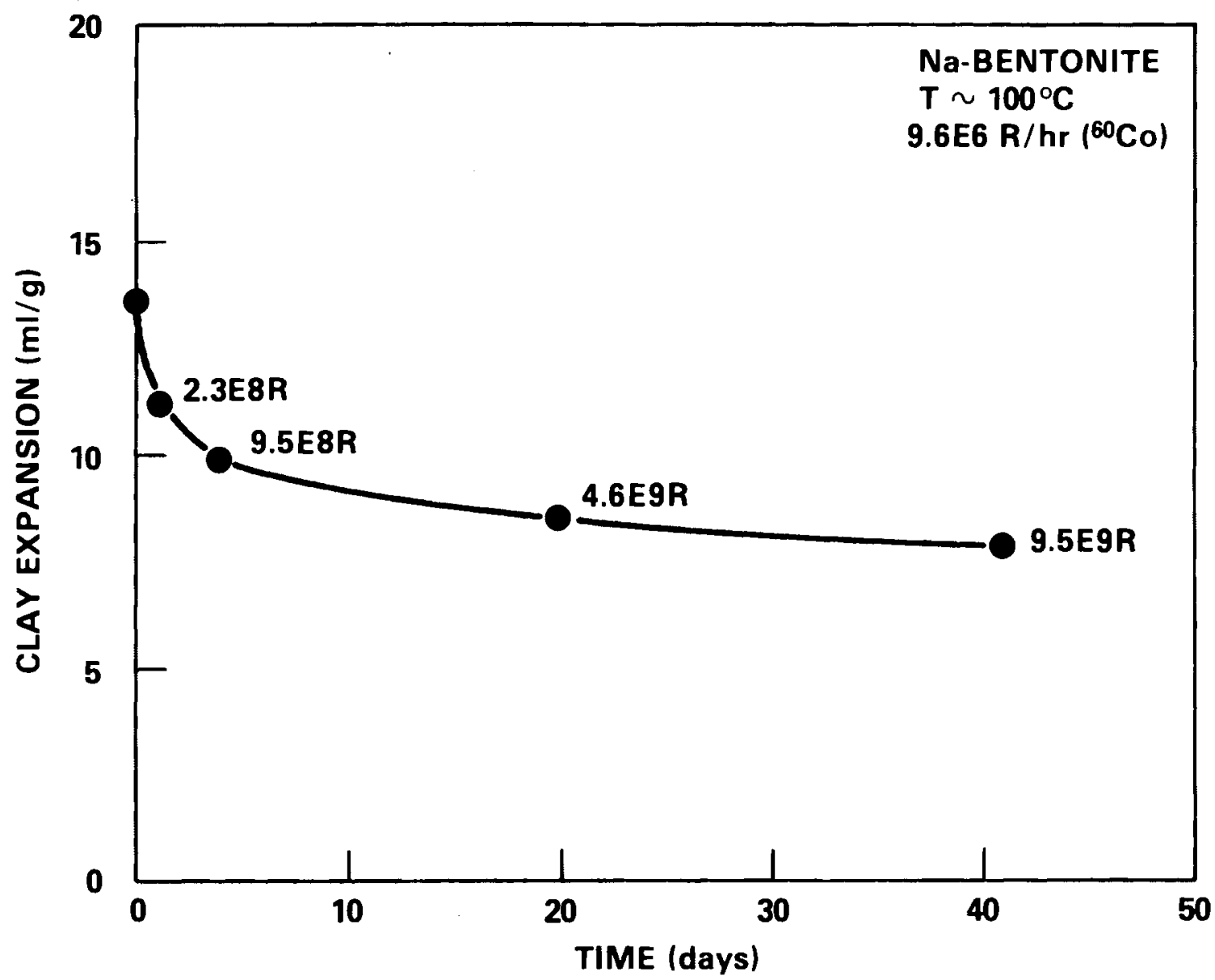

FIGURE 11. Clay Expansion As a Function of Time for Sodium Bentonite Irradiated with 60 Co up to Doses of $9.5 \times 10^{9} \mathrm{R}$ 
Conclusions

The conclusions from the work described in this section are summarized as follows:

- Movement of water through clay compacts takes place by two distinct mechanisms: 1) relatively rapid diffusion; and 2) much slower permeation (Darcian flow) of liquid water through the clay. Tests with thick samples indicate that movement of the liquid water flow front through a thick backfill may be a very long term process.

- Permeability tests indicate no significant differences between basalt and tuff ground water for sodium bentonite. Permeabilities measured for both sodium and calcium bentonites are small enough that diffusion of radionuclides, not the rate of radionuclide transport resulting from water movement, is expected to be the controlling mechanism for radionuclide release through a backfill media.

- Batch sorption studies with candidate back fill material in reference basalt ground water indicate sodium and calcium bentonite will strongly retard the migration of $\mathrm{Sr}, \mathrm{Cs}$, and $\mathrm{Am}$ and will moderately retard the migration of $U$ and $\mathrm{Np}$. The actinides would probably be more strongly retarded in a reducing geologic environment. Zeolites will strongly retard $\mathrm{Sr}, \mathrm{Cs}$, and $\mathrm{Am}$ and will moderately retard $U$ and Np. In these dilute ground waters zeolites offer few advantages over bentonites. Charcoal will strongly retard TC, I, U, Np, and Am; however, at least part of this is probably a result of reduction and precipitation.

- Batch sorption studies with tuff ground water give results very similar to those obtained with reference basalt ground water. One interesting difference is the higher retardation of $I$ on bentonites in tuff ground water, probably a result of the higher halogen content of the basalt ground water.

- It is possible to produce bentonite compacts with densities as high as $2.2 \mathrm{~g} / \mathrm{cm}^{3}$ that are strong enough for extensive handling and that do not disintegrate upon dehydration. 
- Preliminary measurements on both dry and damp bentonites indicate that compacted bentonites have thermal conductivities considerably higher than those reported for uncompacted bentonite, values that are comparable to those expected for tuff and basalt. The room temperature values for damp bentonite should be considered as lower, conservative values because thermal conductivity should increase both with increasing water content and increasing temperature.

- There are small changes in the swelling and hydraulic properties of bentonites as a result of heating or gamma irradiation. Most of the change in both cases occurs early in the treatment and decreases with time at temperature or integrated radiation dose. This indicates that the long term effects may not be much more significant than those observed in the relatively short term tests.

STRUCTURAL BARRIERS

Objective

The objective of the work on structural barriers is to select, characterize, and recommend these materials for use as a part of a high-level nuclear waste package for disposal in basalt and tuff repositories.

\section{Approach}

The technical approach followed in the structural barrier development effort consists of three major elements:

- General (uniform) corrosion testing for material screening and corrosion degradation predictions

- Irradiation-corrosion testing

- Environmental-mechanical testing.(a)

(a) The term "environmental-mechanical testing" is used to denote a general testing approach that determines whether an environment has an effect on the propagation of a pre-existing flaw. It includes that aspect of stress-corrosion cracking that follows crack initiation. Because flaw initiation is presumed to have taken place, the testing approach is by definition conservative. 
General corrosion testing is useful for the preliminary, "first-cut" screening of candidate materials. It is logical that these tests be done first, for three reasons: a) because materials vary so greatly in their corrosion response to a given aggressive environment; b) because the resistance to corrosion is so important to structural barrier reliability; and $c$ ) because the corrosion screening test is frequently less expenisive and time-consuming than, for exampie, certain mechanical property tests. These tests act first of all as an initial material selection/rejection tool, and second, when done in a repository-relevant fashion, as a basis for longevity predictions. In addition to providing data on uniform corrosion, the tests are expected to provide information on the susceptibility of materials to pitting and intergranular corrosion.

Irradiation-corrosion testing is essential because unless special precautions are taken, such as the use of a thick carister or overpack that will absorb essentially all of the radiation emanating from the nuclear waste, or the use of backfill totally impermeable to water, the surface of the outermost structural barrier will be exposed at some time to ground water modified by irradiation. In the case of a young, fission-product containing waste, the major radiolysis effect will be due to gamma radiation. The radiation intens$i$ ty at the surface of the barrier is difficult to estimate, as it depends on time, thickness of the barrier element, barrier material, waste loading in the waste form, age of the waste, composition of the waste, etc. Calculations indicate that a dose rate lying in the range of $10^{5}$ to $10^{6} \mathrm{rad} / \mathrm{hr}$ is the probable maximum that would be expected at the surface of a thin canister containing 10-year-old commercial high-level waste.

Any radiation effect observed in the degradation of structural barriers is expected to be due to the alteration of the aqueous environment by the gamma-induced radiolysis of the water and the effect of the radiation on the chemical species in solution in the water. Predicting the effects of such radiolysis on metal corrosion rates is difficult a priori. For example, in pure water, radiolysis produces strong oxidizing agent, such as peroxides. Presence of peroxides can increase the corrosion rate of metals by facilitating the cathodic process, i.e., by acting as cathodic depolarizers. This could 
enhance the corrosion rates of iron-based alloys, for example. On the other hand, presence of such species can lead to anodic passivation, decreasing the corrosion rate relative to the non-irradiated environment. Such uncertainties make experimental determination of corrosion essential. In general, it is believed that metals that possess a protective, adherent oxide film, such as titanium alloys, should be little affected by the oxidizing radiolysis products (Glass 1981). In addition to the effects on general corrosion induced by radiation, it is also important to determine the disposition of the liberated hydrogen when the candidate barrier element material, e.g., titanium or zirconium, is known to have a high affinity for hydrogen.

Environmental-mechanical testing is required to determine whether a candidate structural barrier material is susceptible to the environmentally enhanced propagation of cracks from existing flaws. Such failures can occur with little or no warning, e.g., in the absence of general corrosion and with relatively low net-section stresses in susceptible systems. Because the results of such failures are potentially catastrophic and unpredictable, a great deal of effort is being put into determining the resistance of materials to environmentally enhanced fracture. The approach utilizes statistically loaded specimens (U-bends, bold-loaded fracture toughness specimens) exposed in autoclaves, slow-strain-rate-testing, and corrosion-fatigue-testing.

In the low-strain-rate test, a specimen is loaded in the presence of the service environment and strained to failure. A range of (low) displacement rates is often used, so strain-rate effects can be investigated. The straining of any metal in tension increases the surface area and continually breaks up the corrosion product film, so that unoxidized material is continuously exposed.

Slow-strain-rate tests are used to indicate susceptibility of metals to environmentally enhanced fracture, as determined by three methods:

1. loss of ductility relative to an inert environment

2. ductility diminution at particular strain rates relative to other strain rates

3. fractographic evidence of embrittlement. 
In the fatigue-crack-growth-rate test, a crack is forced to grow by cycling the load on a specimen and measuring the rate of crack growth. Crack growth rate is found to be a function of cyclic stress intensity. Stress intensity is, in this case, a function of applied stress and crack length. When the tests are conducted in an environment representative of the service environment, the data can be used to compare the susceptibility of various materials to environmentally enhanced cracking or to provide information useful in designing barrier elements so they will not be susceptible to cracking over the design lifetime.

There are two ways of qualitatively evaluating the effects of an environment on fatigue crack growth rate: 1) frequency dependence and 2) accelerated crack growth rate relative to an inert environment. Environmental interactions are time-dependent; therefore, there is some high frequency at which the fatigue crack growth rate is independent of environment (analogous to higher strain rates in the flow strain rate test). At lower frequencies, the crack growth rate may be advanced or retarded due to the effects of the particular environment on the crack tip. Tests which determine the growth rates of environmental fatigue cracks are usually considered conservative, rigorous measures of resistance to environmentally enhanced cracking; they combine the effects of notch chemistry with triaxial stress states and forced exposure of fresh, unoxidized materials.

The three major testing areas listed, i.e., general corrosion, irradiation-corrosion, and environmental-mechanical testing, are of fundamental importance, and, it is believed, form an adequately sound basis for preliminary material recommendations. Other potentially important degradation modes do exist; however, these areas are beyond the scope of the current PNL program. Some are currently being addressed at other laboratories; e.g., hydrogen embrittlement of titanium alloys is being studied at Sandia National Laboratory (SNL) (Molecke et al. 1981).

Wherever possible, an experimental approach has been adopted in the PNL studies that will yield empirical data that are both conservative and repository relevant. 


\section{Materials}

Early screening studies (Westerman 1980) revealed the possibility of using relatively inexpensive, abundant iron-base materials in oxic(a) Hanford basalt ground water. The excellent corrosion resistance of titanium alloys, shown both in PNL screening studies and in SNL brine investigations, (Molecke 1981) qualified these materials also as primary candidates for waste package applications. Accordingly, the basalt/tuff repository barrier material studies have emphasized five materials:

- Ductile (nodular) iron (cast)

- $1-1 / 4 \% \mathrm{Cr}, 1 / 2 \%$ Mo steel (cast)

- 2-1/2\% Cr, $1 \%$ Mo steel (cast)

- Ti Grade 2 (wrought sheet)

- Ti Grade 12 (wrought sheet)

The compositions of the alloys studied and their mechanical properties are presented in Tables 8 through 10 .

TABLE 8. Composition of Titanium Alloys with ASTM Nominal Compositions for Comparison

\begin{tabular}{|c|c|c|c|c|c|c|c|}
\hline \multirow{2}{*}{$\begin{array}{l}\text { Titanium } \\
\text { Alloy }\end{array}$} & \multicolumn{7}{|c|}{ Element, wt\% } \\
\hline & $\bar{N}$ & $\bar{C}$ & $\mathrm{H}$ & 0 & $\mathrm{Fe}$ & Mo & $\mathrm{Ni}$ \\
\hline Grade 2 , actual & 0.009 & 0.011 & 0.005 & 0.12 & 0.12 & & \\
\hline $\begin{array}{l}\text { Grade } 2 \text {, } \\
\text { ASTM Nominal (a) }\end{array}$ & 0.030 & 0.100 & 0.015 & 0.250 & 0.300 & & \\
\hline Grade 12 , actua 1 & 0.008 & 0.021 & 0.005 & 0.013 & 0.12 & $0.3 n$ & 0.67 \\
\hline $\begin{array}{l}\text { Grade } 12, \\
\text { ASTM Nominal (a) }\end{array}$ & 0.03 & 0.08 & 0.015 & 0.250 & 0.300 & 0.2 to 0.4 & 0.6 to 0.9 \\
\hline
\end{tabular}

(a) Maximum elemental levels, except as noted, per ASTM B-265-78.

(a) In the context of this report, "oxic" refers to ground water having dissolved oxygen content approximately equivalent to that which would be expected if the water were equilibrated with air under ambient conditions. 
TABLE 9. Composition of Iron-Base Alloys

\begin{tabular}{|c|c|c|c|c|c|c|c|}
\hline Iron-Base Alloy & C & Mn & $\mathrm{Si}$ & $\underline{P}$ & $S$ & Mo & $\mathrm{Cr}$ \\
\hline $2-1 / 2 \% \mathrm{Cr}, 1 \% \mathrm{Mo}$ & 0.116 & 0.57 & 0.57 & 0.020 & 0.004 & 1.02 & 2.46 \\
\hline $1-1 / 4 \% \mathrm{Cr}, 1 / 2 \% \mathrm{Mo}$ & 0.117 & 0.76 & 0.59 & 0.018 & 0.001 & 0.49 & 1.31 \\
\hline $\begin{array}{l}\text { Ductile Cast } \\
\text { I ron, (ASTM } \\
\text { A } 536-77 \text {, Grade } \\
60-40-18 \text { ) }\end{array}$ & 3.53 & 0.31 & 2.51 & 0.05 & 0.004 & & \\
\hline
\end{tabular}

TABLE 10. Roon Temperature Mechanical Properties of Iron and Titanium-Based Alloys

\begin{tabular}{|c|c|c|c|}
\hline Material & $\begin{array}{c}\text { Yield } \\
\text { Strength, } \\
\text { ksi (MPa) }\end{array}$ & $\begin{array}{l}\text { Tensile } \\
\text { St;rength, } \\
\text { ksi (MPa) }\end{array}$ & $\begin{array}{c}\text { Elongation, } \\
\%\end{array}$ \\
\hline Ti Grade 2, $L(a)$ & $51(351)$ & $74(497)$ & 29 \\
\hline Ti Grade 2, $T(a)$ & $57(393)$ & $72(517)$ & 28 \\
\hline Ti Grade $12, \mathrm{~L}$ & $62(427)$ & $87(600)$ & 22 \\
\hline Ti Grade $12, T$ & $87(600)$ & $101(696)$ & 18 \\
\hline $2-1 / 2 \% \mathrm{Cr}, 1 \% \mathrm{Mo}^{(b)}$ & $73.5(506)$ & $92.0 \quad(633)$ & 25 \\
\hline $1-1 / 4 \% \mathrm{Cr}, 1 / 2 \% \mathrm{Mo}_{0}(\mathrm{~b})$ & $71.5(492)$ & $90.5(6.23)$ & 27 \\
\hline $\begin{array}{l}\text { Ductile cast } \\
\text { Iron }(c)\end{array}$ & $44.9(309)$ & $67.6(466)$ & 20 \\
\hline
\end{tabular}

(a) $L=$ longitudinal (parallel to rolling direction); $T=$ transverse (perpendicular to rolling direction).

(b) Normal compositions. Materials are low-alloy cast steels.

(c) ASTM A536-79, Grade 60-40-18 nodular iron.

The ductile cast iron is representative of a large group of cast irons having good impact and ductility properties relative to the still-cheaper gray irons. The low-alloy cast steels evaluated are more expensive than the cast irons, but have superior mechanical properties. The low levels of chromium and 
molybdenum in the cast steels represent an effort to learn what beneficial effects, if any, such modest alloy additions might have on the corrosion resistance of cast iron-base materials.

The specimens of cast ferrous material used in the present study were obtained from castings each weighing $\sim 350 \mathrm{lb}$, with a minimum dimension of 5 in.

Ti Grade 2 is a commercial purity titanium alloy. Titanium Grade 12, a $\mathrm{Ti}-\mathrm{Ni}-\mathrm{Mo}$ alloy, was developed for superior high-temperature corrosion resistance and resistance to crevice corrosion, and is an outstanding performer in brines representative of salt repositories (Molecke 1981).

Prior to corrosion testing the cast steel specimens are ground with an aluminum oxide wheel to produce a surface finish of $32 \mu \mathrm{m}$ root mean square (rms) in the grinding direction and $63 \mu \mathrm{m} \mathrm{rms}$ in the transverse direction. The same wheel produces a surface finish of $8 \mathrm{\mu m}$ rms in both directions on the ductile iron specimens. The titanium sheet stock is tested in the as-received (mill annealed and pickled) condition.

The approximate composition of the basalt rock used in the structural barrier studies is given in Table 11. The basalt was obtained from an Umtanum surface flow outcrop near the Hanford Reservation.

The approximate composition of the tuff rock used in this study is given in Table 12. The tuff rock was obtained from an outcropping of the Bullfrog horizon on the Nevada Test Site. The composition of the specific lot of rock used in the present study has not been determined, but it is expected to lie within the composition ranges shown in Table 12 .

Results and Discussion

The results of the material degradation studies, and the implications of the results to the candidate materials' barrier applications, are presented in this section of the report, in the following order: General Corrosion Studies, Irradiation-Corrosion Studies, and Environmental-Mechanical Studies. 
TABLE 11. Composition of Umtanum Flow Basalt (Johnson and Palmer 1981)

\begin{tabular}{cc} 
Constituent & Weight Percent \\
\cline { 2 - 2 } $\mathrm{SiO}_{2}$ & 54.9 \\
$\mathrm{Al}_{2} \mathrm{O}_{3}$ & 14.3 \\
$\mathrm{Fe} 0$ & 13.2 \\
$\mathrm{CaO}$ & 7.2 \\
$\mathrm{MgO}$ & 3.4 \\
$\mathrm{Na}_{2} \mathrm{O}$ & 2.6 \\
$\mathrm{TiO}_{2}$ & 2.2 \\
$\mathrm{~K}_{2} \mathrm{O}$ & 1.6 \\
$\mathrm{P}_{2} \mathrm{O}_{5}$ & 0.4 \\
$\mathrm{MnO}$ & 0.2
\end{tabular}

TABLE 12. Composition Range of Welded Silicic Tuff (Wolfsberg et al. 1981)

\begin{tabular}{lc} 
Constituent & \multicolumn{2}{c}{ Typical } \\
Range (wt\%) \\
\cline { 2 - 2 } $\mathrm{SiO}_{2}$ & $58-75$ \\
$\mathrm{TiO}_{2}$ & $0.0-0.4$ \\
$\mathrm{Al}_{2} \mathrm{O}_{3}$ & $10-17$ \\
$\mathrm{Fe}_{2} \mathrm{O}_{3}$ & $0.1-2.0$ \\
$\mathrm{FeO} \mathrm{O}$ & $0.1-2.0$ \\
$\mathrm{MnO}$ & $0.0-0.2$ \\
$\mathrm{MgO}_{\mathrm{CaO}}$ & $0.1-1.5$ \\
$\mathrm{Na}_{2} \mathrm{O}$ & $0.5-2.5$ \\
$\mathrm{~K}_{2} \mathrm{O}$ & $1.0-6.0$ \\
$\mathrm{P}_{2} \mathrm{O} 5$ & $2.0-7.0$ \\
$\mathrm{~S}$ & $0.0-2.0$ \\
$\mathrm{H}_{2} \mathrm{O}(\mathrm{a})$ & $0.0-2.0$ \\
& $1.0-5.0$
\end{tabular}

(a) Does not include pore water. 


\section{General Corrosion}

Al1 general corrosion tests are performed in refreshed (flowing) autoclave systems. A schematic diagram of a typical general corrosion test facility is shown in Figure 12. A reservoir contains simulated ground water, either made up to a specified composition or obtained directly from an aquifer containing water considered typical of the site in question. A positive displacement pump delivers influent water to the autoclave at $\sim 35 \mathrm{~mL} / \mathrm{hr}$. The water flows upward through a bed of crushed rock (basalt or tuff) 1 to 2 inches deep as it attains the test temperature, to "fine-tune" the water chemistry prior to its contacting the specimens. Of course, true equilibrium between the rock and the water is not attainable under these dynamic conditions.

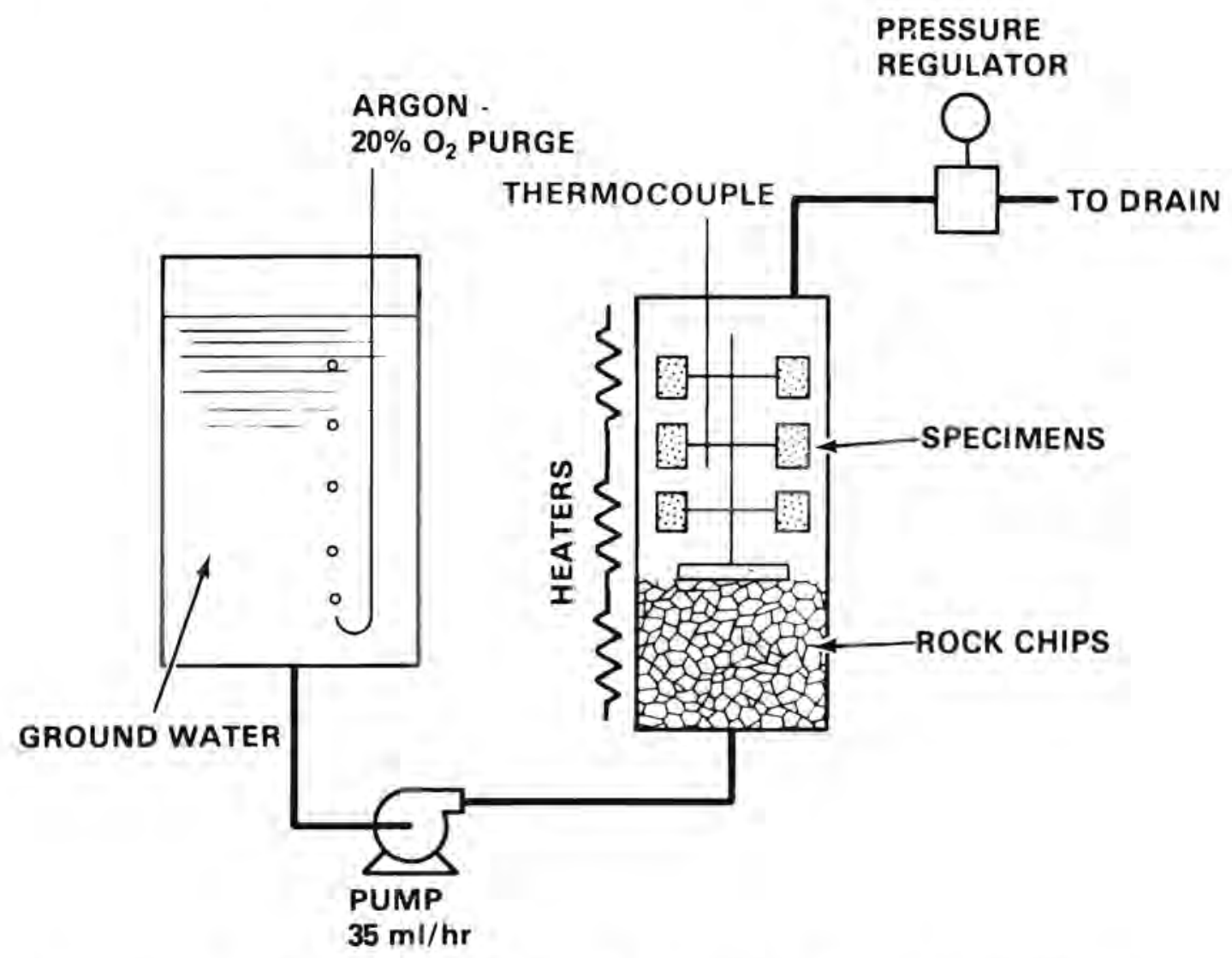

FIGURE 12. Schematic Diagram of Typical Refreshed Autoclave System used in General Corrosion Study 
The autoclaves are operated at a pressure several hundred psi higher than the vapor pressure of water at the given test temperature; e.g., they are operated at 800 to $1000 \mathrm{psi}$ when the test temperature is $250^{\circ} \mathrm{C}$.

The inlet ground water is equilibrated in all cases in its reservoirs with an argon-oxygen mixture containing $20 \%$ oxygen. Thus, the inlet water enters the autoclave containing 6 to $8 \mathrm{ppm}$ dissolved oxygen. It is unclear what the dissolved oxygen level will be, as a function of time, in a repository after closure. In the present study oxic tests have been emphasized over anoxic tests in the belief that oxic tests are usually more severe than anoxic tests, and conservative tests are performed wherever possible.

It has been found that a bed of crushed basalt rock alone in the autoclave will decrease the oxygen level of the effluent water to levels as low as $0.3 \mathrm{ppm}$ at $250^{\circ} \mathrm{C}$. This is attributed to the reducing effects of large amounts of divalent iron present in the basalt rock. The tests are still considered oxic, however, as the level of oxygen present in the autoclave represents a large oxygen fugacity compared with that which is expected to eventually exist in equilibrium with basalt rock after a basalt repository is sealed. The effect of tuff rock on the level of oxygen present in the water is at present not known.

When the desired test duration has been achieved, the specimens are removed and visually examined. Selected specimens of iron-base alloys, generally duplicates, are stripped of their corrosion product films by a combination of gentle abrasion coupled with immersion in formaldehyde-inhibited $\mathrm{HCl}$. The specimens are then weighed, and the weight loss exhibited is converted to a metal penetration. The data in this report are all derived from specimens that have been stripped only once, i.e., for one reported weight change (or metal penetration). 
The general corrosion behavior of three Fe-base materials is being determined in three aqueous media. The experimental matrix is given below:

\begin{tabular}{|c|c|c|c|}
\hline Material & $\begin{array}{l}\text { Aqueous } \\
\text { Medium (oxic) }\end{array}$ & $\begin{array}{c}\text { Test } \\
\text { Temperature } \\
\end{array}$ & $\begin{array}{c}\text { Maximum Test } \\
\text { Duration Reported }\end{array}$ \\
\hline Cast ductile iron & $\begin{array}{l}\text { Basaltic } \\
\text { Ground Water }\end{array}$ & $\begin{array}{l}250^{\circ} \mathrm{C} \\
150^{\circ} \mathrm{C}\end{array}$ & $\begin{array}{l}6 \text { months } \\
6 \text { months }\end{array}$ \\
\hline $\begin{array}{c}\text { Cast } 2-1 / 2 \% \mathrm{Cr} \text {, } \\
1 \% \text { Mo stee } 1\end{array}$ & Tuffacepus & $250^{\circ} \mathrm{C}$ & 1 month \\
\hline $\begin{array}{r}\text { Cast } 1-1 / 4 \% \mathrm{Cr} \text {, } \\
1 / 2 \% \text { Mo stee } 1\end{array}$ & $\begin{array}{l}\text { Ground Water } \\
\text { Deionized Water }\end{array}$ & $250^{\circ} \mathrm{C}$ & 3 months \\
\hline
\end{tabular}

More data has been obtained on specimens exposed to the basaltic ground water than on specimens exposed to the other two media. For this reason, the basalt data are used as the basis of comparison of general corrosion data and radiation-corrosion data throughout this report.

Basalt ground water studies. The general corrosion of the candidate ferrous materials in basalt ground water at $250^{\circ} \mathrm{C}$, expressed as mil/yr (or, equivalently, in./1000 yr) penetration is shown in Figure 13 . The rate of penetration is expressed as a linear rate, based on the metal penetration determined at the end of a given autoclave run. The rate of penetration is clearly decreasing with time of exposure, indicating that the corrosion product film has some ability to protect the substrate from attack. After 6 months' exposure, a maximum rate of only $0.30 \mathrm{mil} / \mathrm{yr}(0.30 \mathrm{in.} / 1000 \mathrm{yr})$ is observed for all of the materials. In general, the ductile iron is found to corrode more rapidly than the low alloy steels; and, of the low alloy steels, the higher chromium alloy corrodes at the lowest rate. No gross pitting attack or other evidence of significant non-uniform corrosion was seen on any specimen after 6 months' exposure.

The $150^{\circ} \mathrm{C}$ basalt ground water corrosion data are superimposed on the $250^{\circ} \mathrm{C}$ data in Figure 14 . The same general trends are observed as in the case of the $250^{\circ} \mathrm{C}$ data, except that the corrosion rates are lower. After 6 months, all of the data lie under a rate of $0.20 \mathrm{mil} / \mathrm{yr}(0.2 \mathrm{in.} / 1000 \mathrm{yr})$. Though no gross pitting of the specimens is evident after 6 months, the ductile iron 


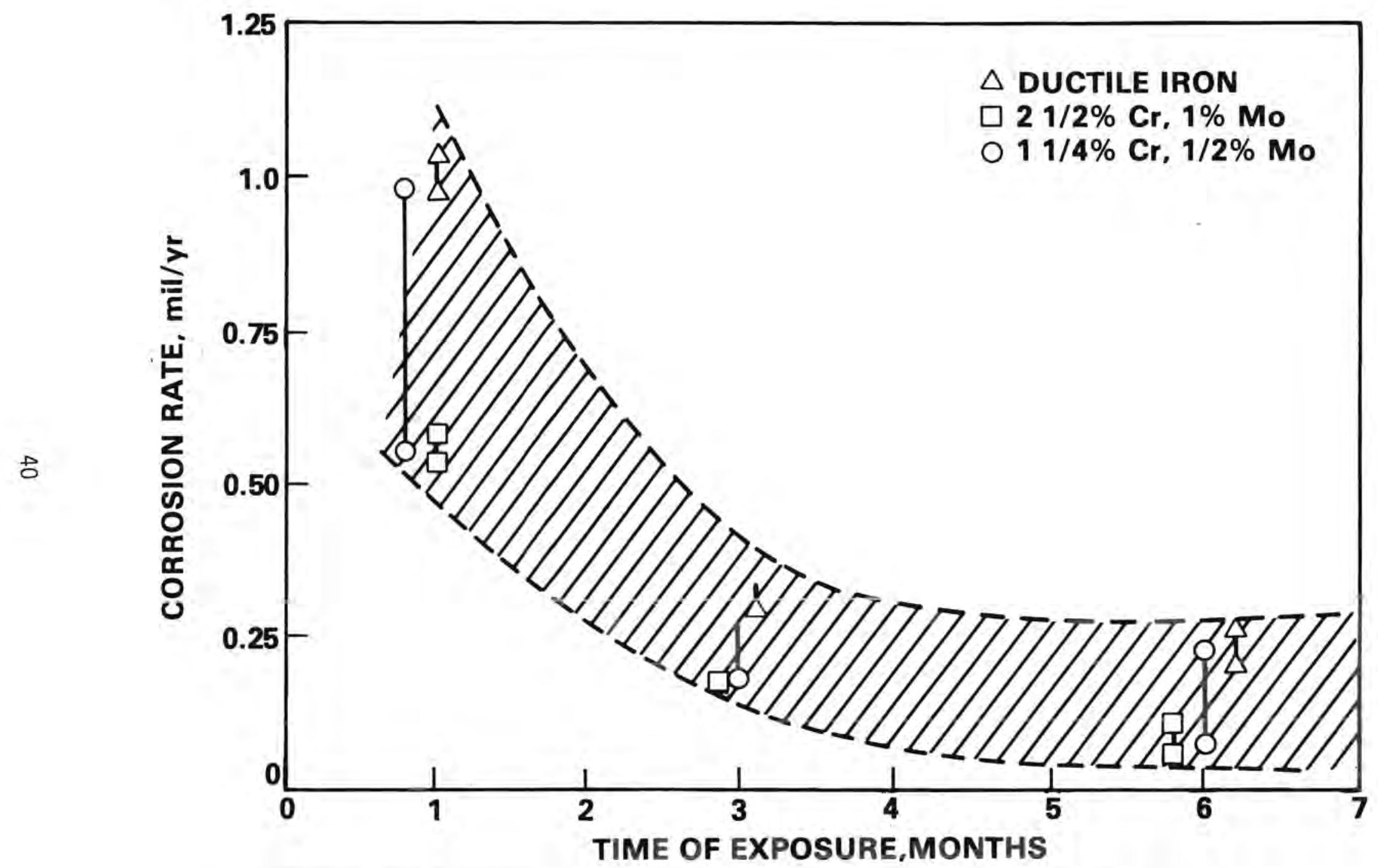

FIGURE 13. The General Corrosion of Cast Ferrous Materials in Basalt Ground Water at $250^{\circ} \mathrm{C}$, Based on Linear Corrosion Kinetics 


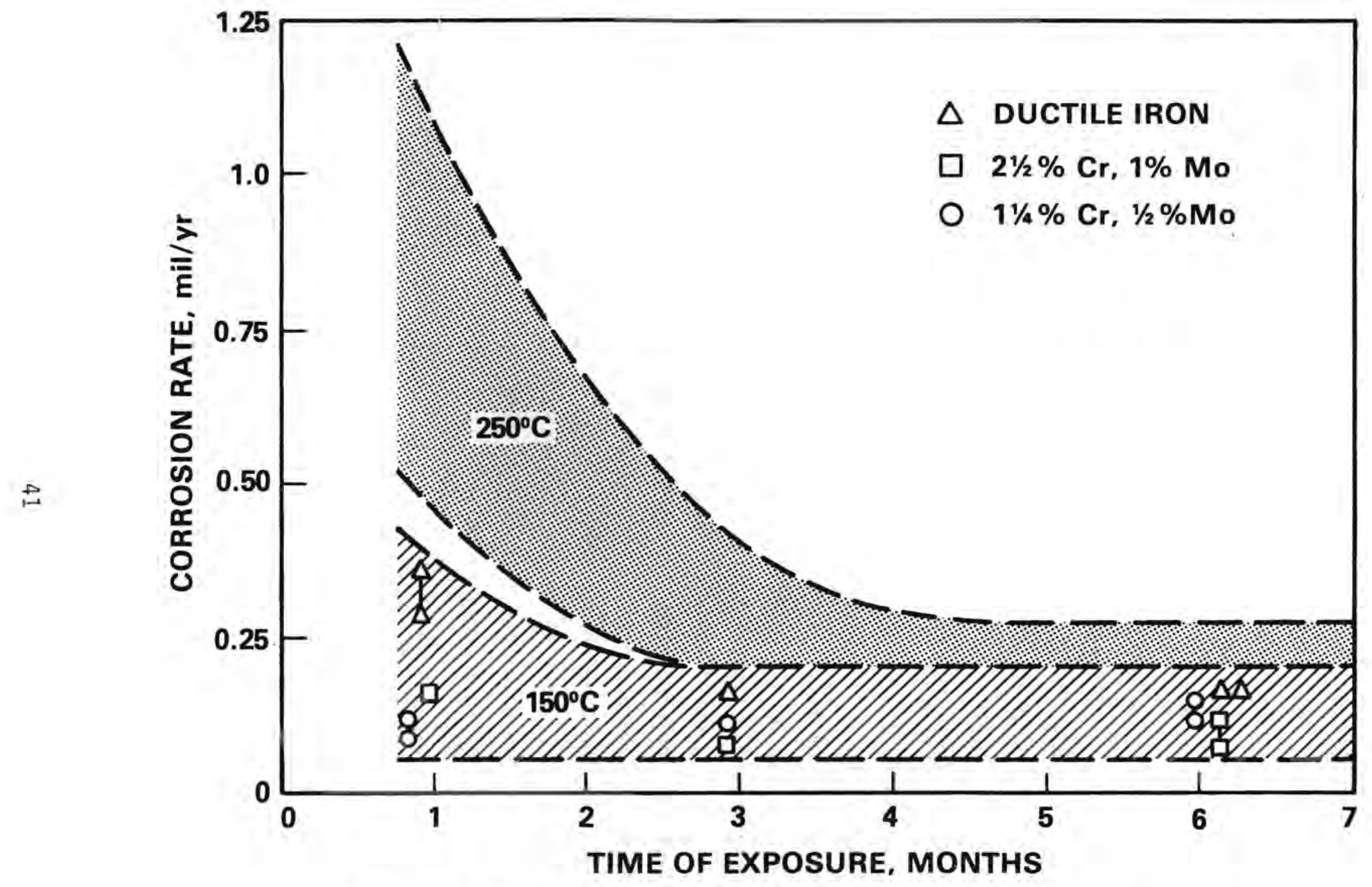

FIGURE 14. The General Corrosion of Cast Ferrous Materials in Basalt Ground Water at $150^{\circ} \mathrm{C}$ and $250^{\circ} \mathrm{C}$ Based on Linear Corrosion Kinetics 
specimens present a much rougher appearance under microscopic inspection than the steel specimens. This roughness may be a prelude to a pitting mode of degradation. Pitting attack is, of course, a potentially serious form of barrier degradation, and any tendency of a candidate barrier material to show such non-uniform attack must be taken into account when barrier elements are being designed.

The corrosion data presented in Figures 13 and 14 suggest that ferrous materials offer a great deal of promise as waste package structural barrier elements in a basalt repository for time periods up to 1000 years. Of course, possible effects of radiation and the possible interaction of environmental and mechanical considerations, as in stress corrosion cracking, are not addressed in the general corrosion results presented in these figures.

Elucidation of the corrosion mechanism would be extremely valuable for data extrapolation to very long times. A procedure commonly used to ascertain the operative mechanism is to determine, at a given temperature, whether the corrosion data can be expressed in terms of a time rate law, i.e., metal weight loss (penetration) $=f(t)$. In Figures 15 and 16 the weight loss exhibited by the specimens is plotted against exposure time. The $250^{\circ} \mathrm{C}$ data (Figure 15) show no correlation with a continuous function of time, as the specimen weight loss does not change appreciably with time after one month. The $150^{\circ} \mathrm{C}$ data (Figure 16), on the other hand, show a fairly good adherence to a linear rate law. The data of Figures 15 and 16 represent only a first attempt to fit the existing short-term data to a tractable mathematical expression, and so must be viewed as simply a preliminary exercise.

The next logical step in the procedure to elucidate the corrosion mechan$i s m$ involves characterization of the corrosion product layer that forms on the sample surface. The corrosion product layer on the surface of a specimen of ductile iron exposed to $250^{\circ} \mathrm{C}$ basalt ground water for 5 months was analyzed by $X$-ray diffraction. A strong indication of analcime, $\mathrm{NaAlSi}{ }_{2} \mathrm{O}_{6}{ }^{*} \mathrm{H}_{2} \mathrm{O}$, was found. Microscope examination revealed discrete "islands" of crystals of this compound scattered over the specimen surface. The principal corrosion product on the surface of the specimen, however, was found to be nontronite ( $\mathrm{Fe}, \mathrm{Al}) \mathrm{Si}_{2} \mathrm{O}_{5}$ $(\mathrm{OH}) \cdot n\left(\mathrm{H}_{2} \mathrm{O}\right)$. The diffraction pattern was diffuse, indicative of a weakly 


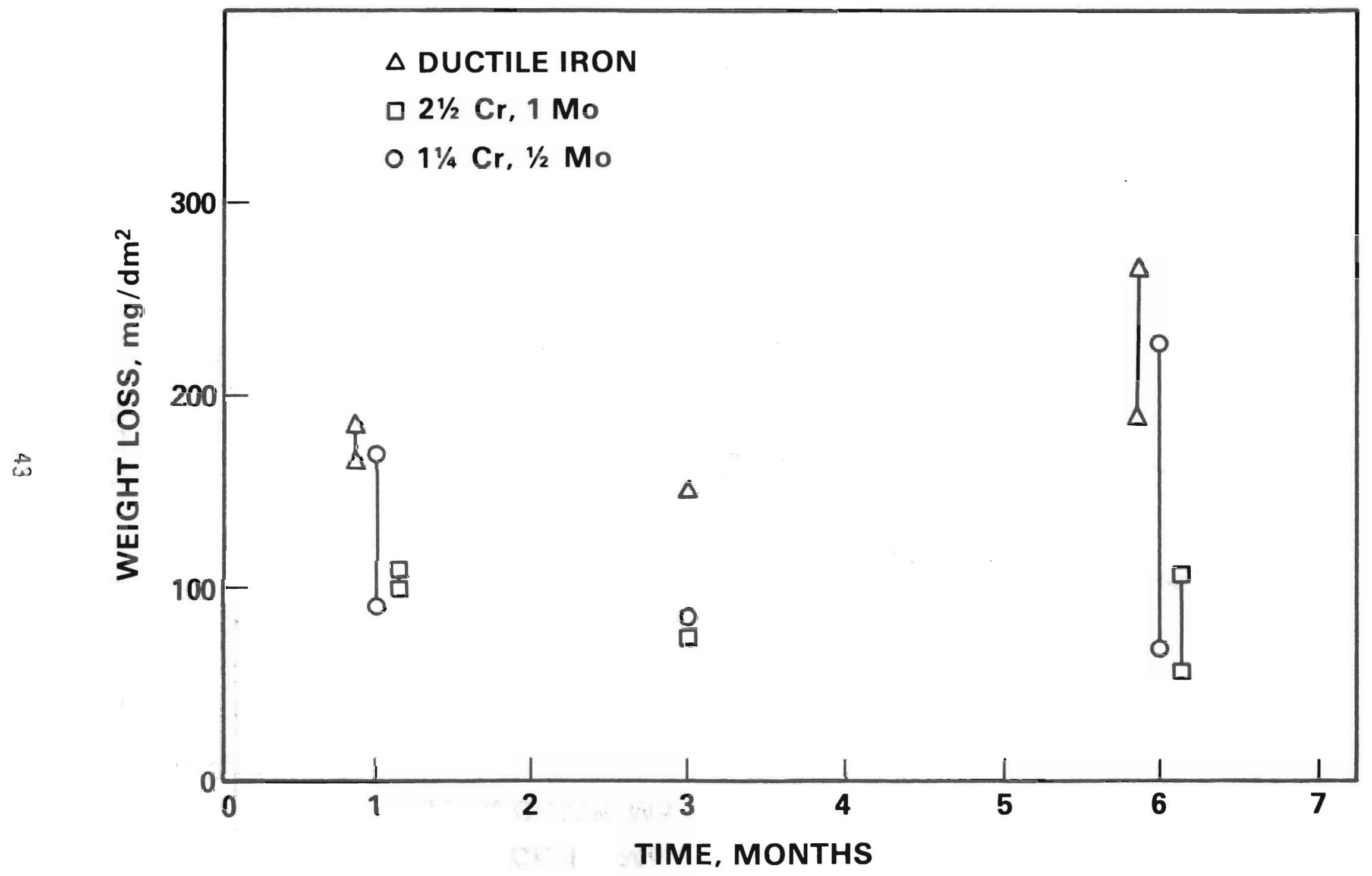

FIGURE 15. Specimen Weight Loss As a Function of Exposure Time in Basalt Ground Water at $250^{\circ} \mathrm{C}$ 


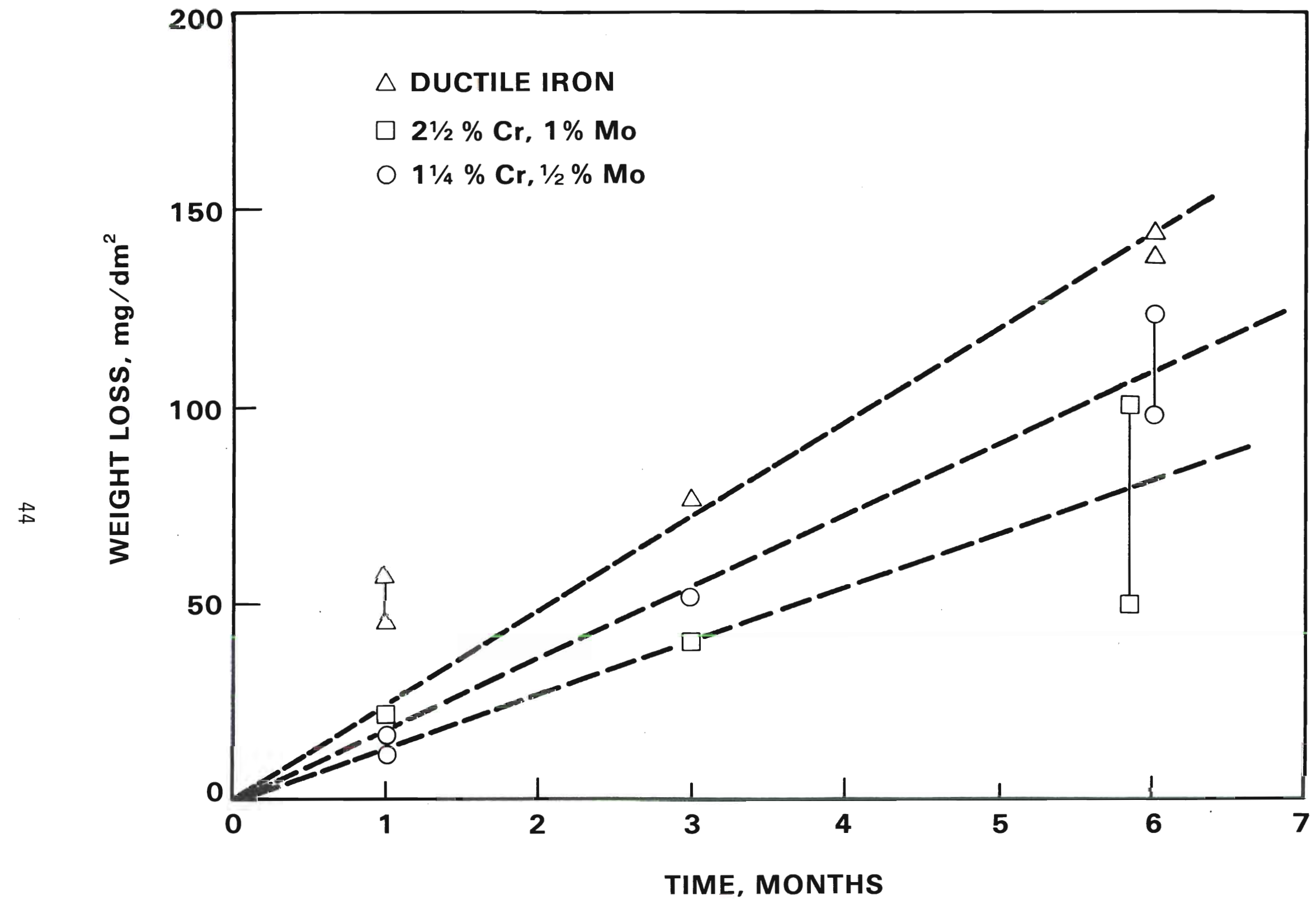

FIGURE 16. Specimen Weight Loss As a Function of Exposure Time in Basalt Ground Water at $250^{\circ} \mathrm{C}$ 
organized crystal structure. No indication was found of hematite, $\mathrm{Fe}_{2} \mathrm{O}_{3}$, or magnetite, $\mathrm{Fe}_{3} \mathrm{O}_{4}$. A photomicrograph of the corrosion product film crosssection is shown in Figure 17. A notable feature of the film is the numerous small crystallites incorporated in it that have apparently been derived from the basalt in the bottom of the autoclave. The film appears otherwise to be of uniform structure.

Further characterization of specimens in this study is planned after 12 months of exposure.

Tuffaceaus ground water studies. Only a limited amount of data are available to date for the general corrosion of iron-base materials in tuffaceous ground water. One-month data, once again conservatively expressed in terms of a linear rate, are shown in Figure 18. For purposes of comparison they are superimposed on the basalt ground water corrosion data scatter band. These preliminary results suggest a corrosion penetration behavior that is somewhat less than that exhibited by the basalt ground water. The $1-1 / 4 \% \mathrm{Cr}, 1 / 2 \% \mathrm{Mo}$ data point lying above the data point cluster represents a specimen that lay

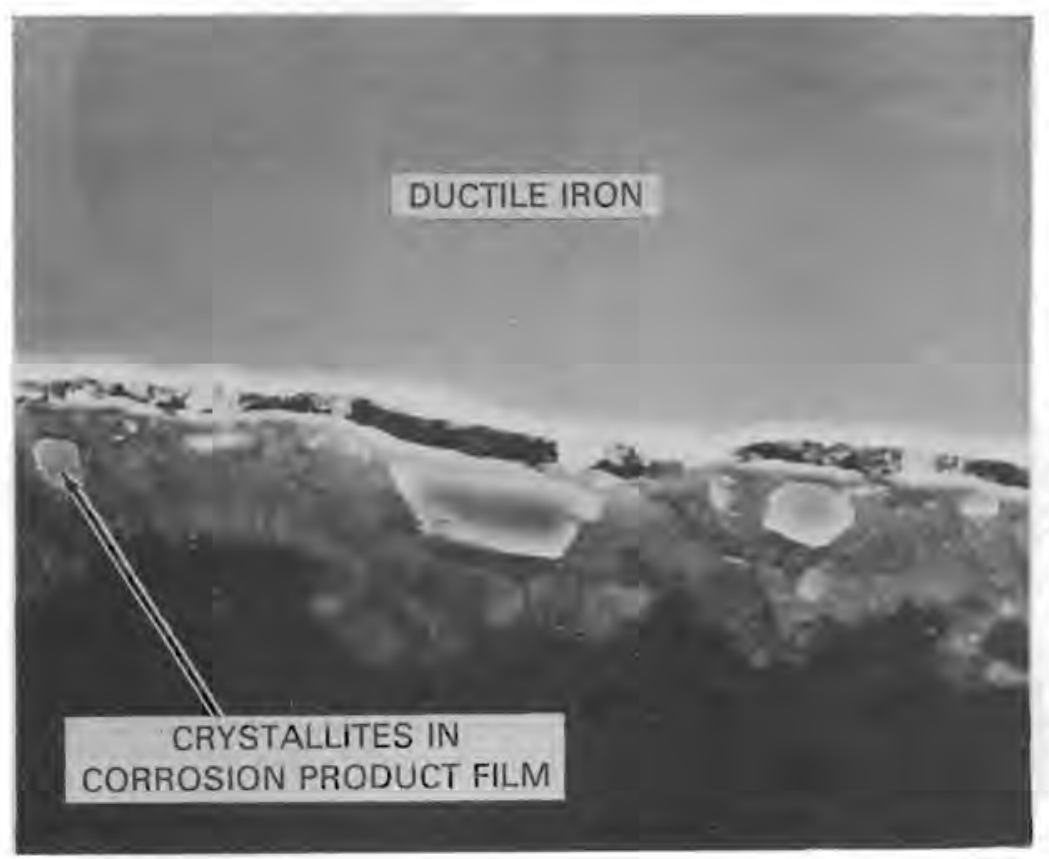

FIGURE 17. Photomicrograph of Cross Section of Corrosion Product Film on Ductile Iron Specimen After 5-Month Exposure in Basalt Ground Water at $250^{\circ} \mathrm{C}$ 


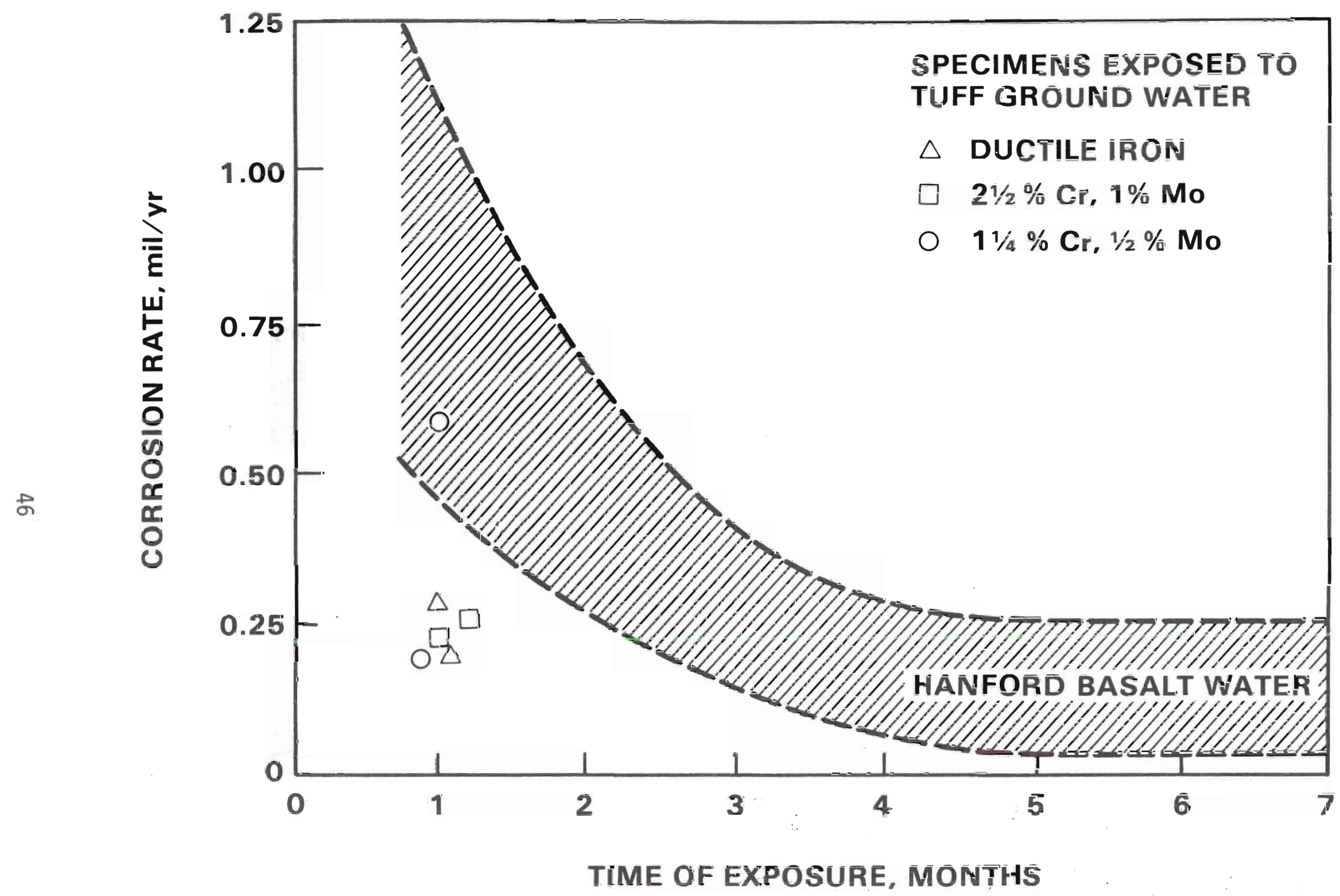

FIGURE 18. The General Corrosion of Cast Ferrous Materials in Tuff Ground Water at $250^{\circ} \mathrm{C}$, Compared to the Rates Found in Basalt Ground Water, Based on Linear Corrosion Kinetics 
partly in the vapor phase for $21 / 2$ day following a rupture disc failure on the inlet line to the autoclave.(a) During this time the autoclave remained pressurized (560 psi) and at temperature. It is not known for certain whether the vapor phase is more corrosive than the liquid phase, hence the cause of the relatively high weight gain. The "water-line" is definitely visible on the specimen, however, and a visual observation would lead one to suspect a higher corrosion rate on the vapor-phase end of the sample.

A ductile iron specimen having a water-line was examined by $X$-ray diffraction. Both nontronite ( $\mathrm{Fe}, \mathrm{Al}) \mathrm{Si}_{2} \mathrm{O}_{5}(\mathrm{OH}) \cdot \mathrm{nH}_{2} \mathrm{O}$ and magnetite $\left(\mathrm{Fe}_{3} \mathrm{O}_{4}\right)$ were found below and above the water line. Below the line magnetite predominated; above the line nontronite yielded the stronger pattern. A 2-1/2\% $\mathrm{Cr}, 1 \%$ Mo specimen from the test, having no water-line, showed only magnetite on its surface. A $1-1 / 4 \% \mathrm{Cr}, 1 / 2 \%$ Mo specimen, also without a water line, showed both magnetite and nontronite.

Deionized water studies. The general corrosion of the candidate cast ferrous materials is being determined in oxic deionized water to provide a corrosion data base obtained in the absence of the ground water constituents normally present in basalt or tuffaceous ground waters. It is anticipated that this data base will provide insights into the effect of certain ground water constituents on the corrosion process, i.e., which corrosion products form and the rate at which they form, and so assist in the elucidation of corrosion mechanisms.

The 1- and 3-month data obtained in $250^{\circ} \mathrm{C}$ oxic deionized water are shown in Figure 19, expressed in terms of linear kinetics and superimposed on the basalt ground water data scatter band. It can be seen that the corrosion rates found in distilled water lie entirely within the basalt data scatter band, suggesting that deionized water is approximately as corrosive toward the candidate ferrous materials as is the basalt ground water. The corrosion product found

(a) The inlet line is prone to plugging due to formation of a calcium carbonate deposit where the line becomes heated as it penetrates the autoclave head. (Both calcite and aragonite have been found to make up the carbonate plug.) The plug tends to retain the contents of the autoclave after failure of the inlet rupture disc. 


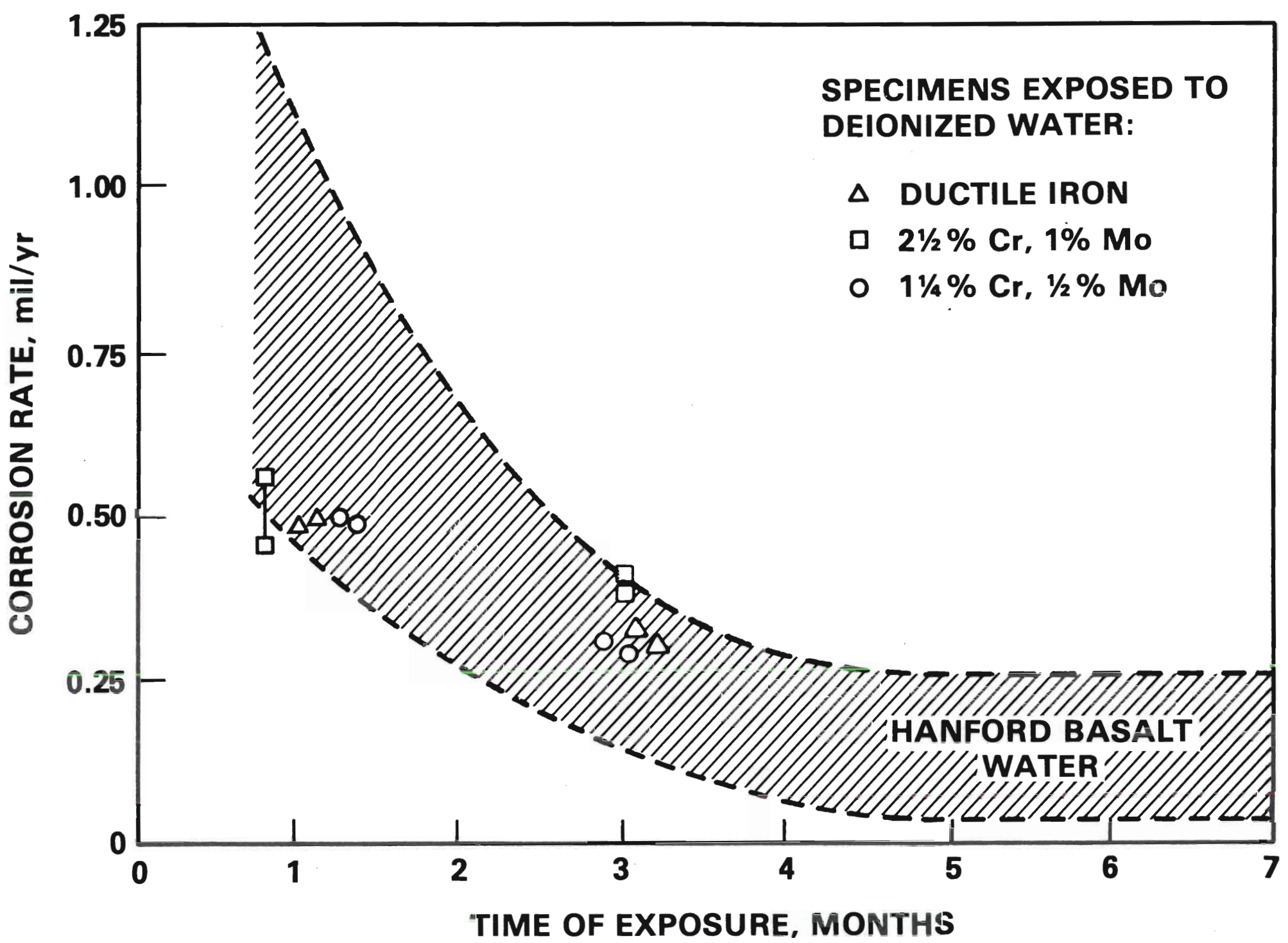

FIGURE 19. The General Corrosion of Cast Ferrous Materials in Deionized Water at $250^{\circ} \mathrm{C}$, Compared to Basalt Ground Water Based on Linear Kinetics 
on the surface of a ductile iron specimen exposed for 2 months test duration consisted, not surprisingly, only of magnetite $\left(\mathrm{Fe}_{3} \mathrm{O}_{4}\right)$. This corrosion product is apparently about as protective as the nontronite layers formed on the specimens in the basalt water study. It has been found to be more difficult to strip the corrosion products from the deionized water exposed specimens than from specimens exposed to the basaltic or tuffaceous ground waters preparatory to sample weighing.

\section{Irradiation-Corrosion}

In order to study irradiation effects on the corrosion and hydriding of candidate structural barrier materials under repository-relevent conditions, an existing ${ }^{60}$ Co irradiation facility $(a)$ was modified to accept three highpressure, high-temperature refreshed autoclaves. A schematic diagram of the facility is shown in Figure 20. The electrically heated autoclaves lie within dry access tubes in the water pool. Each autoclave has its own independent water inlet, sampling, and effluent system. The system is capable of exposing specimens to flowing simulated ground water environments at a maximum temperature of $300^{\circ} \mathrm{C}$ and a maximum radiation dose rate to the specimen environment of $\sim 2 \times 10^{6} \mathrm{rad} / \mathrm{hr}$.

As in the case of the unirradiated specimen tests, a layer of the appropriate crushed rock $\sim 2$ in. deep is placed in the bottom of the autoclave to "fine-tune" the water chemistry as the ground water passes upward through the rock bed into the region of the autoclave occupied by the specimens. The autoclaves are of approximately $1 \mathrm{~L}$ volume. The usual flow rate (refreshment rate) is $\sim 35 \mathrm{~mL} / \mathrm{hr}$. The iron-base specimens currently area being exposed in an autoclave made of Inconel 600, a corrosion-resistant nickel-base alloy. The titanium specimens are in a Titanium Grade 2 autoclave. The autoclaves are operated at $\sim 700$ psi to maintain the water in the liquid phase during $250^{\circ} \mathrm{C}$ operation.

The eventual exposure of waste package barrier elements to an environment altered by gamma radiation is highly probable, as discussed in the Approach section of this report. Because of the great difficulty in predicting

(a) The irradiation facility is administered by the Westinghouse Hanford Company. 


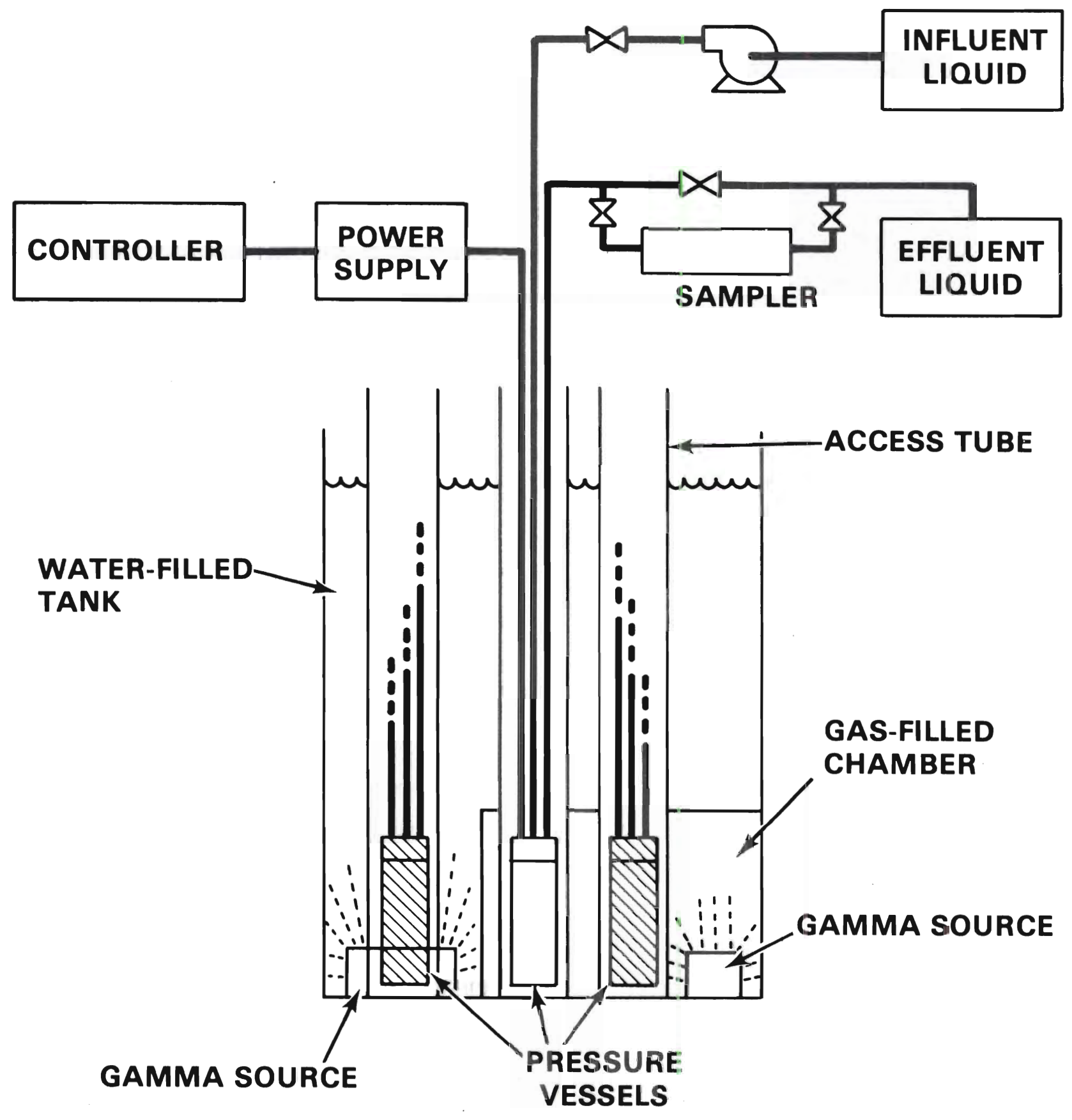

FIGURE 20. Schematic Diagram of Irradiation-Corrosion Test Facility 
theoretically the effects of radiation-altered environments on the degradation of candidate barrier materials, recourse must be made to obtain experimental results that combine the effects of radiation with the high-temperature aqueous environment. The experimental irradiation-corrosion test matrix is presented below:

\begin{tabular}{|c|c|c|c|c|}
\hline Materials & $\begin{array}{l}\text { Aqueous } \\
\text { Medium }\end{array}$ & $\begin{array}{c}\text { Test } \\
\text { Temperature } \\
\end{array}$ & $\begin{array}{l}\text { rDose Rate, } \\
\mathrm{rad} / \mathrm{hr} \text { (max.) } \\
\end{array}$ & $\begin{array}{l}\text { Max. Test } \\
\text { Duration } \\
\text { Reported } \\
\end{array}$ \\
\hline $\begin{array}{l}\text { Cast ductile iron } \\
\text { Cast } 2-1 / 2 \% \mathrm{Cr}, \\
1 \% \text { Mo steel }\end{array}$ & $\begin{array}{l}\text { Oxic basaltic } \\
\text { ground water }\end{array}$ & $250^{\circ} \mathrm{C}$ & $\sim 2 \times 10^{5}$ & 3 months \\
\hline $\begin{array}{ll}\mathrm{Ti} & \text { Grade } 2 \\
\mathrm{Ti} & \text { Grade } 12\end{array}$ & $\begin{array}{l}\text { Oxic basaltic } \\
\text { ground water }\end{array}$ & $250^{\circ} \mathrm{C}$ & $\sim 1 \times 10^{6}$ & 3 months \\
\hline
\end{tabular}

The corrosion rates of the cast ferrous materials in oxic basalt ground water, based on a linear-kinetics data interpretation, are shown in Figure 21. The data are superimposed on the data band from the nonirradiated, but otherwise equivalent, system for comparison. The corrosion rates showed a substantial increase in progressing from the 1-month test duration to the 3-month exposure. The ductile iron sample showing the highest corrosion rate exhibited non-uniform corrosion, not apparent in the other samples. The attack consisted of a mass of closely-spaced, shallow pits, covering about two-thirds of one sample surface.

Between the 1- and 3-month data analysis points the autoclave operated in the vapor phase, apparently because of a silightly elevated temperature, for several days. It is not known whether this operational anomaly could have a bearing on the increased corrosion rates observed.

The corrosion product on the surface of a specimen of ductile iron removed from the irradiation-corrosion test after a 1-month exposure consisted entirely of nontronite, $(\mathrm{Fe}, \mathrm{Al}) \mathrm{Si}_{2} \mathrm{O}_{5}(\mathrm{OH}) \cdot \mathrm{nH}_{2} \mathrm{O}$. After the 3-month exposure, $X$-ray diffraction analysis of a ductile iron specimen revealed large amounts of analcime, $\mathrm{NaAlSi}{ }_{2} \mathrm{O}_{6} \cdot \mathrm{H}_{2} \mathrm{O}$, and hematite, $\mathrm{Fe}_{2} \mathrm{O}_{3}$. No nontronite was present. A specimen of $2-1 / 2 \% \mathrm{Cr}, 1 \%$ Mo steel, examined after 3 months of exposure, also 


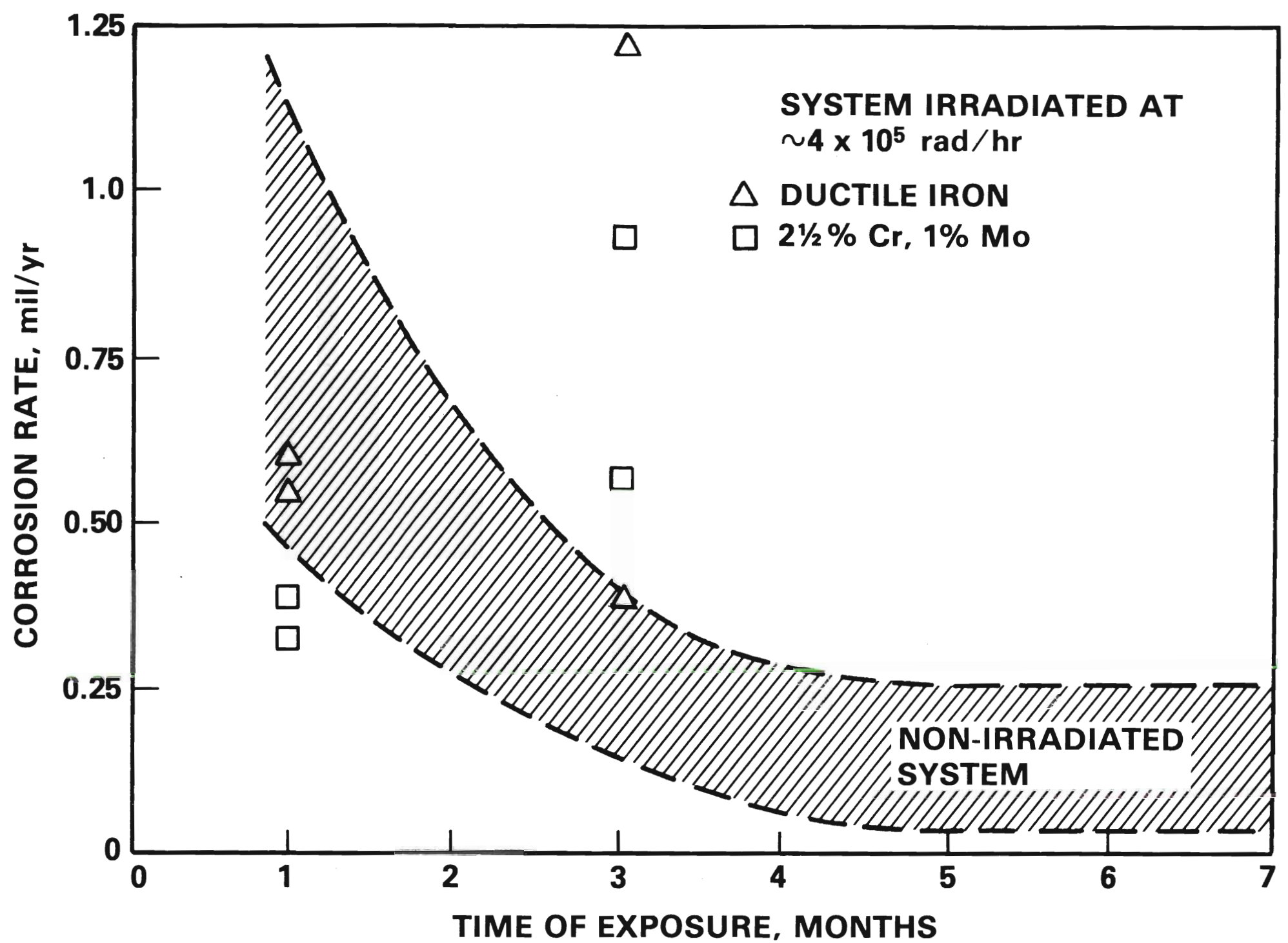

FIGURE 21. The General Corrosion of Two Cast Ferrous Materials in Basalt Ground Water at $250^{\circ} \mathrm{C}$, with and without Radiation, Based on Linear Corrosion Kinetics 
showed evidence of analcime and hematite. Also, it was found that some areas of the specimen were covered only with a film of magnetite, $\mathrm{Fe}_{3} \mathrm{O}_{4}$. Again, nontronite was not present.

The finding of relatively high corrosion rates in the radiation-corrosion test raises some questions regarding the stability of iron-base alloys in the irradiated basalt ground water environment. Further testing must be relied upon to resolve the validity of the observations and the potential implications to the design of ferrous waste package barrier elements.

Titanium Grade 2 and Grade 12 materials are being exposed to the irradiated oxic basalt ground water environment in four different specimen configurations: corrosion coupons, U-bend specimens, Charpy V-notch impact specimens, and compact tension fracture toughness specimens bolt-loaded to a stress intensity level of $20 \mathrm{ksi} \sqrt{\mathrm{in}}$. The fully-loaded specimen holder is shown in Figure 22.

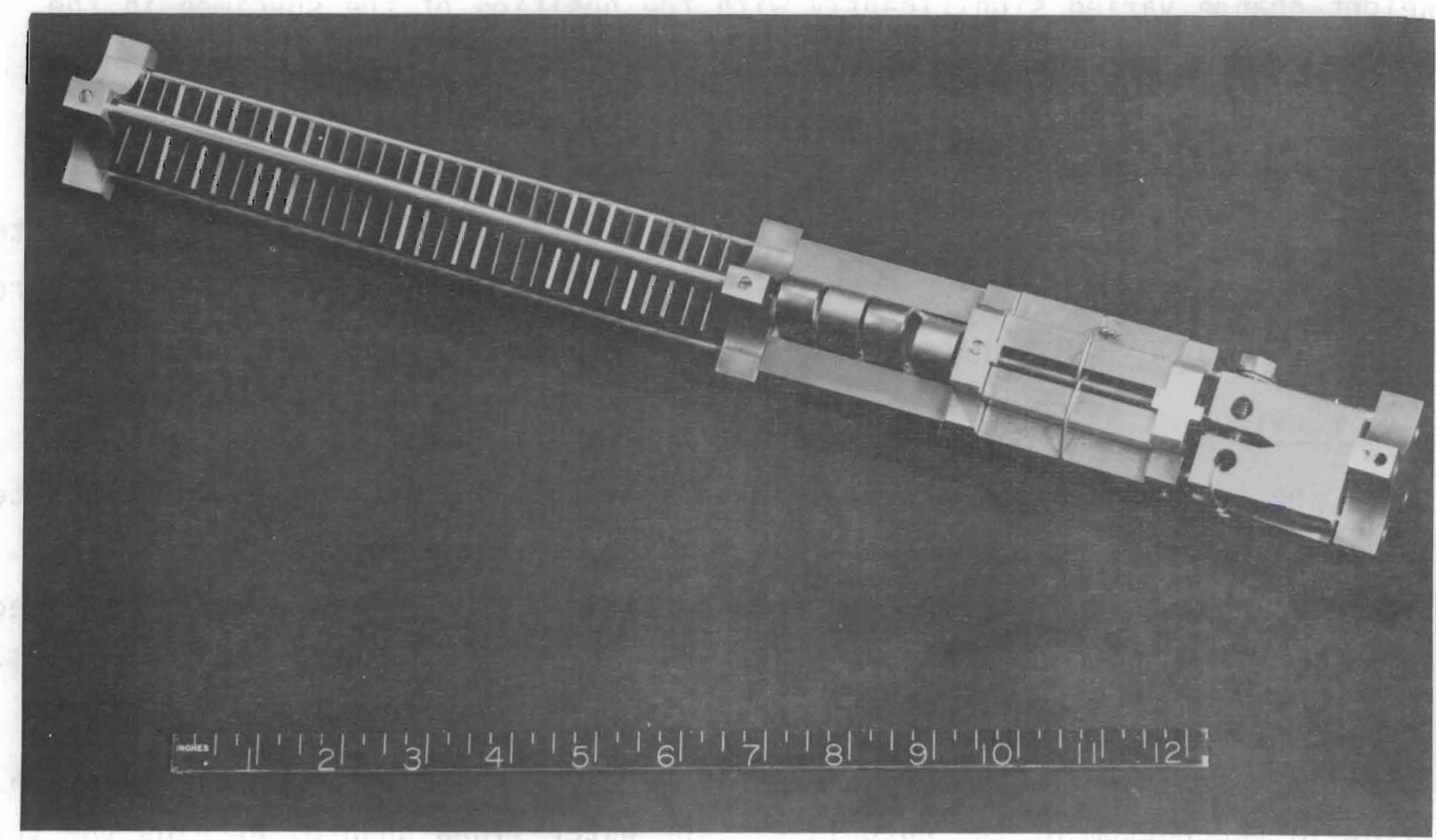

FIGURE 22. Sample Holder Containing Titanium Alloy Specimens for Irradiation-Corrosion Study 
The radiation intensity is not uniform throughout the autoclave holding the titanium specimens. The approximate variation of radiation intensity with the position of samples in the sample holder is shown in Figure 23. Note that the corrosion coupons are exposed to a maximum radiation intensity of about $1 \times 10^{6} \mathrm{rad} / \mathrm{hr}$, with the maximum occurring at the bottom of the holder. The minimum radiation intensity (at the top of the holder) cannot be accurately estimated but it is thought to be no more than $1 \times 10^{4} \mathrm{rad} / \mathrm{hr}$.

After an exposure of 3 months, stress-corrosion cracking failures were not observed in the U-bend specimens, and crack extension was not observed in the bolt-loaded compact tension specimens.

Two corrosion coupon specimens, one of Grade 2 and one of Grade 12 alloy, were removed from the sample holder for surface analysis after 3 months exposure. No rutile $\left(\mathrm{TiO}_{2}\right)$ was found on the sample surfaces--only titanite, CaTiSiO $0_{5}$, was observed.

The corrosion coupons were all weighed after 3 months' exposure. The weight change varied significantly with the position of the specimen in the sample holder, presumably due to radiation effect (Figure 24). The Grade 2 material corrodes at a much more rapid rate than the Grade 12 alloy in the irradiated environment. If the corrosion product film is assumed to be completely composed of titanite, the Grade 2 material is only corroding at a rate of $\sim 0.04 \mathrm{in}$. in 1000 years. The radiation effect observed would therefore probably not be considered particularly important to a waste package designer.

\section{Envi ronmental-Mechanical}

The environmental-mechanical tests consist primarily of slow-strain-rate testing and fatigue-crack-growth-rate testing. A diagram of a typical slowstrain-rate testing apparatus is shown in Figure 25. The specimen is strained to failure at a fixed rate while it is immersed in a repository-relevant environment using an approach similar to that used in the corrosion screening studies, i.e., simulated ground water is pumped through a bed of crushed rock lying in the bottom of the autoclave. The water flows upward, attains the test temperature, passes over the specimen, then flows out to the drain through a pressure-control valve on a once-through basis. The specimen load and strain 


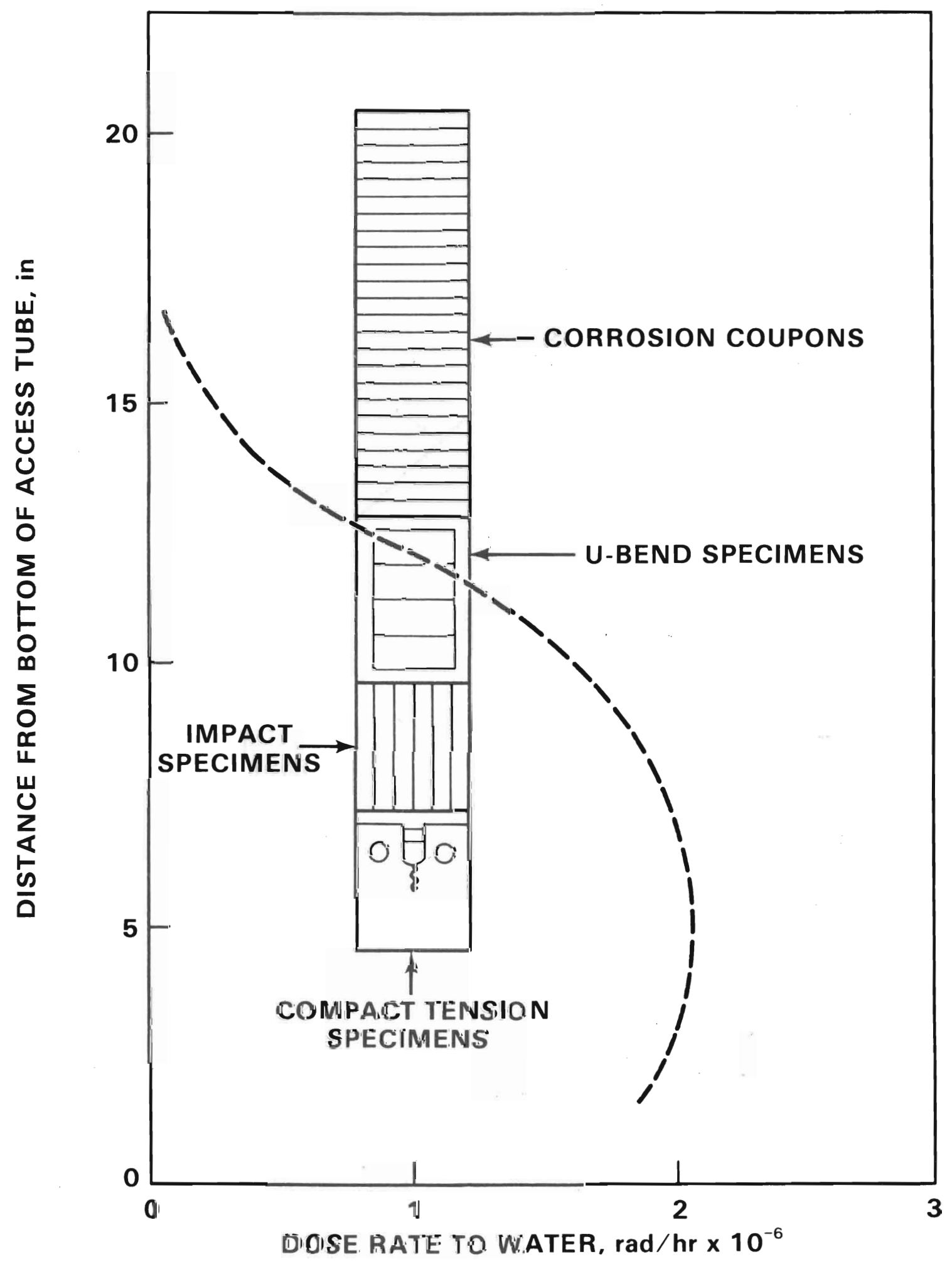

FIGURE 23. Variation of Local Radiation Intensity with Position of Specimen in Holder 


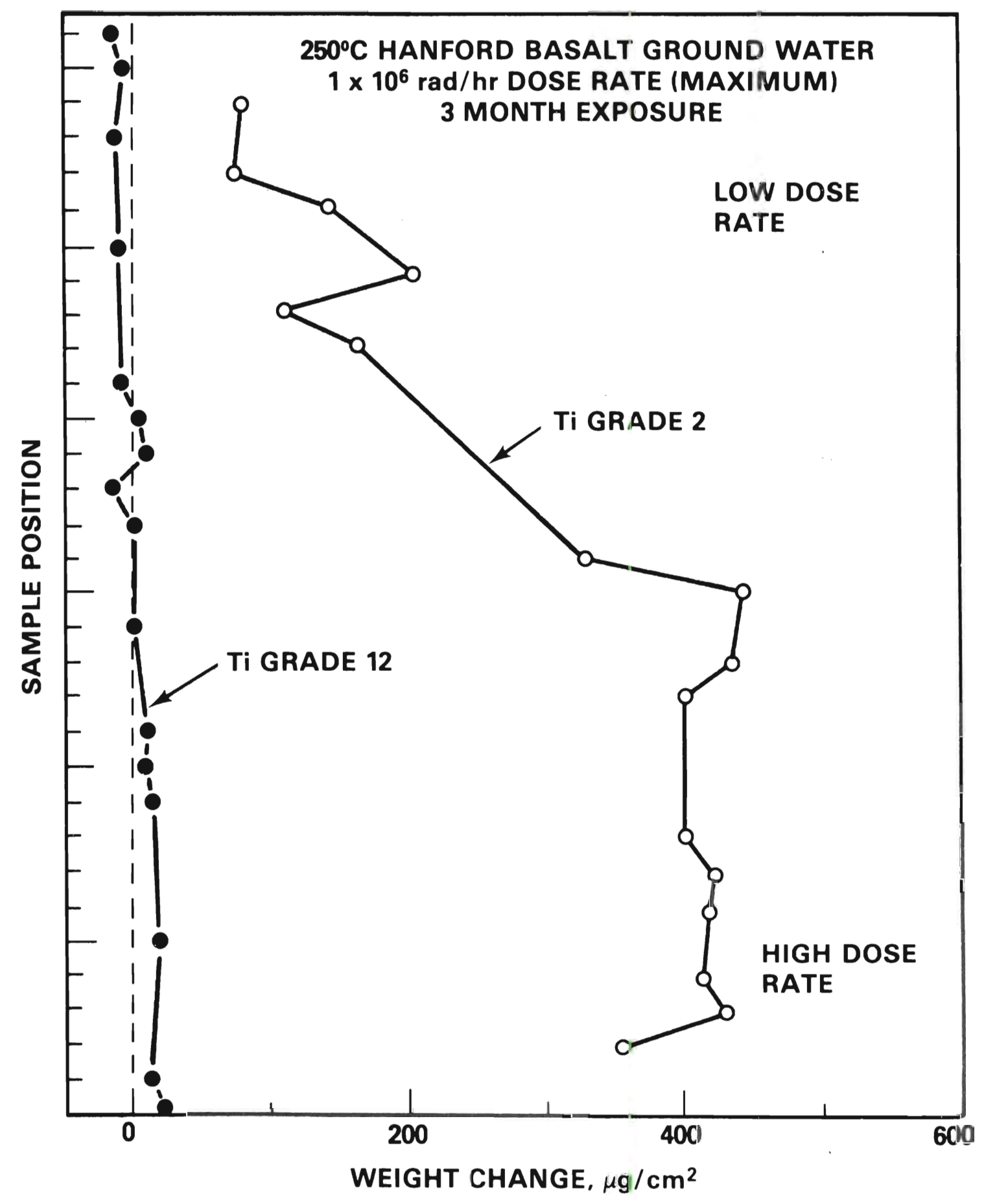

FIGURE 24. Effect of Sample Position on Weight Change Observed 


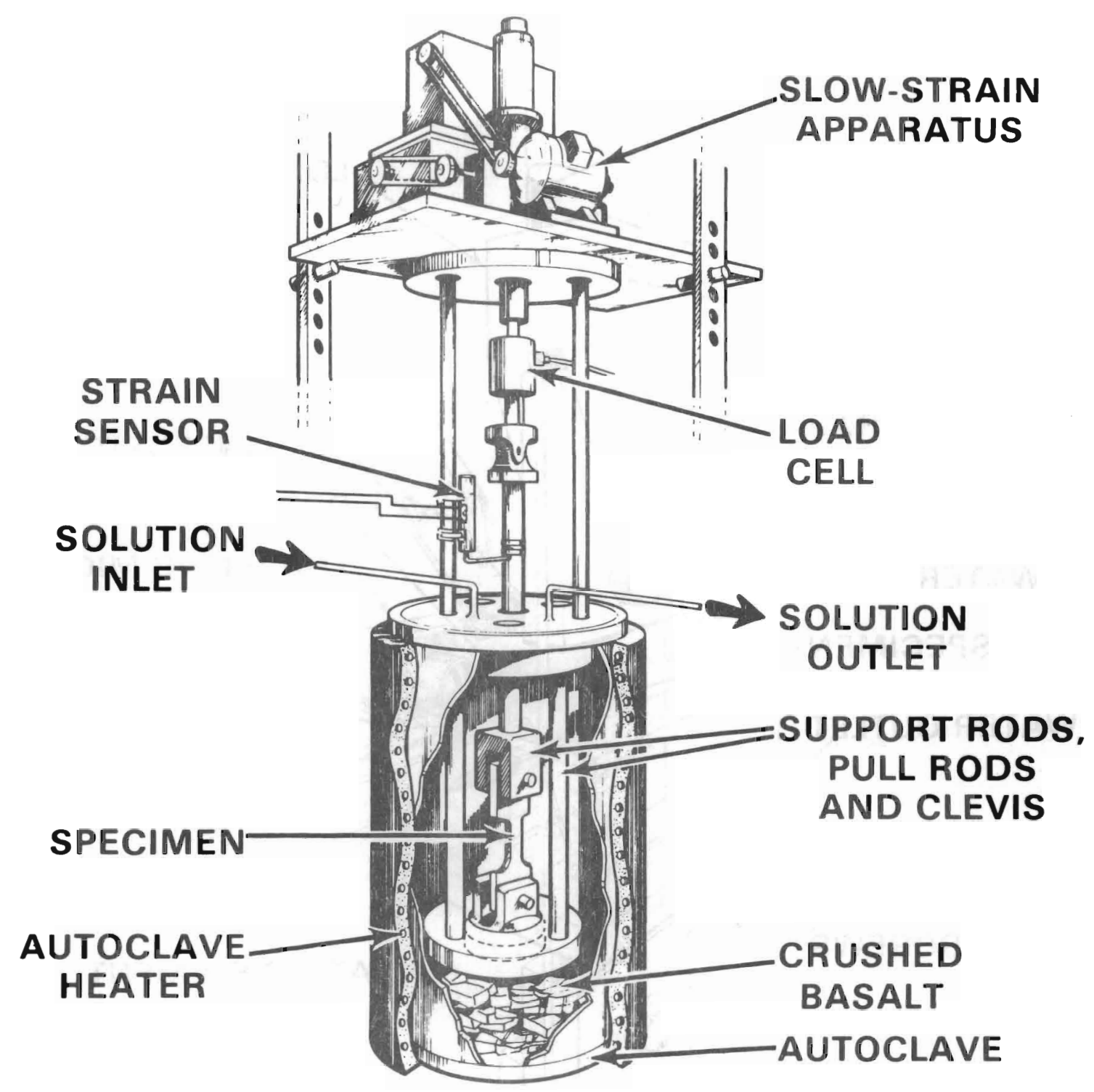

FIGURE 25. Typical Slow-Strain Rate System

are continuousiy monitored. Strain rates of $10^{-4}$ in./in.-sec to $2 \times 10^{-7}$ in.l in.-sec are routinely employed.

A diagram of the ambient-pressure, fatigue-crack-growth-rate apparatus is shown in Figure 26. In this apparatus, a pre-flawed specimen is cyclically loaded at a controlled load and cycling rate while it is submerged in simulated ground water. Because of the ambient pressure constraint, temperatures in this facility are limited to $\sim 90^{\circ} \mathrm{C}$. The small tank of simulated ground water surrounding the specimen is continually refreshed on a once-through basis. The 


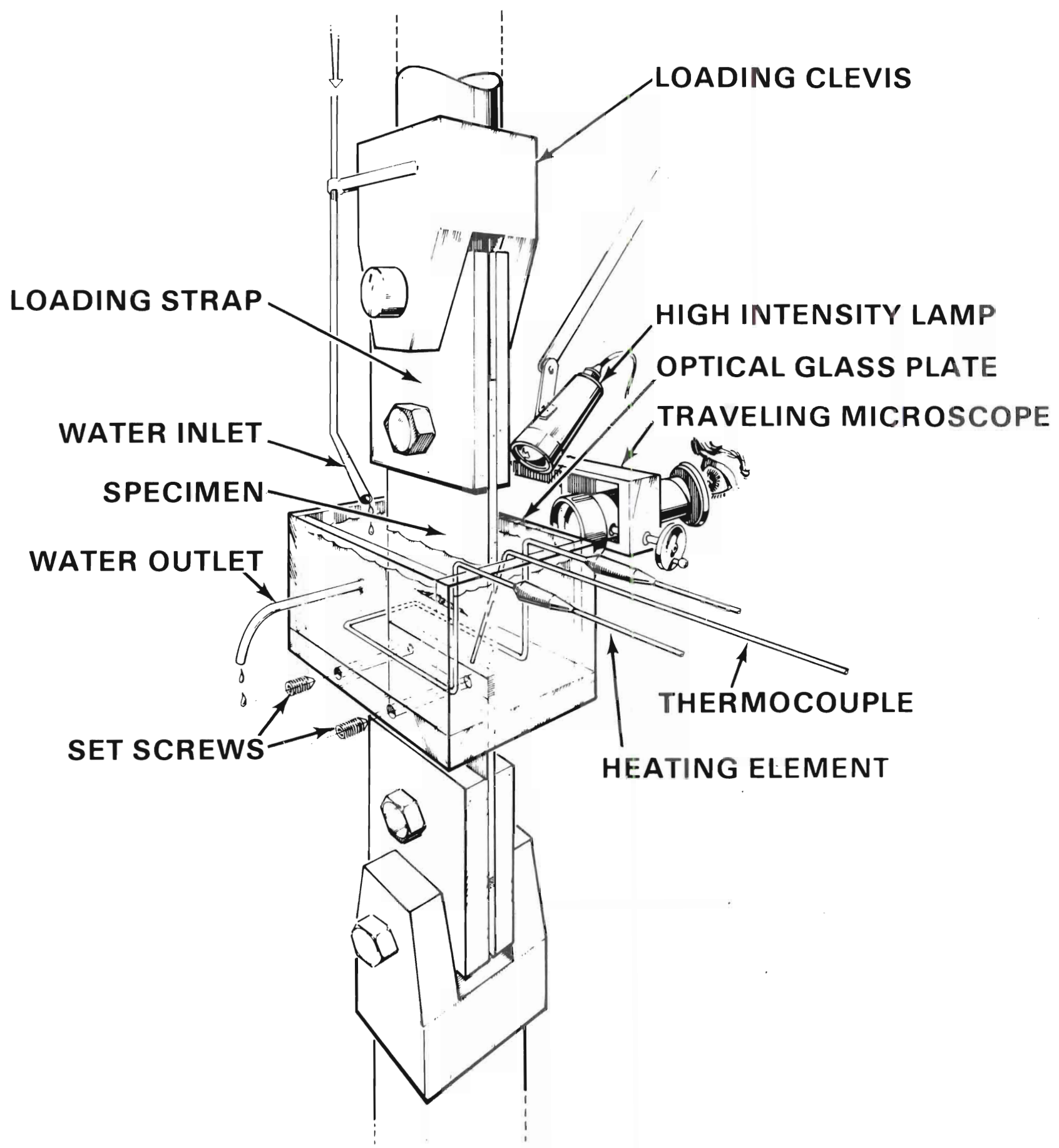

FIGURE 26. Fatigue Crack Growth Rate Test System 
water is allowed to equilibrate with the surrounding air. A traveling microscope is used to determine crack extensions. The ambient pressure constraint on this apparatus clearly prevents the attainment of repository-relevant conditions surrounding the specimen. To correct this testing deficiency, facilities are currently under construction that will be capable of housing the specimen and the surrounding environment in special high-pressure, high temperature autoclaves.

The environmental-mechanical studies have primarily sought to determine the susceptibility, if any, of Titanium Grade 2 and Titanium Grade 12 alloys to environmentally enhanced fracture in Hanford basaltic ground water. Two major test methods have been used: slow-strain-rate testing and fatigue-crackgrowth-rate testing. In this report a sma11, but representative, portion of the results obtained to date are presented, i.e., the effect of strain rateon ductility and the effect of temperature on ductility of Grade 2 and Grade 12 materials by slow-strain-rate methods, and the crack growth rate of Grade 2 and Grade 12 materials in basalt ground water and inert environments by fatiquecrack-growth-rate test methods.

\section{Slow-Strain-Rate Results}

As discussed in the Approach section of this report, a material's susceptibility to environmentally induced fracture frequently shows up as a ductility reduction in a strain-rate-range intermediate between the relatively rapid strains that do not allow the environment sufficient time to interact with the metal specimen and the very slow strain rates that allow a specimen time to repassivate through relatively long contact with the environment. The results of slow-strain-rate tests of titanium Grade $2, \mathrm{LT}^{(\mathrm{a})}$ orientation, in $250^{\circ} \mathrm{C}$ basalt ground water and $250^{\circ} \mathrm{C}$ air, in which the ductility is described in terms of both reduction of area $(b)$ and elongation $(c)$ and plotted as a function of the

(a) The first letter refers to the direction of loading, i.e., longitudinal (rolling direction) in this example; the second letter refers to the direction of crack propagation, in this case transverse (perpendicular to the rolling direction).

(b) The difference between the smallest cross-sectional area of a specimen after fracture and the original cross-sectional area expressed as a percentage of the original area.

(c) The permanent elongation (plastic strain) of the gauge section of the specimen expressed as a percentage of the original gauge length. 
strain rate, is shown in Figure 27. The ductility of the Grade 2 material is slightly lower at lower strain rates, but there is no ductility "minimum" in the strain rate range investigated. The ductility measured in the air tests is approximately the same as that measured in the ground water tests. As air is considered to be inert (in a crack-enhancement sense) to Titanium Grade 2, it is concluded that there is no susceptibility of the material to crack propagation enhancement in the basaltic ground water.

The Titanium Grade 12 materia1, LT orientation (Figure 28), is clearly affected by strain rate. Once again, there is no ductility "minimum," and there appears to be no difference between the results of the ground water tests and the air tests. This indicates, as before, that the lack of ductility is not caused by the ground water environment, but by an embrittling phenomenon, perhaps a strain-aging process, operating within the metal. The lack of environmentally associated effects indicates that the ability of the metal to accept deformation without cracking is not likely to undergo significant changes over time. The results of similar tests, except on the TL orientation of Titanium Grade 12, are shown in Figure 29. In this case there is an even more profound effect of strain rate on ductility, but once again the air data and the basalt water data agree quite closely. Comparison of Figures 28 and 29 reveals the strong effect of orientation on the mechanical properties of titanium alloys. An analysis of the fracture surfaces of Grade 12 specimens, $\mathrm{TL}$ orientation, tested at the highest and lowest strain rates in $250^{\circ} \mathrm{C}$ basalt ground water is shown in Figure 30. The fracture surfaces are very similar, suggesting an internal strengthening mechanism, not an environmentally-induced failure.

The ductility of Titanium Grade 2, at a constant strain rate of $10^{-4} \mathrm{in./}$ in.-sec, is presented as a function of temperature in Figure 31. Ductility, expressed in terms of reduction of area, is not adversely affected over the temperature range $\left(20\right.$ to $\left.300^{\circ} \mathrm{C}\right)$ investigated; ductility in terms of elongation does, however, show a modest reduction with reduced test temperature. The fracture surfaces of specimens tested at each temperature were observed by 


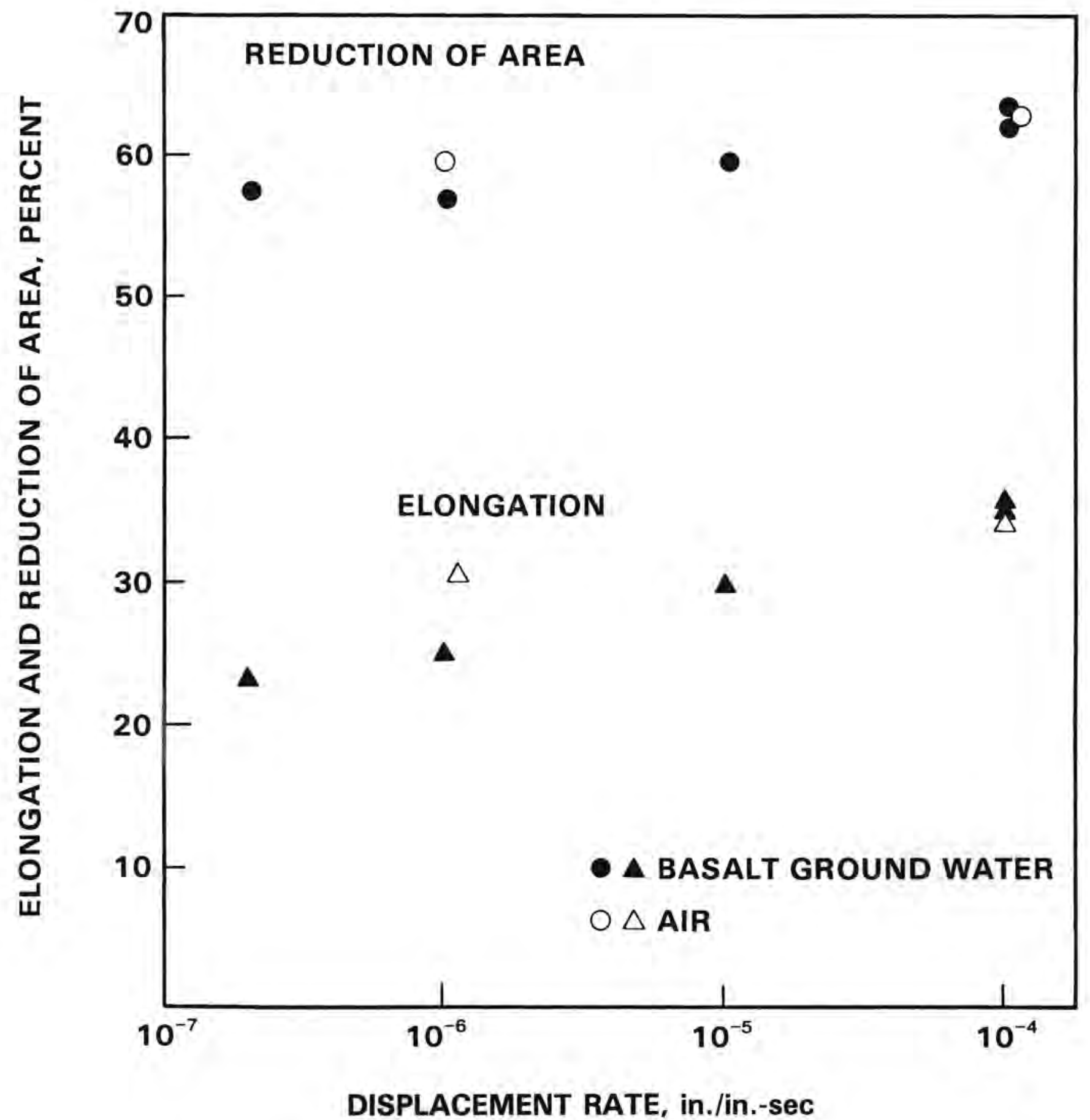

FIGURE 27. Results of Slow-Strain-Rate Testing of Titanium Grade 2, LT Orientation, in Basalt Ground Water and Air at $250^{\circ} \mathrm{C}$ 


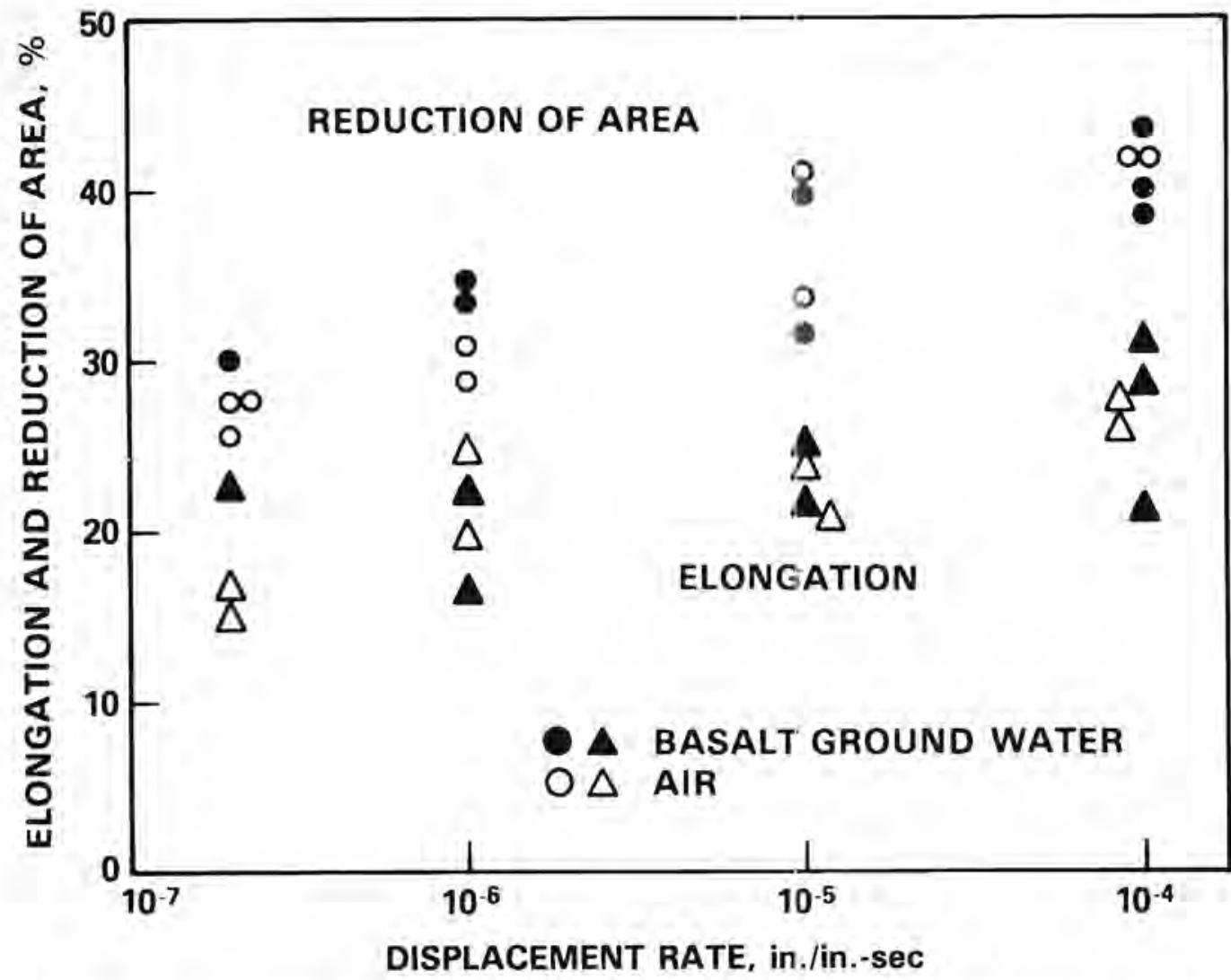

FIGURE 28. Results of Slow-Strain-Rate Testing of Titanium Grade 12, $\mathrm{TL}$ Orientation, in Basalt Ground Water and Air at $250^{\circ} \mathrm{C}$

means of a scanning electron inicroscope. No significant differences were observed between specimens; microvoid coalescence, typical of ductile rupture, was found to be the fracture mode in all cases.

Fatigue crack growth rate tests of Titanium Grade 2 and Grade 12 have been run in basalt ground water, fluoride-ion-enhanced basalt ground water, and high-purity water at $90^{\circ} \mathrm{C}$. Cyclic loading frequencies of $5,1,0.1$, and 0.01 $\mathrm{Hz}$ have been used.

Low frequencies and high flouride ion concentration are considered to represent relatively severe "accelerated" test conditions. Lower frequencies allow relatively long times for the environment to act on the advancing crack tip during each loading cycle, thus potentially increasing the environmentally induced crack growth occurring per cycle. It is known that fluoride ion can, under certain circumstances, break down the passivating film on titanium 


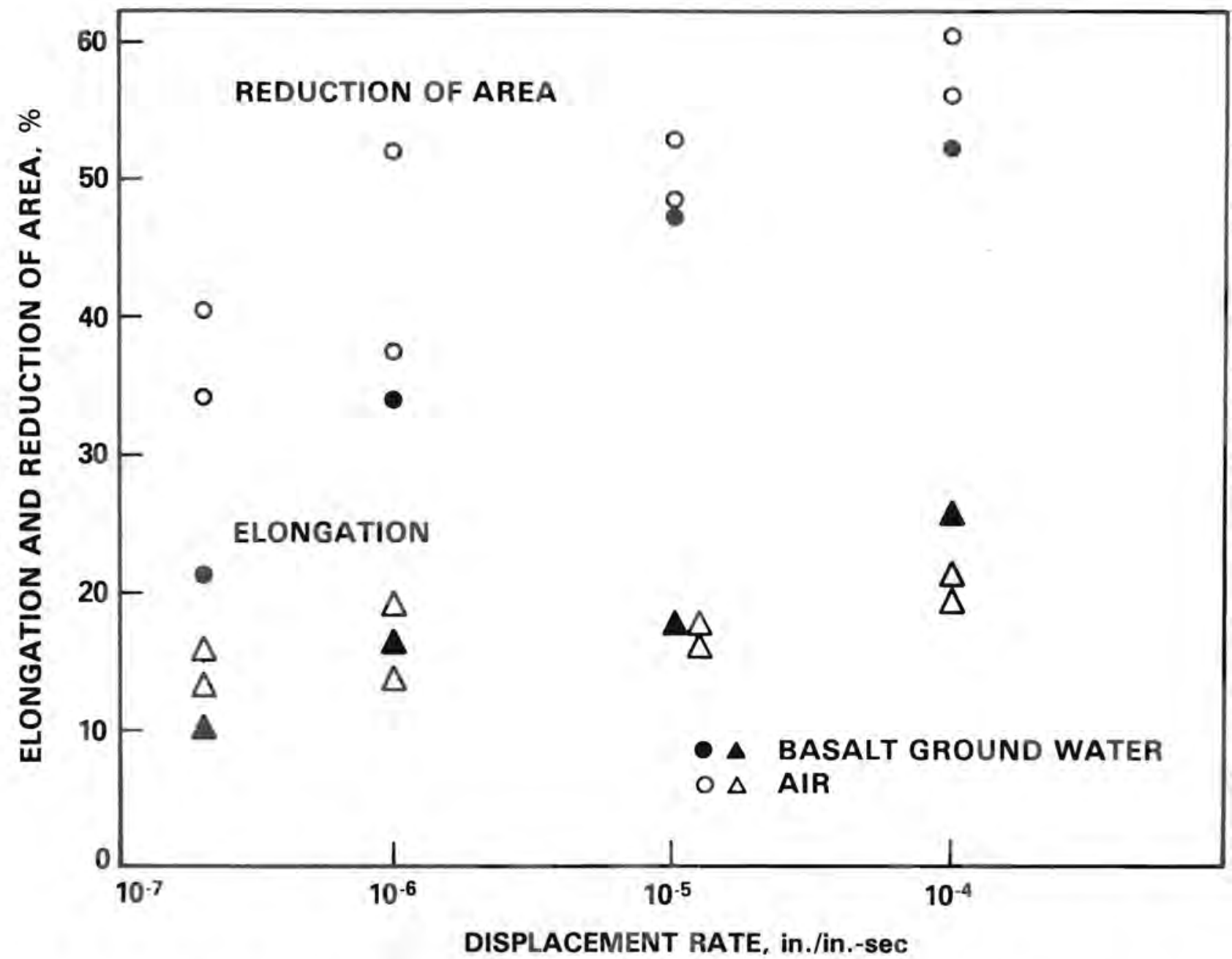

FIGURE 29. Results of Slow-Strain-Rate Testing of Titanium Grade 12, TL Orientation, in Basalt Ground Water and Air at $250^{\circ} \mathrm{C}$ 


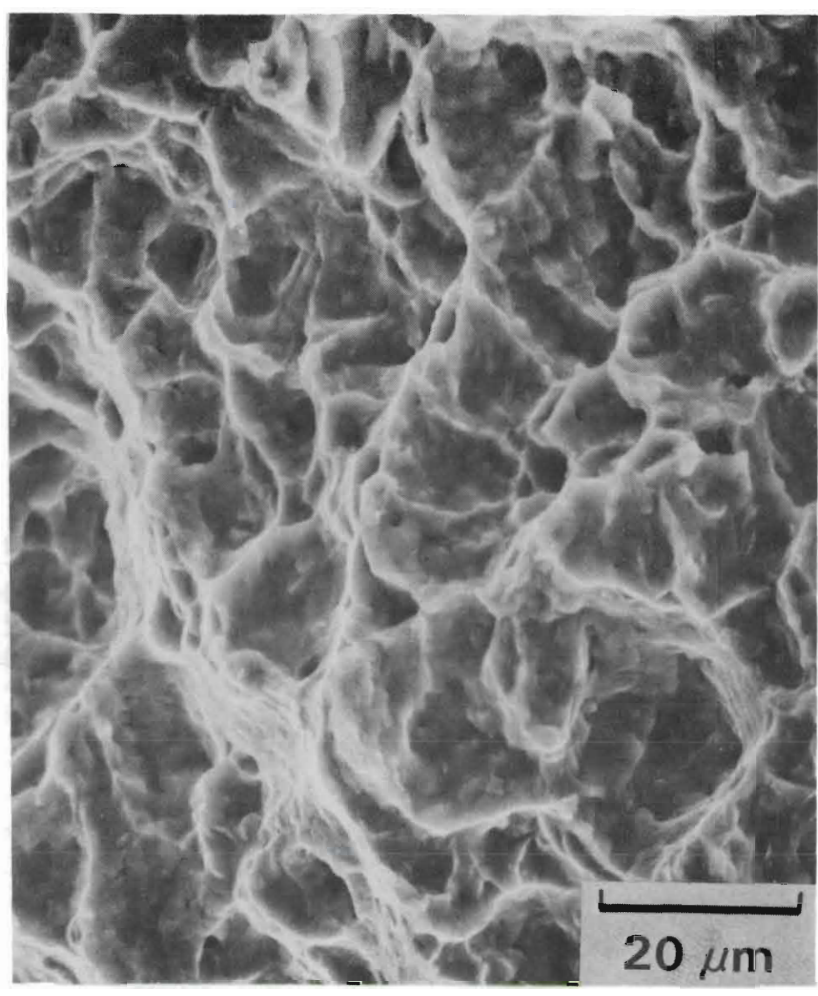

(a)

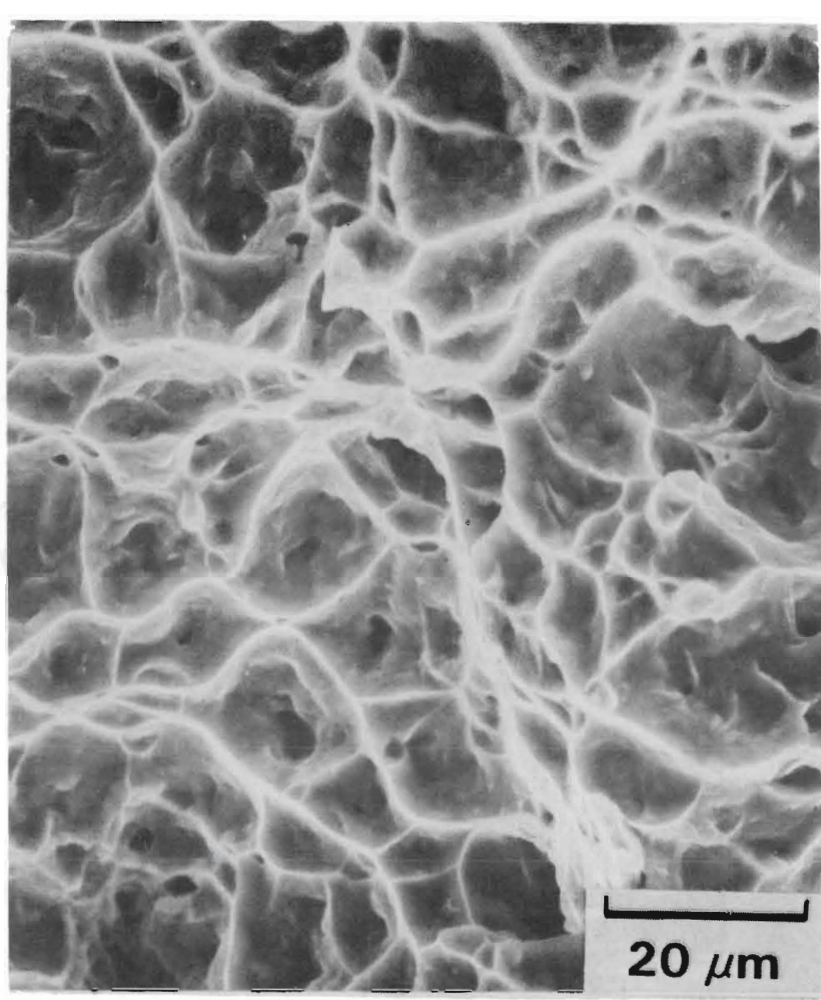

(b)

FIGURE 30. Typical Fracture Surfaces of Titanium Grade 12 Specimens, IL Orientation, Strained to Failure at (a) $10^{-4}$ in./in. -sec and (b) $2 \times 10^{-7}$ in./in. -sec in Basalt Ground Water at $250^{\circ} \mathrm{C}$ 


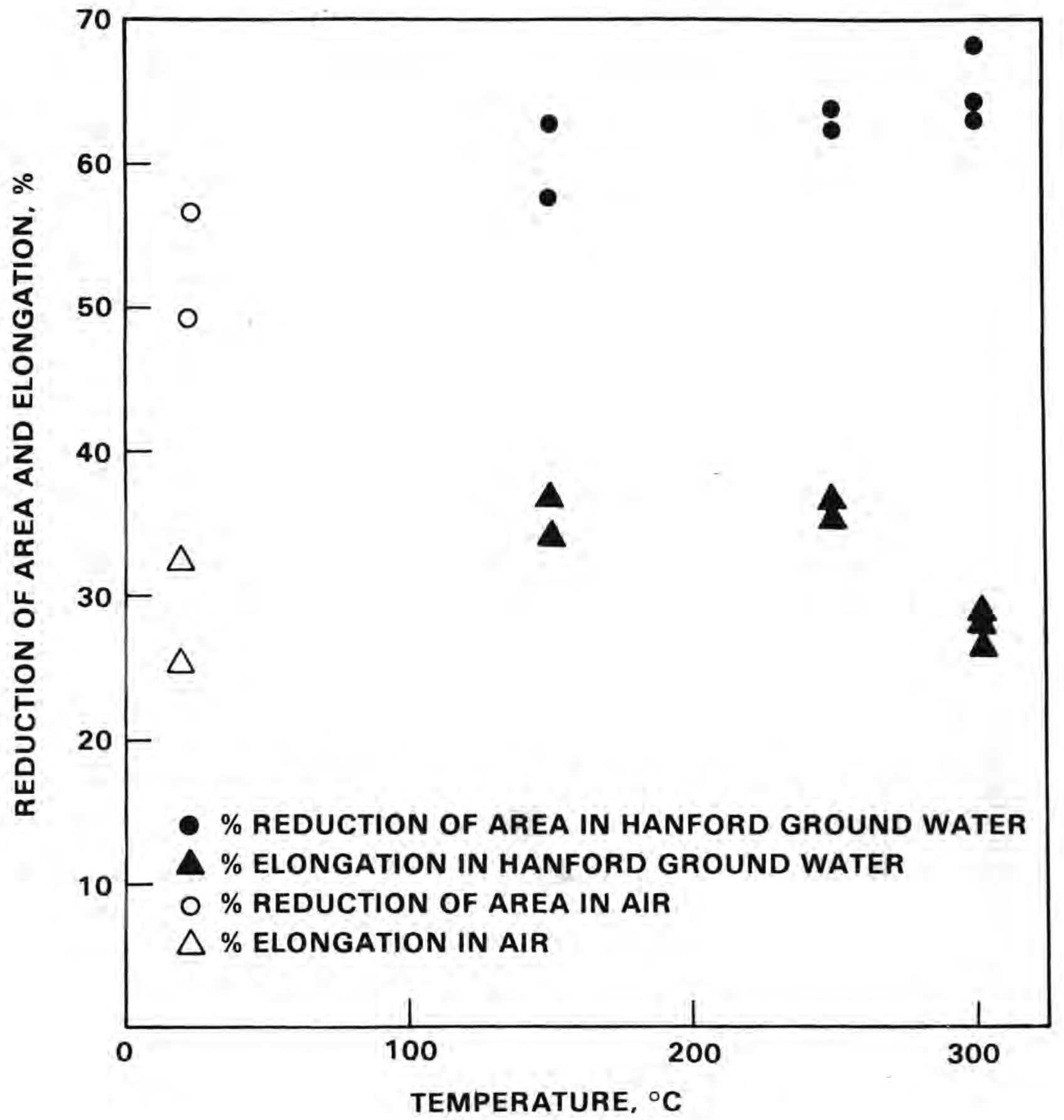

FIGURE 31. Effect of Temperature on Ductility at Constant Strain Rate Slow-Strain-Rate Test Results, Titanium Grade 2, LT Orientation, 10-4 in./in.-sec 
alloys, thereby allowing environmental attack to occur. In the test data presented in Figures 32 and 33, low frequencies and enhanced fluoride ion content (220 ppm instead of the normal $37 \mathrm{ppm}$ ) were employed in an effort to make the tests severe.

Titanium Grade 2 (Figure 32) was unaffected by loading frequency and by the high fluoride ion content. Results of the two tests shown in this figure do not cover the same stress-intensity range; however, these data points

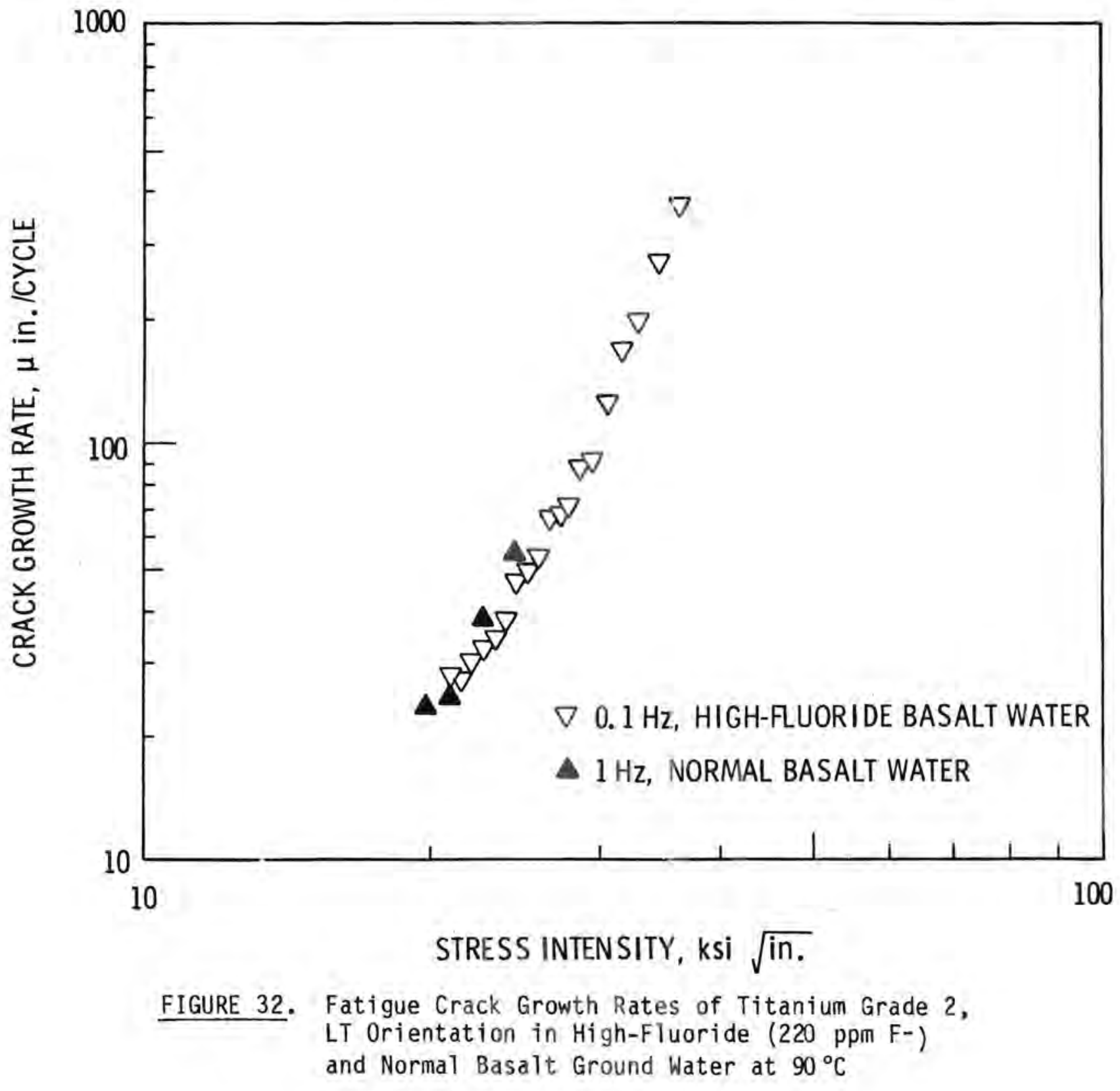




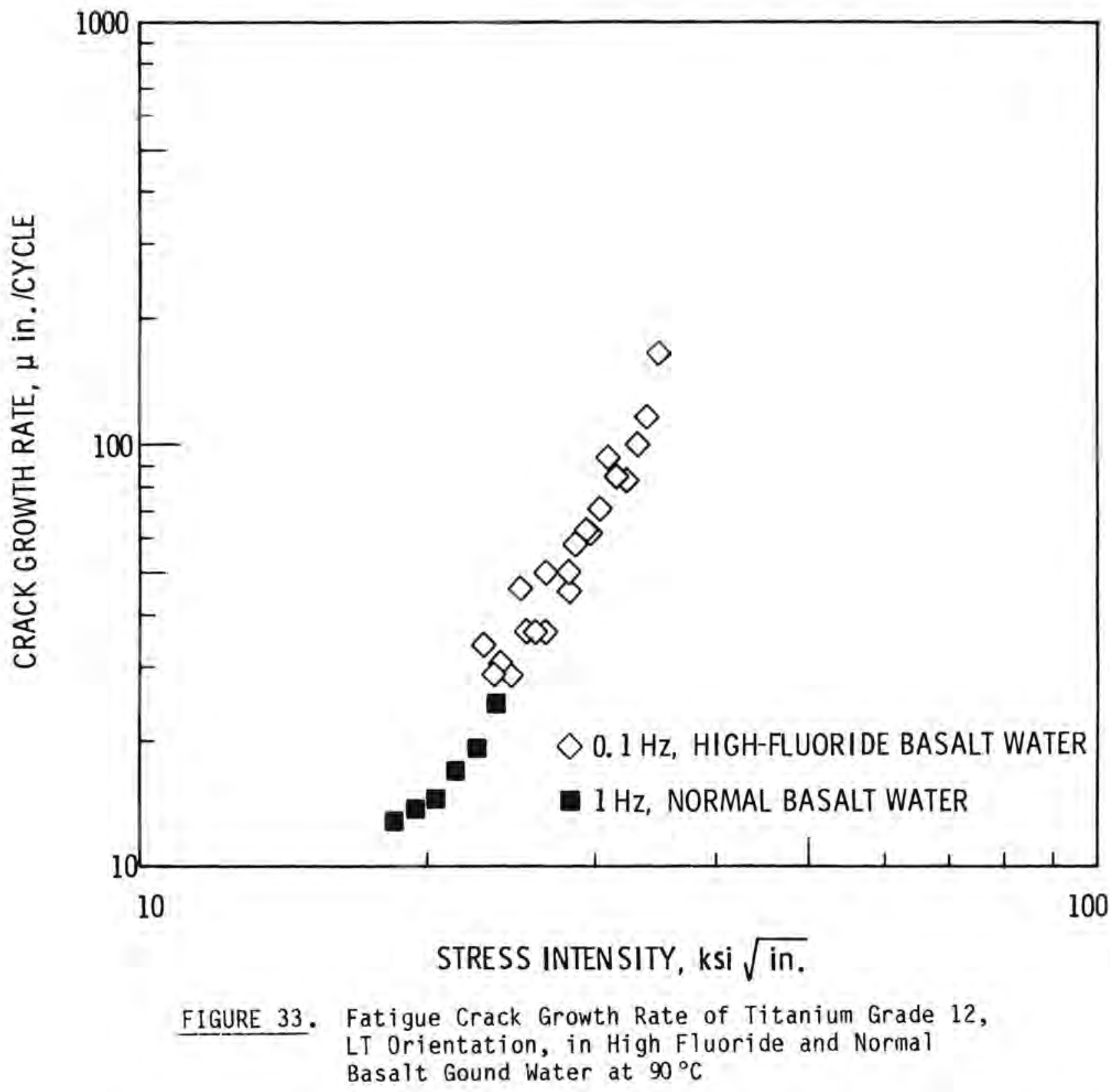

closely match those of tests conducted in air (not shown). This indicates that acceleration of fatigue crack growth rate due to environmental effects was not present.

Tests analogous to those shown in the previous figure were performed on Titanium Grade 12 (LT orientation). As shown in Figure 33, neither lower frequency $(0.1 \mathrm{~Hz}$ relative to $1 \mathrm{~Hz}$ ) nor increased fluoride ion content (from 37 to $220 \mathrm{ppm}$ ) increased the crack growth rate at $90^{\circ} \mathrm{C}$. 
The environmental-mechanical investigations of Titanium Grades 2 and 12 using slow strain rate tests to $300^{\circ} \mathrm{C}$ in normal basalt ground water and fatigue crack growth rate tests at $90^{\circ} \mathrm{C}$ in normal and fluoride-enhanced basalt ground water have so far revealed no positive proof of crack growth rate enhancement attributable to environmental effects alone.

Conclusions

The conclusions from the work described in this section are summarized as follows:

- Based on 6-month corrosion data in oxic Hanford basalt ground water at 150 and $250^{\circ} \mathrm{C}$, and the assumption of linear corrosion kinetics (a conservative assumption as the corrosion rates are expected to decrease with time), it would appear that cast iron or cast steel can be employed as a structural barrier for a basalt repository waste package with a $1000-y r$ corrosion allowance of only $1 / 2 \mathrm{in}$. However, this conclusion must be tempered by the 3 -month, $250^{\circ} \mathrm{C}$ basalt water irradiation-corrosion data, which shows a required corrosion allowance of $\sim 1$ in. Until the situation is better understood, a conservative approach would utilize a 1-in. corrosion allowance.

- The relatively low corrosion rates found in the short-term (1-month) corrosion studies of cast ferrous materials in unirradiated, $250^{\circ} \mathrm{C}$ oxic, tuffaceous ground water suggest that a corrosion allowance of $1 / 2$ in. would be satisfactory for 1000 -year barrier element service in a tuff repository.

- Corrosion studies of cast ferrous materials in oxic deionized water at $250^{\circ} \mathrm{C}$ indicate a corrosion rate approximately the same as that found in the basaltic water studies, in spite of the significant differences in corrosion products formed on the sample surfaces. 
- Irradiation-corrosion studies of Titanium Grade 2 and Grade 12 in $250^{\circ} \mathrm{C}$ basaltic ground water show that the corrosion of the Grade 2 alloy is affected by radiation to a much greater extent than the Grade 12 material, after 3 months' exposure, though the corrosion of the Grade 2 material observed is not significant from a waste package design standpoint.

- The environmental enhancement of crack-growth in Titanium Grade 2 and Grade 12 has not yet been positively observed in any environment to which these materials have been exposed; i.e., as U-bend and boltloaded compact tension specimens in irradiated basalt ground water at $250^{\circ} \mathrm{C}$, as tensile specimens in slow strain rate tests in basalt ground water to $300^{\circ} \mathrm{C}$, or as compact tension specimens in normal and enhanced-fluoride fatigue-crack-growth-rate tests at $90^{\circ} \mathrm{C}$. It can therefore be concluded that these materials would be expected to show an extremely high resistance to stress corrosion cracking in a basalt repository environment.

\section{WASTE FORM RELEASE CHARACTERISTICS}

Objective

The studies reported here on waste form experiments were performed to characterize waste form/solution interactions under repository relevant conditions using basalt and tuff site-specific aqueous solutions.

Approach

When the barriers of a waste package are breached, the waste form is exposed to an aqueous solution which results in elemental removal.

Until recently, investigations involving leaching and interaction characteristics of waste forms have been conducted in either deionized or generic ground waters. Experiments conducted this year have primarily utilized reference basalt and tuff ground waters. In many cases the results in deionized water are included for comparison or clarification. Additionally, this year's 
activities have included the effects on leaching on variations in sample surface area to solution volume ratio and the effects on leaching of gamma radiolysis.

The experimental approach is thus reported here in three sections:

- ground water effects

- sample surface area/solution volume ratio effects

- gamma radiolysis effects.

Ground Water Effects

The effects of ground water composition on elemental release from the waste form are important to investigate as part of a comparison of different repository sites. Additionally, the ground water composition effects aid in the understanding of release mechanisms from the waste form.

Surface Area/Solution Volume Ratio Effects.

Variations in the ratio of sample surface area to solution volume of the leachate (SA/V) are important for understanding many aspects of elemental release including apparent temperature effects, leach rates and solubility limits. We have found in previous tests that $S A / V$, when multiplied by the time duration of the test, is a constant. Therefore, increases in SA/V can be used to diminish the time necessary to achieve a similar leachate composition and thus compress the time scale for leaching. These accelerated tests are useful for long-term predictive characteristics of elemental release from waste forms.

\section{Gamma Radiolys is Effects}

In the event of early water intrusion into the repository, gamma radiolysis effects on elemental release from waste forms could become important. The effects of gamma radiolysis products on metals corrosion are also important to be able to predict waste form exposure time to aqueous solutions. The radiolysis products formed control $\mathrm{pH}$ and are dependent upon the original water composition. It is therefore necessary and important to investigate radiolysis effects in all relevant ground waters. 


\section{Materials}

The waste form that is being used for studying interactions in the waste form/solution system is PNL 76-68 waste glass. Its composition is given in Table 13. The other materials used in these studies, such as the site-specific ground waters, have been listed in previous tables.

Results and Discussion

Until recently, investigations involving leaching and interaction characteristics of waste forms have been conducted in either deionized or generic ground waters. Experiments conducted this year have primarily utilized simulated basalt and actual tuff ground waters. Additionally, this year's activities have included the effects on leaching of variations in sample surface area to solution volume ratio, of gamma radiolysis, and of interactions between the glass and other waste package constituents. This report describes some of the more recent leaching results that were obtained in basalt and tuff ground waters. In many cases the results in deionized water are included for comparison or clarification.

TABLE 13. Composition of PNL 76-68 Waste Glass (McVay and Buckwalter 1982)

\begin{tabular}{|c|c|c|c|c|c|}
\hline 0xide & $\begin{array}{l}\text { Amount } \\
\text { (wt\%) }\end{array}$ & Oxide & $\begin{array}{l}\text { Amount } \\
\text { (wt\%) }\end{array}$ & Oxide & $\begin{array}{l}\text { Amount } \\
\text { (wt\%) }\end{array}$ \\
\hline $\mathrm{SiO}_{2}$ & 39.80 & $\mathrm{Cen}_{2}$ & 1.26 & $\mathrm{Sm}_{2} \mathrm{O}_{3}$ & 0.35 \\
\hline $\mathrm{Na}_{2} \mathrm{O}$ & 12.80 & $\mathrm{RuO}_{2}$ & 1.13 & $\mathrm{TeO}_{2}$ & 0.28 \\
\hline $\mathrm{Fe}_{2} \mathrm{O}_{3}$ & 10.34 & $\mathrm{Cs}_{2} \mathrm{O}$ & 1.09 & $Y_{2}{ }^{0} 3$ & 0.23 \\
\hline $\mathrm{B}_{2} \mathrm{O}_{3}$ & 9.47 & $\mathrm{BaO}$ & 0.59 & $\mathrm{NiO}$ & 0.21 \\
\hline$Z n 0$ & 4.97 & $\operatorname{Pr}_{6}{ }^{0} 11$ & 0.56 & $\mathrm{Rh}_{2} \mathrm{O}_{3}$ & 0.18 \\
\hline $\mathrm{Nd}_{2} \mathrm{O}_{3}$ & 4.67 & $\operatorname{La}_{2} \mathrm{O}_{3}$ & 0.56 & $\mathrm{Rb}_{2} \mathrm{O}$ & 0.13 \\
\hline $\mathrm{TiO}_{2}$ & 2.97 & $P d 0$ & 0.56 & $\mathrm{Eu}_{2} \mathrm{O}_{3}$ & 0.08 \\
\hline $\mathrm{MOO}_{3}$ & 2.42 & $\mathrm{P}_{2} \mathrm{O}_{5}$ & 0.51 & $\mathrm{Gd}_{2} \mathrm{O}_{3}$ & 0.05 \\
\hline $\mathrm{CaO}$ & 2.00 & $\mathrm{Cr}_{2} \mathrm{O}_{3}$ & 0.44 & $\mathrm{Cd}$ & 0.04 \\
\hline $\mathrm{Zn}_{3}$ & 1.88 & Sro & 0.40 & $\mathrm{Ag}_{2} \mathrm{O}$ & 0.03 \\
\hline
\end{tabular}




\section{Ground Water Effects}

Static leaching experiments were conducted using deionized water, a reference basalt ground water, and tuff ground water obtained from Well J-13 at the Nevada Test Site. The compositions and initial pH values of the ground waters are the same as those listed previously. Time-dependent $90^{\circ} \mathrm{C}$ leaching results in a sample surface area to solution volume ratio (SA/V) of $10 \mathrm{~m}^{-1}$ for PNL 76-68 glass in the three solutions are shown in Figure 34 by the solid and dashed lines for cesium and boron, respectively. These elements were chosen

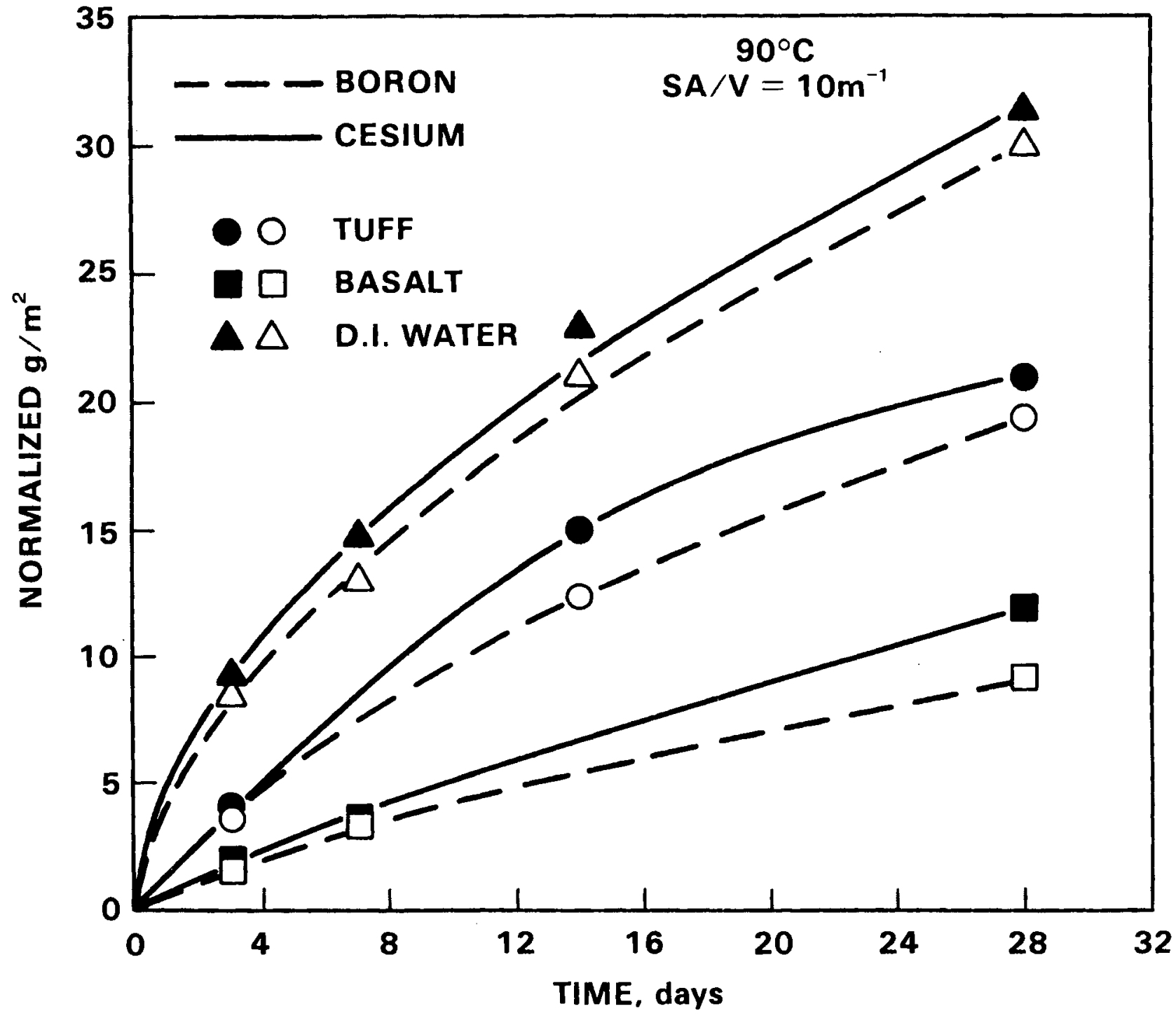

FIGURE 34. Boron and Cesium Release from PNL 76-68 Glass As a Function of Leachate 
for illustration because they are not in the original ground water composition and because boron and cesium represent both matrix and mobile modifier elements.

Solution concentrations were normalized by the elemental fractions in the sample and by the sample surface areas for ease of comparison. As can be seen in Figure 34, the leaching characteristics of the glass are quite different in the various leachates. The deionized water results show the characteristic initial rapid release rate, which decreases with leach time. Tuff ground water, which contains more elements than deionized water, shows lower heginning leach rates and less total leaching. Basalt ground water, which has the most elements prior to leaching, has the lowest starting release rates and the least total leaching. In fact, there is little evidence for an initial enhanced leach rate in basalt ground water. These observations are consistent with the theory that for a given waste form, the solution composition controls the leaching characteristics; and as elemental concentrations increase in the leachate, elemental release rates decrease (Buckwalter et al. 1982).

As can be seen from the compositions of basalt and tuff ground waters used in this investigation (see Tables 1 and 2), many elements such as $\mathrm{Ca}$, $\mathrm{Na}$, and $\mathrm{Si}$, which would normally be present in simpler waters after leaching a glass sample, are already present in the starting water composition. The basalt ground water contains the greatest concentration of elements with the tuff ground water being intermediate between basalt ground water and deionized water. Therefore, one might expect the initial leaching characteristics of the glass in basalt and tuff ground waters to be similar to that observed at longer times in deionized water.

\section{Surface Area/Solution Volume Ratio Effects}

Monolithic glass samples were used in these leaching experiments at a temperature of $90^{\circ} \mathrm{C}$ in deionized water. Sample surface area/solution volume ratios (SA/V) of $1,10,100$, and $16,000 \mathrm{~m}^{-1}$ were used in the investigation. The highest value was attained by sandwiching $0.125 \mathrm{~mm}$ diameter platinum wire between two glass samples. 
Elemental release per unit exposed surface area of PNL 76-68 glass generally decreased and became more selective with increased SA/V values. Similarly, high $S A / V$ conditions resulted in smaller reaction layer thicknesses for a specified leaching time and in an increased abundance of surface precipitates rich in zinc, silicon, and iron. Neither congruent dissolution nor thinning of the reaction layer, once it was formed, were evident at any time--in contrast to earlier studies ( $\mathrm{Cl}$ ark et al. 1981, Hench et al. 1980, Ethridge et al. 1979). Corrosion of the glass appeared to be strongly influenced by the approach of silicon solubility limits in the present experiments, where the glass dominated the solution $\mathrm{pH}$.

Changes in the $S A / V$ values strongly affected elemental release rates per unit exposed surface area of PNL 76-68 waste glass. At an SA/V value of $1 \mathrm{~m}^{-1}$, soluble components leached at nearly equivalent rates when normalized to their respective weight fractions in the glass. As the $S A / V$ values were increased, dissolution rates of all of the components decreased, although not equally, with silicon and calcium most strongly affected. These results are shown in Figure 35 , which is a plot of the normalized elemental release per unit area versus the $\log$ of the $S A / V$ ratio for samples leached 14 days at $90^{\circ} \mathrm{C}$. This figure also contains previously reported powder (McVay and Buckwalter 1980) and Soxhlet (Grambow 1981) leaching data. Nearly equivalent normalized elemental releases per unit area were obtained for many soluble components for SA/V values of $1 \mathrm{~m}^{-1}$ or less. Release for $S A / V$ values greater than $1 \mathrm{~m}^{-1}$ decreased as $S A / V$ increased--but at unequal rates. The data plotted in Figure 35 contain the results of 14-day leach tests only; thus, it is expected that the $\log S A / V$ axis would be shifted to the right for long leaching times and to the left for shorter leaching times.

Present leaching data at various $S A / V$ values were compared to the results of static (MCC-1) leaching tests for periods up to one year (Strachan and Barnes 1980) to evaluate the usefulness of increased SA/V to simulate longer leaching times. These comparisons are given for silicon, sodium, and calcium in Figures 36,37 , and 38 , respectively, which are plots of concentration versus leaching time and $S A / V$. An increase by an order of magnitude in the $S A / V$ ratio resulted in an order of magnitude decrease in the time required to reach 


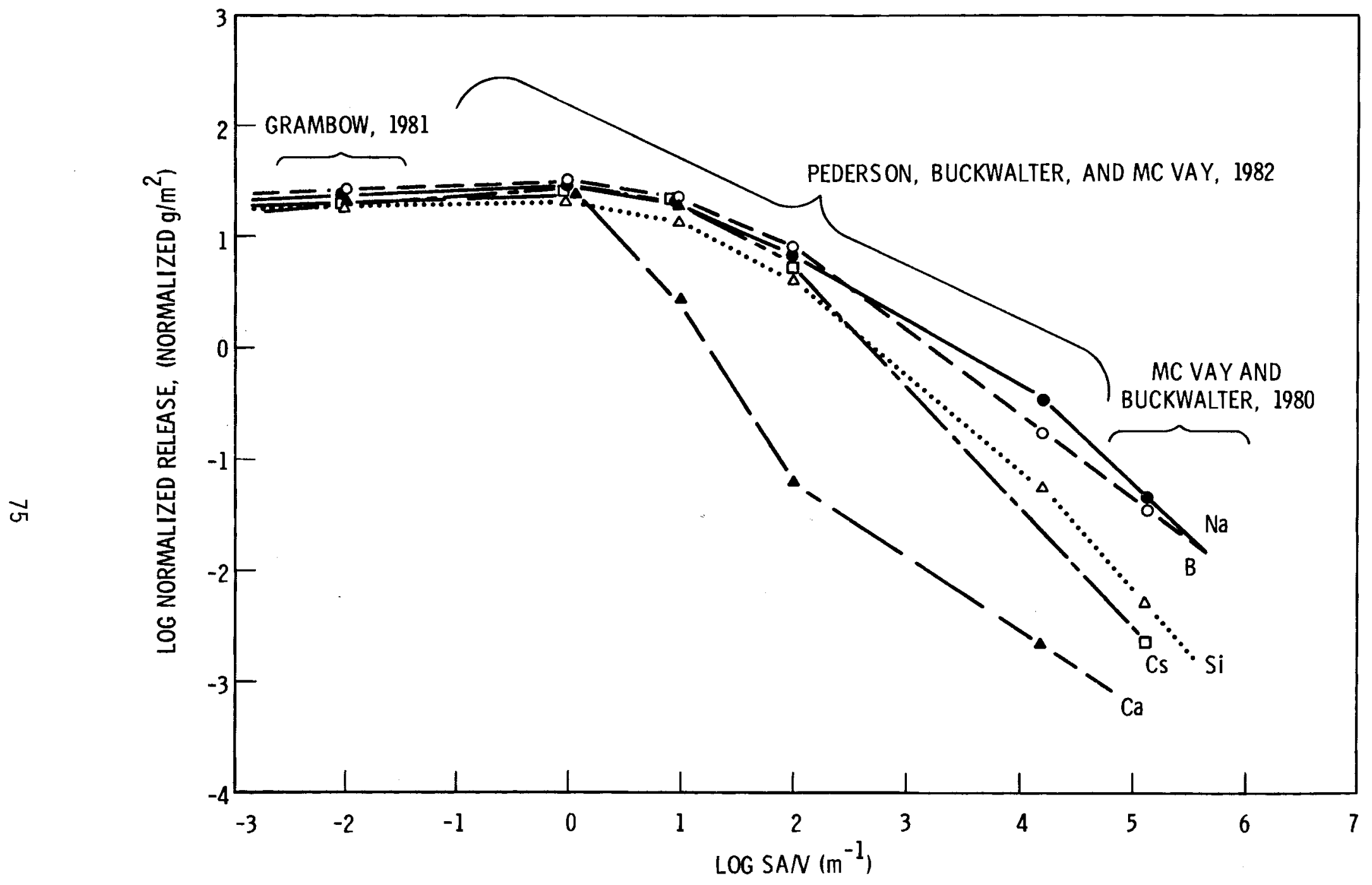

FIGURE 35. Release of Various Elements from PNL $76-68$ Glass at $90^{\circ} \mathrm{C}$ in Deionized Water As a Function of SA/V 


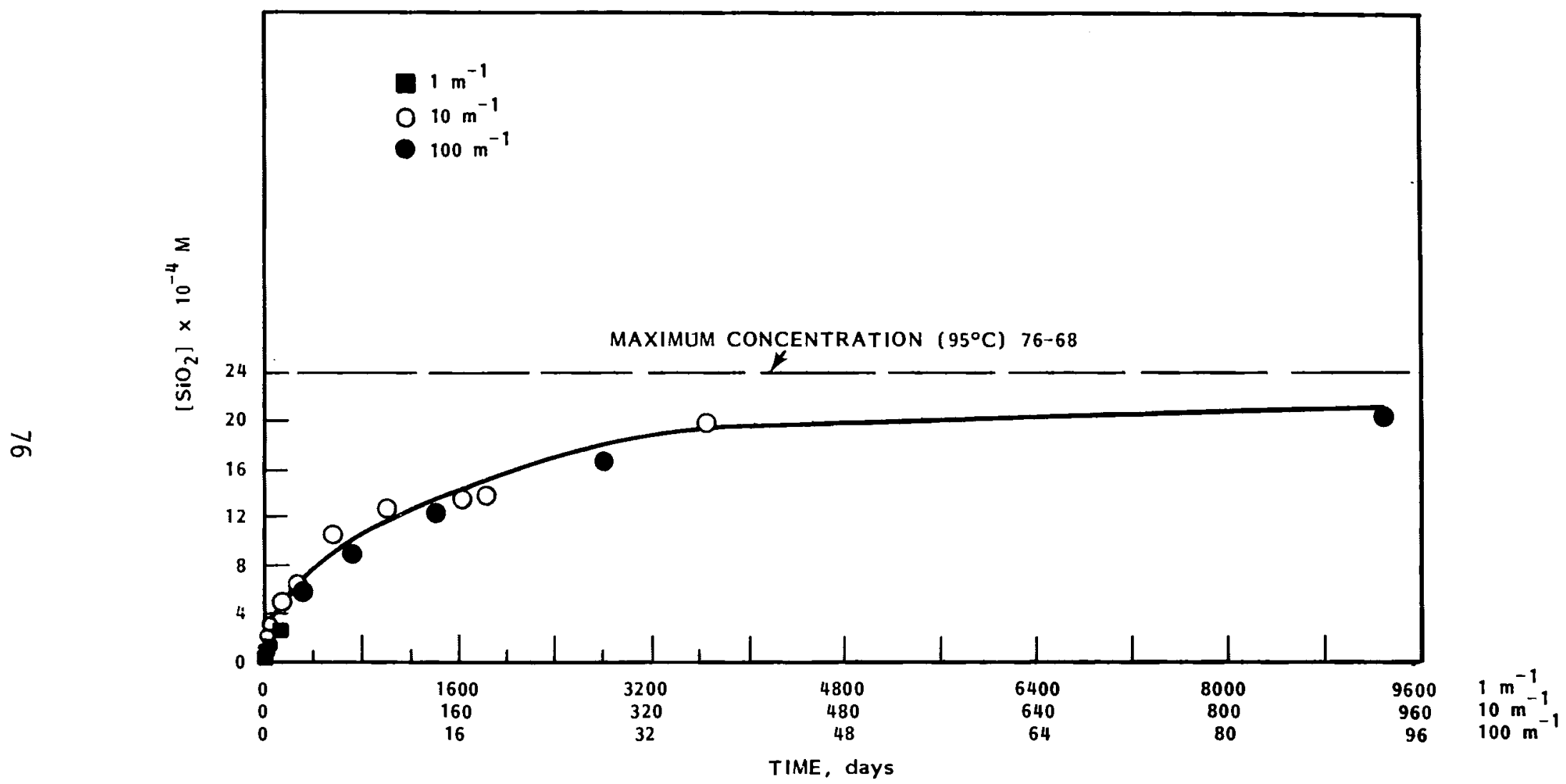

FIGURE 36. Concentration As a Function of Leaching Time and SA/V for Silicon Release from PNL 76-68 Glass in $90^{\circ} \mathrm{C}$ Deionized Water 


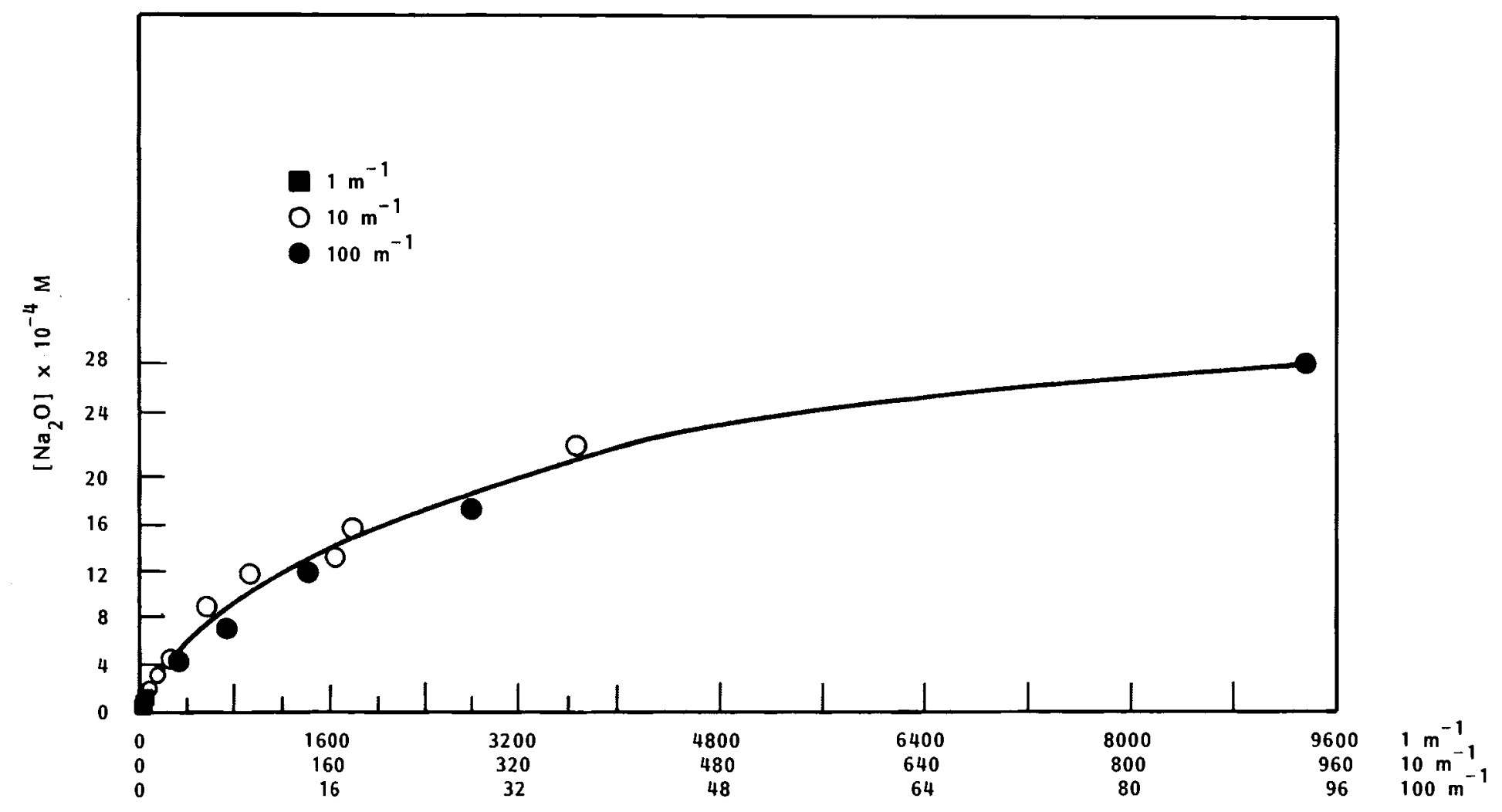

FIGURE 37. Concentration As a Function of Leaching Time and SA/V for Sodium Release from PNL $76-68$ Glass in $90^{\circ} \mathrm{C}$ Deionized Water 


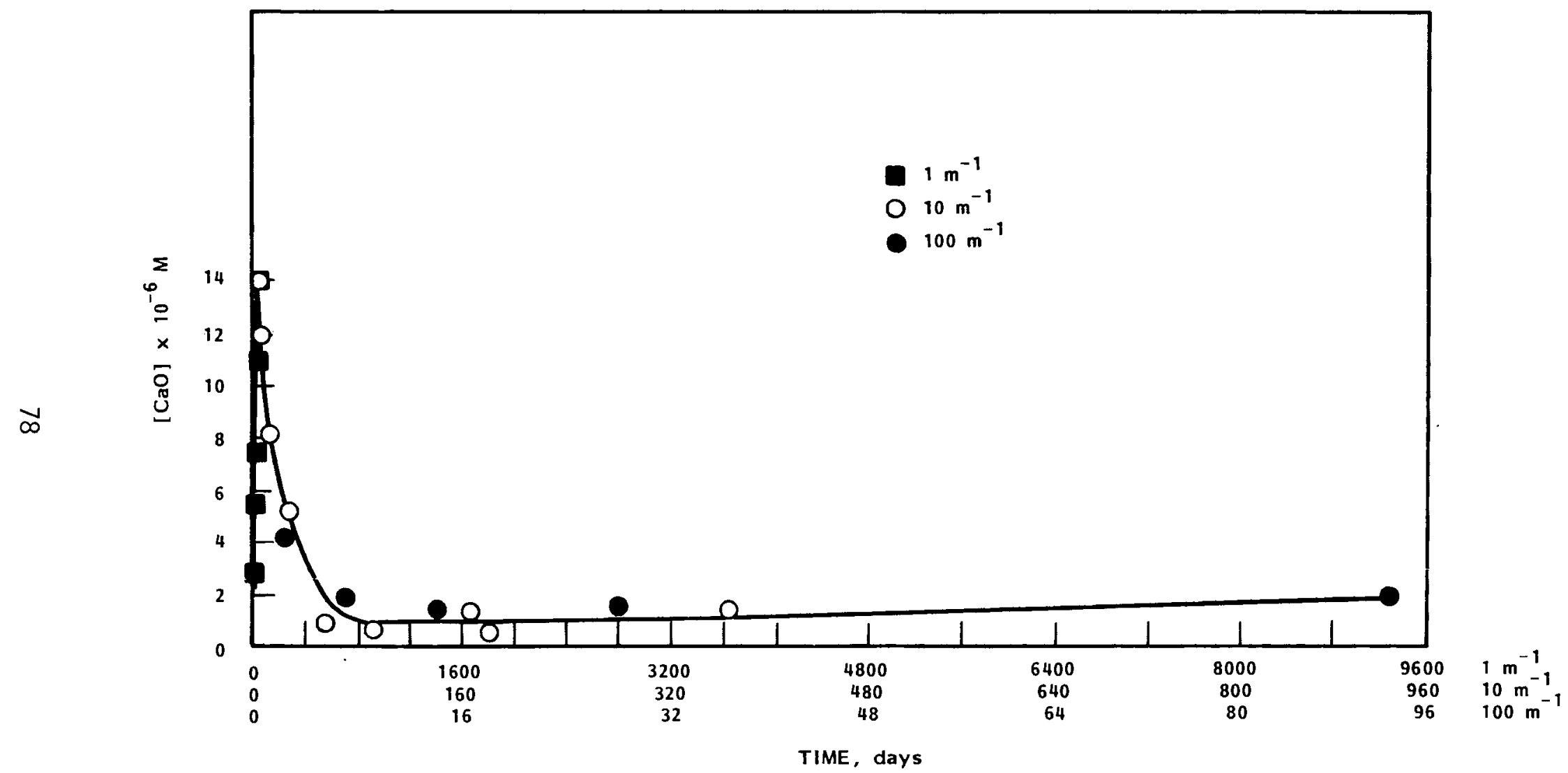

FIGURE 38. Concentration As a Function of Leaching Time and SA/V for Calcium Release from PNL 76-68 Glass in $90^{\circ} \mathrm{C}$ Deionized Water 
the same concentration of a given component in solution. In addition, the shapes of the leaching curves were very similar for the different SA/V values (after correcting for the time scale compression). Thus, it would appear that, considering only the concentration of components in the leachate solution, changes in the SA/V ratio can be used to perform accelerated leach testing. Earlier studies reported a linear relation between the time to begin matrix dissolution and SA/V--largely a result of an upward drift of the solution pH with leaching time (Clark et al. 1981, Hench et al. 1980, and Ethridge et al 1979). However, in the present $90^{\circ} \mathrm{C}$ measurements, the $\mathrm{pH}$ of solution stabilized after relatively short leaching times, and congruent matrix dissolution was never observed. It was concluded in the previous section that except for very short leaching times, silicon solubility limitations control the rate of glass corrosion and thus render time compression possible by the use of high $S A / V$ value.

While concentrations in the leachate may be identical following leaching at high $S A / V$ values for short times and at low $S A / V$ values for correspondingly long times, reaction layer thicknesses are not equivalent. Variations in the reaction layer thicknesses with SA/V are demonstrated in the Secondary Ion Mass Spectroscopy (SIMS) results in Figure 39. To yield the same solution concentration, a glass leached at a relatively high $S A / V$ value needs to release considerably less material per unit surface area than one leached at a low SA/V value. Thus, the latter sample will develop a much larger reaction layer. Leaching rates per unit surface area are equivalent when the solution concentrations are equal for two leach tests having different SA/V values, which can be inferred from Figures 36,37 , and 38 , in spite of the marked difference in the reaction layer thicknesses. This behavior demonstrates the relative unimportance of the reaction layer in moderating the rate of glass corrosion and makes the use of diffusion control in leach models appear inappropriate.

The highest SA/V value that can be practically used in a leaching test with monolithic specimens and still allow sufficient solution for analysis is approximately $10^{4} \mathrm{~m}^{-1}$. Thus, a one-year leach test at $10^{4} \mathrm{~m}^{-1}$ would simulate the solution concentration of a $10^{3}$-year leach test at $10 \mathrm{~m}^{-1}$ following the MCC-1 procedure. Alternately, powders carefully prepared to remove fines and 


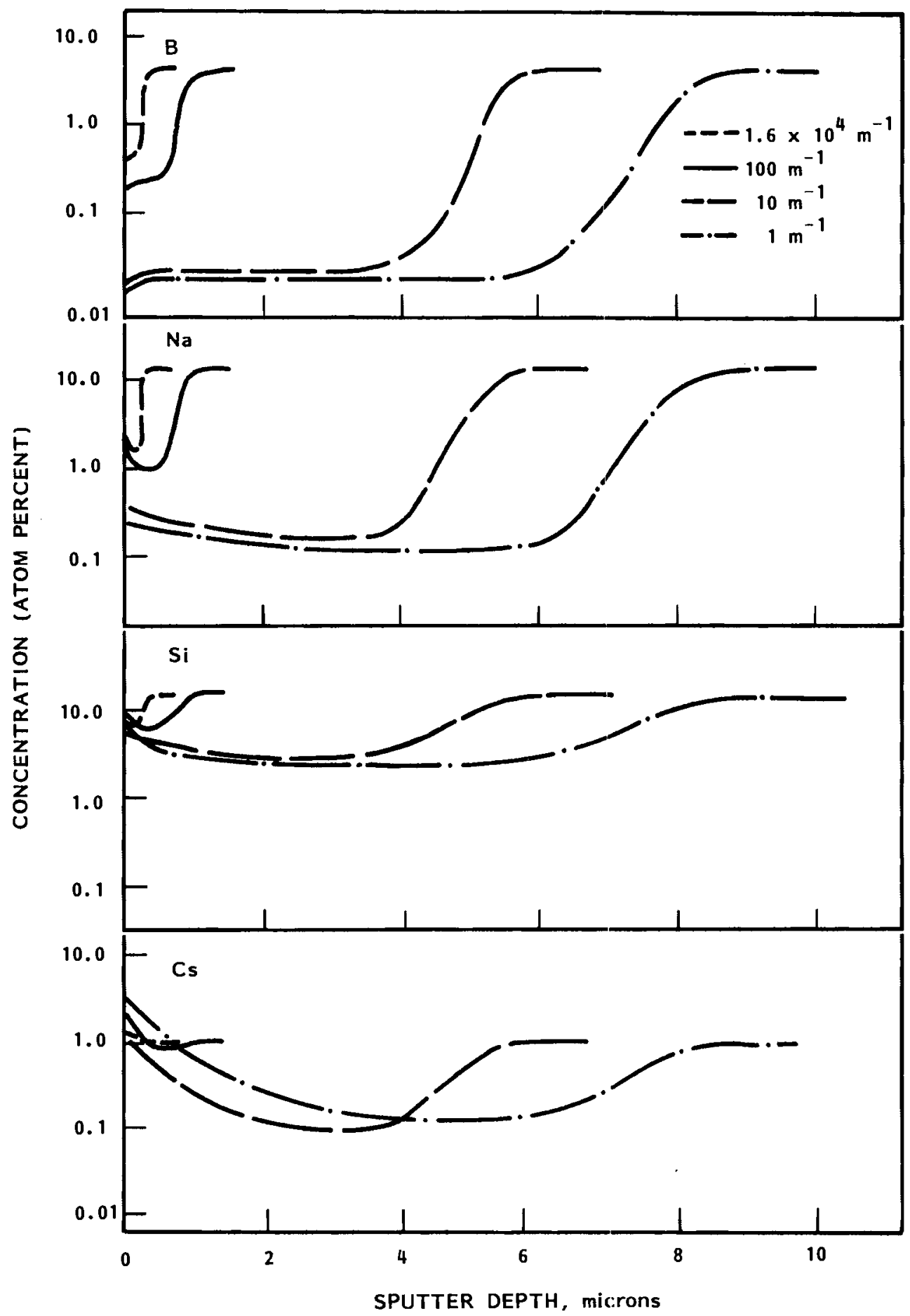

FIGURE 39. Effect of SA/V Ratio on Elemental Depletion Depths in PNL 76-68 Glass Leached 14 Days at $90^{\circ} \mathrm{C}$ in Deionized Water 
agitated during leaching to minimize concentration cell effects could extend the time compression by one to two orders of magnitude, since higher glass surface areas can be obtained. It must be recognized that reaction layer thicknesses will not be the same following the short-term tests as with long-term leaching, which the former simulate. Only release from the waste form will be identical-assuming that leaching occurs in the regime of silicon solubility control. Of course, there may be a limit to the usefulness of this proportionately because of colloidal particles and/or alteration phases that may form in the actual repository and change the relative activity of silicon in solution.

Although the results presented above for $S A / V$ ratio effects were for deionized water, enough data have been gathered on basalt and tuff ground waters to indicate that the same relationships hold. Therefore, SA/V variations can be used for time compression in basalt and tuff ground waters as well as deionized water.

\section{Gamma Radiolysis Effects}

Since nuclear waste contains radioactive elements, it becomes necessary to evaluate the effect of radiation on elemental release from the waste form as well as degradation of the waste package barriers. Radiation may affect the glass-water system in several ways. The effects of gamma and alpha radiation on phase stability in glasses has been investigated (weber et al. 1979) and shown not to have a significant effect on elemental release characteristics. However, when water is also exposed to radiation, radiolytic products from the water may attack the waste form or barrier material more aggressively. The effect of water radiolysis on elemental release from PNL 76-68 glass when both the sample and the solution are simultaneously irradiated by gamma radiation was investigated and is reported here.

Samples were irradiated in welded gold capsules at an SA/V of $20 \mathrm{~m}^{-1}$ in both deionized water and reference basalt ground water. The leachates were degassed to remove dissolved air and the capsules were backfilled with helium prior to sealing. This step is necessary because the presence of air causes nitric acid generation during radiolysis. 
Primary radiolytic species $G$ values for gamma- and alpha-irradiation of deionized water are given in Table 14. As can be seen, the gamma irradiation favors the formation of radicals, while alpha irradiation favors the formation of molecular species. Therefore, one cannot infer alpha radiolysis effects from gamma radiation experiments. Both types of experiments must be done. Currently, only gamma radiolysis experiments have been conducted with alpha radiolysis experiments being initiated.

The largest efforts on gamma radiolysis effects on glass leaching have been expended on deionized water with some data being gathered for basalt water. Therefore, a summary of the deionized water results will be given with a comparison to basalt water results following.

Radiolysis effects in deionized water were evaluated as a function of temperature, time, and dose rate. The effects of temperature are summarized in Table 15 for the highest dose rate evaluated, $1.75 \times 10^{6} \mathrm{rad} / \mathrm{hr}$. Release rates of silicon from the glass were chosen as an indicator of reaction between glass and water. From the table it can be seen that the percent increase in silicon leach rate due to radiolysis is highest at the lowest temperature. In fact, at $90^{\circ} \mathrm{C}$ there is no measurable effect due to radiolysis. Therefore, at expected respository temperatures one would not expect a large effect of radiolysis on glass leaching. However, two things must be remembered. First, these results do not necessarily describe actinide behavior, which may be significantly affected by radiolysis. Secondly, if nitrogen and/or dissolved air are present, then nitric acid can be formed which is detrimental at all temperatures.

TABLE 14. Primary Radiolytic Species G Values for Gamma $\left({ }^{60} \mathrm{Co}\right)$ and $5 \mathrm{MeV}$ Alpha Radiation (Anbar 1968, Appleby and Schwarz 1969)

Species

$$
\mathrm{H}^{+} \quad \mathrm{e}^{-\mathrm{aq}}
$$

$\mathrm{H} \quad \mathrm{OH}$

$\mathrm{HO}_{2}$

$\mathrm{H}_{2}$

$\mathrm{H}_{2} \mathrm{O}_{2} \quad \mathrm{H}_{2} \mathrm{O}$

Gamma

$2.7 \quad 2.7 \quad 0.61$

2.86

0.03

0.43

$0.61-4.14$

5 MeV Alpha

0.3

0.3

0.3

0.5

0.10

1.4

$1.3-3.3$ 
TABLE 15. Gamma-Irradiation Effects on Silicon Leach Rate from PNL 76-68 Glass (a)

\begin{tabular}{|c|c|c|c|}
\hline \multirow[b]{2}{*}{ Temp. ${ }^{\circ} \mathrm{C}$} & \multicolumn{3}{|c|}{ Silicon Release Rate (ppm/hr) } \\
\hline & $\begin{array}{l}\text { Irradiated } \\
1.75 \times 10^{6} \mathrm{rad} / \mathrm{hr} \\
\end{array}$ & Unirradiated & $\%$ Increase \\
\hline 50 & $2.2 \times 10^{-2}$ & $8.2 \times 10^{-3}$ & 168 \\
\hline 70 & $4.0 \times 10^{-2}$ & $2.5 \times 10^{-2}$ & 60 \\
\hline 90 & $6.6 \times 10^{-2}$ & $6.6 \times 10^{-2}$ & 0 \\
\hline
\end{tabular}

(a) Deionized Water $S A / V=20 \mathrm{~m}^{-1}$

The dose rate dependence, as seen in Figure 40, varies with the element. There is little effect for iron, more effect for silicon and cesium, and the most effect for boron and sodium. In all of the elements considered, a strong dose rate effect was only observed at low dose rate values. At higher dose rates, the effect was slight. What this means is that radiolysis effects will persist over most of the thermal pulse period.

Radiolytic products affect elemental removal rates by substantial amounts. The effect of gamma radiolysis on the activation energy for silicon and boron removal is illustrated in figures 41 and 42 , respectively. The activation energy for silicon removal into solution decreases by more than half $(21.5$ to $9.5 \mathrm{kcal} / \mathrm{mole})$ upon exposure to gamma radiation. Activation energy for boron removal also decreases upon exposure to radiation but to a lesser degree ( 17.9 to $10.9 \mathrm{kcal} / \mathrm{mole})$. Radiolysis is affecting the mechanism of leaching. Apparently, the radiolysis effect on leaching is temperature insensitive, and therefore it has a larger effect at low temperatures. As leaching increases at higher temperatures, radiolysis effects are simply swamped out.

Based on information obtained from radiolysis effects in deionized water, a temperature of $50^{\circ} \mathrm{C}$ was chosen for radiolysis effects studies in basalt water. Comparison of boron and cesium elemental removal results in deionized and basalt waters are shown in Figures 43 and 44, respectively. These elements are representative of the results found for all of the elements investigated. Although elemental removal rates were lower in basalt than in deionized water for unirradiated leach tests, the removal rates were essentially identical for 


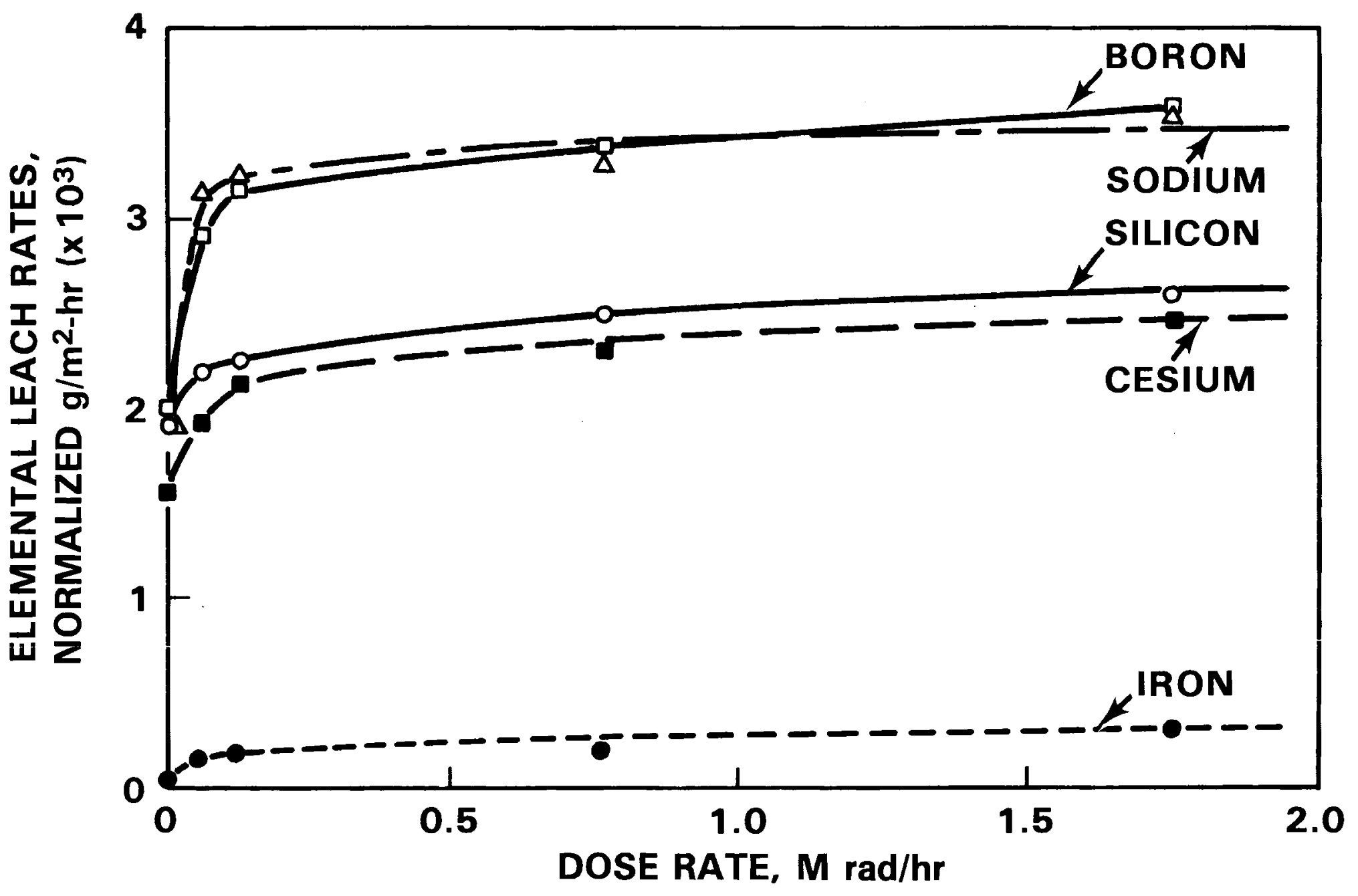

FIGURE 40. Dissolution Rate As a Function of Dose Rate for PNL 76-68 Glass Leached at $70^{\circ} \mathrm{C}$ 


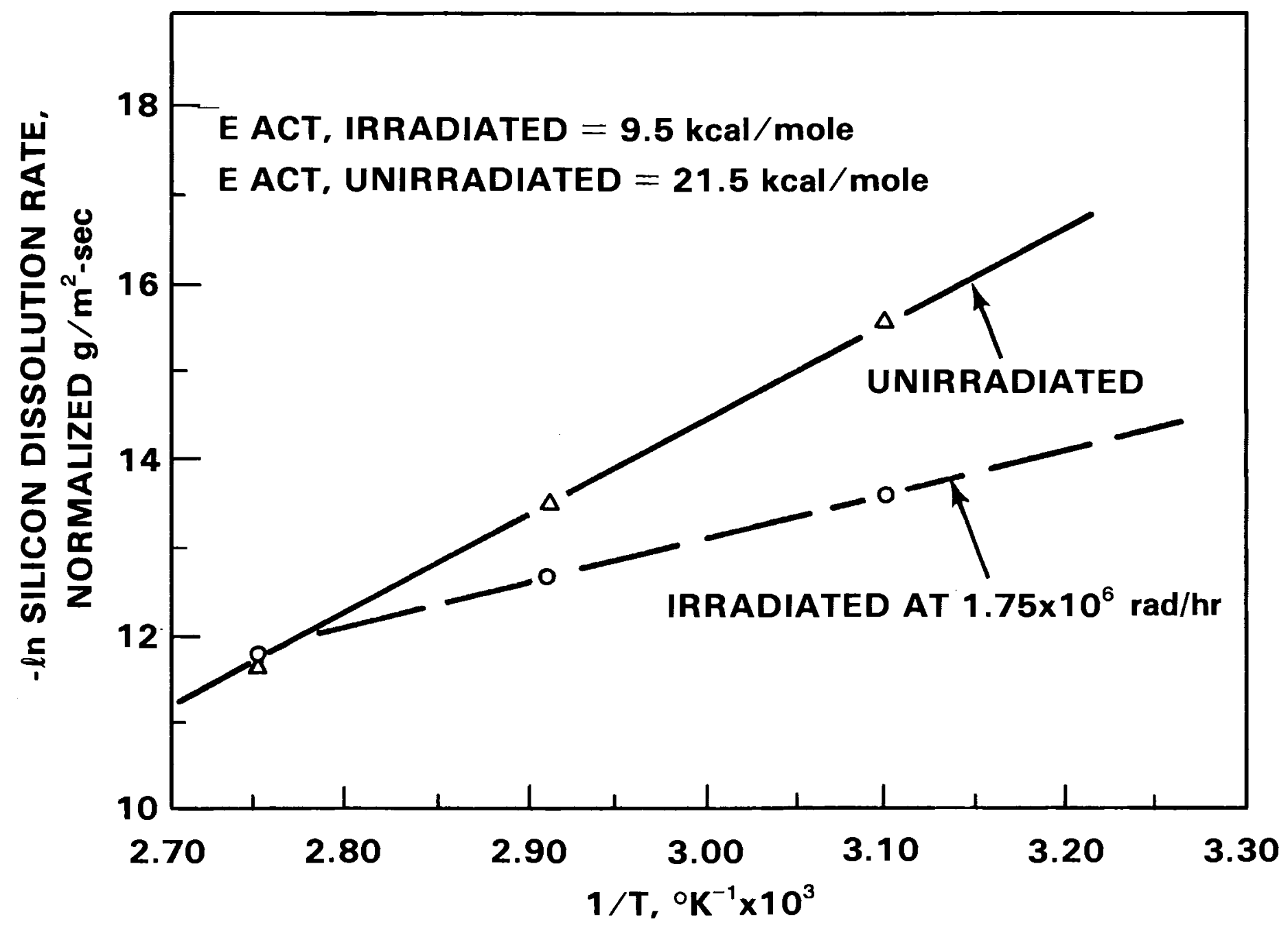

FIGURE 41. Silicon Dissolution Rate As a Function of Reciprocal Temperature for Unirradiated and Irradiated 76-68 Glass 


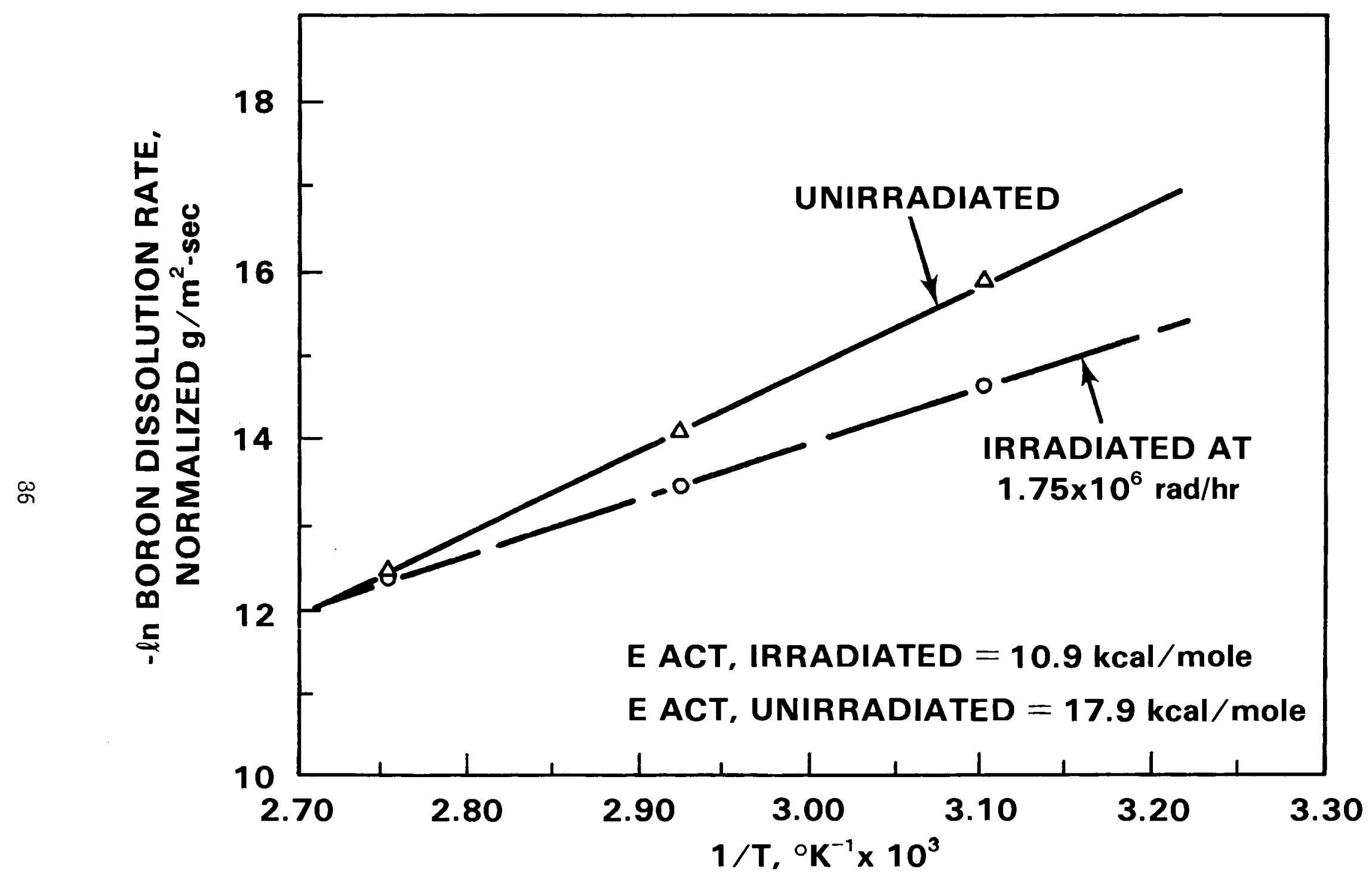

FIGURE 42. Boron Dissolution Rate As a Function of Reciprocal Temperature for Unirradiated and Irradiated 76-68 Glass 


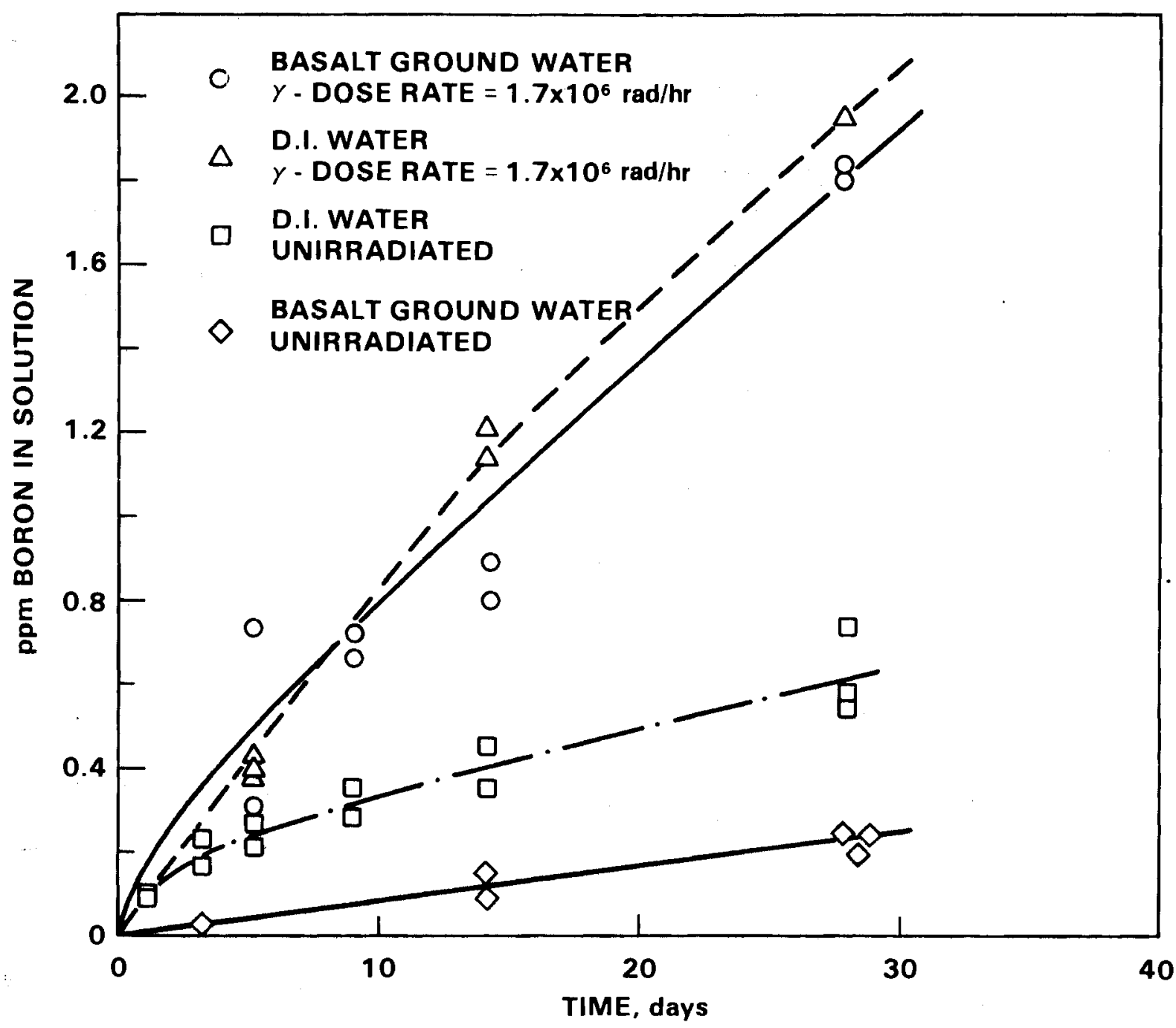

FIGURE 43. Comparison of Radiolysis Effects on Boron Removal from PNL 76-68 Glass in Deionized Water and Basalt Ground Water

the two waters in a gamma radiation field. Radiolysis effects have essentially eliminated the leachate composition effect. Since basalt ground water had an initially lower leach rate, the percent increase due to radiolysis is even larger than for deionized water. It is unfortunate that higher temperature results are not avallable for further evaluation and comparison of basalt ground water in a radiation field.

Unlike deionized water, basalt ground water generates oxalic acid during irradiation, particularly at higher temperatures. These results, along with $\mathrm{pH}$ 


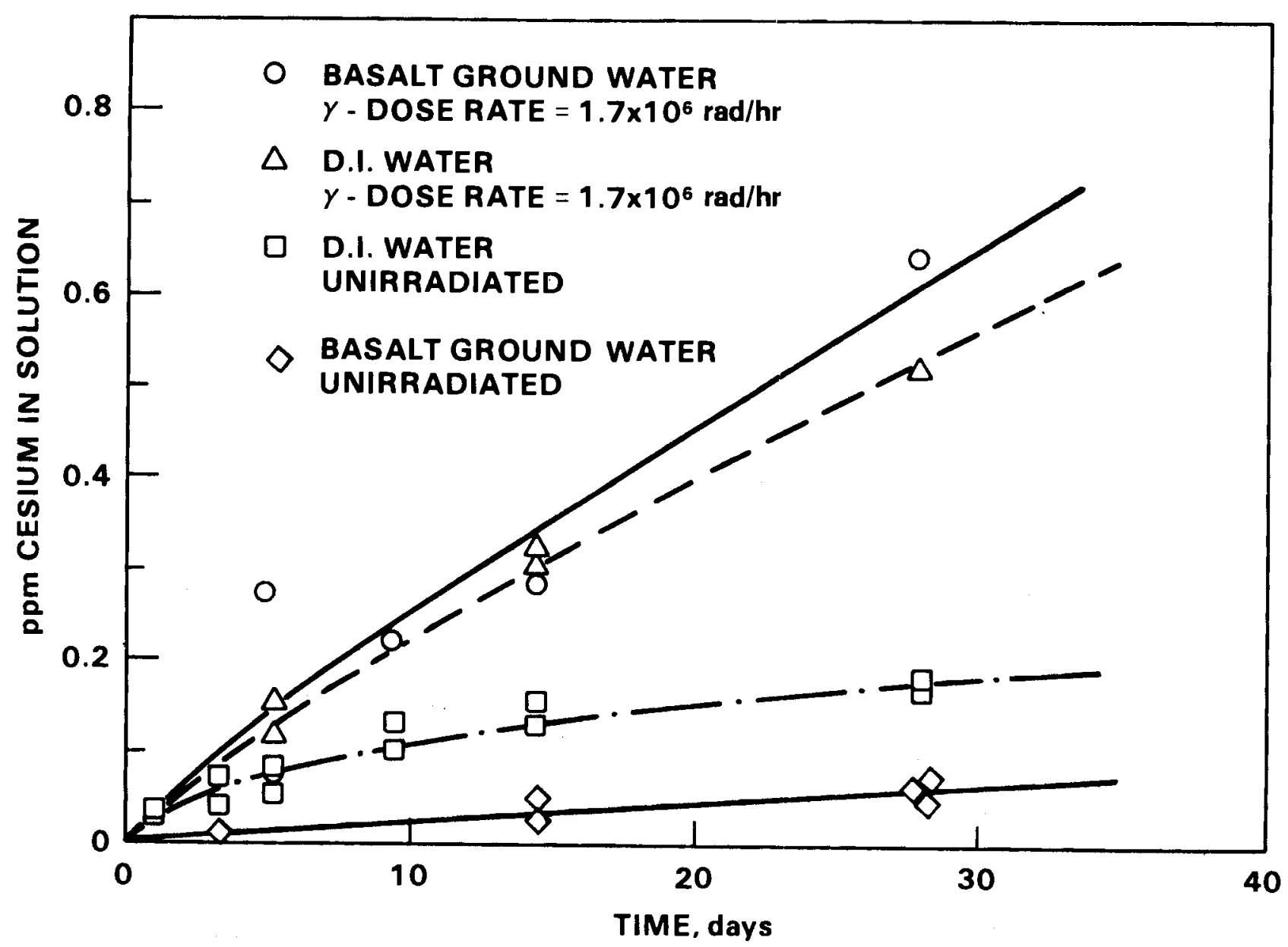

FIGURE 44. Comparison of Radiolysis Effects on Cesium Removal from PNL 76-68 Glass in Deionized Water and Basalt Ground Water

changes, are given in Table 16. In addition to basalt ground water, sodium bicarbonate solutions were irradiated to determine whether bicarbonate was the source of oxalate. As can be seen, this is not the case. Apparently, the relatively complex basalt ground waters have reactions occurring which do not occur in bicarbonate solutions that are favorable to oxalate formation.

It is not clear what effect the oxalates might have on leaching, but they could be more important for actinide removal than for the elements analyzed. Additionally, oxalic acid is sometimes used to keep colloids from flocculating, and as such, it is not desirable in a repository environment. Since oxalic acid is generated at the higher temperatures in basalt water, the temperature effect of radiolysis in basalt water might be different than in deionized 
TABLE 16. Effect of Gamma Radiolysis on Carbonate Waters at a Dose Rate of $2 \times 10^{6} \mathrm{rad} / \mathrm{hr}$

\begin{tabular}{|c|c|c|c|c|}
\hline Solution & Temp., ${ }^{\circ} \mathrm{C}$ & Time, $\mathrm{d}$ & $\begin{array}{c}\mathrm{pH}, \\
\text { Initial/Final } \\
\end{array}$ & $\begin{array}{c}\text { Oxalate, } \\
\text { ppm }\end{array}$ \\
\hline Basalt Ground Water(a) & $90^{\circ} \mathrm{C}$ & $14 d$ & $9.7 / 7.6$ & 83 \\
\hline Basalt Ground Water (a) & $90^{\circ} \mathrm{C}$ & $14 d$ & $9.7 / 7.4$ & 77 \\
\hline Basalt Ground Water & $90^{\circ} \mathrm{C}$ & $14 d$ & $9.7 / 7.2$ & 41 \\
\hline $0.1 \mathrm{M} \mathrm{CO}=$ & $90^{\circ} \mathrm{C}$ & $14 d$ & $11.4 / 11.3$ & 2 \\
\hline $0.001 \mathrm{MCO}_{3}=$ & $90^{\circ} \mathrm{C}$ & $14 d$ & $10.2 / 9.9$ & 0 \\
\hline Basalt Ground Water & $90^{\circ} \mathrm{C}$ & $7 d$ & $9.6 / 8.2$ & 44 \\
\hline Basalt Ground Water & $50^{\circ} \mathrm{C}$ & $7 d$ & $9.6 / 8.6$ & 0 \\
\hline
\end{tabular}

(a) PNL 76-68 glass monolith present.

water. Therefore, higher temperature results must be generated and radiolysis effects on actinide removal investigated.

Conclusions

The conclusions from the work described in this section are summarized as follows:

- Ground waters alone decrease leaching of PNL 76-68 glass in proportion to the amount of silicon they contain.

- Protection of PNL 76-68 glass by a reaction layer does not exist.

- Diffusion control of leaching processes does not exist in PNL 76-68 glass.

- Increased sample surface area to solution volume ratio may be used to accelerate leach testing as it pertains to solution concentrations, since leaching appears to be controlled by silicon concentration in solution.

- Gamma radiolysis effects on leaching of PNL 76-68 glass in deionized water are largest at 10 w temperatures (approximately $50^{\circ} \mathrm{C}$ ) and essentially not measurable at $90^{\circ} \mathrm{C}$. 
- Dose rate effects on PNL 76-68 glass leaching are not large and vary with the element considered.

- Radiolysis effects in deionized water lower the activation energy for elemental removal from PNL 76-68 glass.

- Radiolysis of PNL 76-68 glass in reference basalt ground water results in essentially the same elemental removal rates at $50^{\circ} \mathrm{C}$ as occur in deionized water. This indicates that the basalt leachate causes enhanced elemental removal, since leaching in reference basalt ground water without radiolysis is less than in deionized water.

- Radiolysis of reference basalt ground water at $90^{\circ} \mathrm{C}$ results in the formation of oxalic acid and the generation of large amounts of hydrogen gas.

\section{COMPONENT COMPATIBILITY}

Objective

The objective of the multicomponent testing effort is to investigate interactions between the waste form, waste-package components, and repository rocks under accelerated and repository conditions and to understand the mechanisms of these interactions so that long-term, technically justifiable predictions of their behavior can be made.

Approach

Waste-package interaction tests have been designed to study the alteration of components sequentially from the outside to the inside. Also, sensitivity tests are being conducted to optimize experimental parameters used in the sequential degradation tests. Systems tests are utilized to verify the cumulative results of the sequential degradation. Tests that have been, or are being conducted, include:

- solution/rock interaction tests

- glass/rock interaction tests

- sensitivity tests

- glass/structural barriers and glass/backfill interaction tests

- systems tests. 
Solution/rock interaction tests provide the ground water composition which first encounters the waste packages. During the thermal phase of the repository, rock and associated ground water may be heated to $250^{\circ} \mathrm{C}$. This will change the ambient ground water composition. Fluid with this new composition will contact the outer package component and interact with it. Consequently, it is necessary to establish the higher temperature ground water composition and then use it in subsequent package interaction tests.

Glass/rock interaction tests are employed for studying the behavior of a waste form when little credibility is given to the effects of canisters or overpacks. Low temperature flow tests and digestion and thermal gradient autoclaves have been used for these tests.

Sensitivity tests provide a relatively inexpensive survey for the effects of the many possible experimental variables so that those showing little if any effect can be eliminated in later more sophisticated tests. This reduces the experimental matrix required for achieving an understanding of waste package behavior.

\section{Glass/structural barrier and glass backfill interactions tests were} carried out to determine the effects of other waste package components on waste form behavior. The tests were evaluated from both the solution and the solid surface analytical point of view so that the effects on both components and potential radionuclide release could be evaluated.

Systems tests are used to assess the overall behavior of laboratory-scale waste package assemblies. Information gained from the tests discussed above, as well as those from the preceding sections, serves as a base from which to understand systems interactions tests. Systems tests are also used in the early stages of a waste package testing effort to determine if any gross interactions exist.

Materials

The materials used for these studies are:

- Reference basalt and tuff ground waters (see Tables 1 and 2)

- Basalt and tuff rock (see Tables 11 and 12)

- Ferrous-and titanium-based alloys (see Tables 8, 9 and 10)

- Bentonite clays (see Section 1). 
The compositions and references have been given in previous sections as noted above.

Results and Discussion

Solution/Rock Interaction Tests

Rocking autoclaves are used for these fluid studies since they were designed to study changes in hydrothermal fluid compositions as a function of time. They are optimized for such studies because they allow for:

1. Continuous sample mixing which keeps the solid and liquid phase in maximum contact (i.e., solids cannot settle to the bottom of the autoclave and effectively be removed from reaction with the solution.

2. Reactions to occur within an inert gold bag, thus avoiding changes in the solution due to more reactive vessel walls.

3. Periodic samples to be taken during the run without changing run conditions. Samples are withdrawn through a gold filter and gold sample tube in less than one minute and thus quench effects are minimized. This allows for an analysis of fluids very near to their run condition compositions.

This technique for performing hydrothermal testing on waste package components and studying their interactions is the key to following our philosophy of studying the change in ground water compositions as it moves from the ambient rock through the waste package until it finally encounters the waste form. By investigating the evolution of this fluid in a sequential, stepwise fashion from the outside inward and then outward again, a determination of the rate of release of radioactivity from the waste package to the ambient ground water should be possible.

Samples of reference basalt ground water were run alone at $250^{\circ} \mathrm{C}$ and 300 bars for 4 weeks. The results of this run indicated that the autoclave equipment did not change the composition of the basalt ground water, nor does submitting the water to high temperature and pressure affect the composition other than the predictable decrease in $\mathrm{Ca}$ and $\mathrm{Mg}$. The compounds $\mathrm{CaSO}_{4}$ and $\mathrm{MgSO}_{4}$ are known to have lower solubilities at higher temperatures. 
A sample of Reference Umtanum Entablature-1 Basalt (RUE-1) $(-100,+200$ mesh) was reacted with reference basalt ground water for 2112 hours at $300^{\circ} \mathrm{C}$ and 300 bars. Samples were taken at 100,336, 840, and 2112 hours, and a quenched sample was also taken after the run was terminated. Table 17 presents the analysis of these samples and compares them to similar runs done for the BWIP at Temple University and at Rockwell Hanford. While some minor differences exist, it can be concluded that the three runs provide consistent results. Figure 45 presents the sodium and silica data from PNL and Temple University as a graph of fluid concentration as a function of time. Results indicate that the solution reaches a steady state with respect to $\mathrm{Na}$ concentration very early. For silica, values tended to be decreasing at run termination. Due to the formation of colloids or silica-based alteration products, the variation in silica concentration is not unusual.

The long-term basalt/ground water run resulted in two conclusions:

1. Various laboratories can get consistent results using the rocking autoclave technology.

2. A baseline fluid composition was established for use in subsequent waste package interaction tests.

Since the waste package will first see a fluid which has reacted with rock temperatures above ambient, these tests provide the fluid composition for use in the next test. That will be with a mixture of basalt and bentonite.

Similar tests are underway with Bullfrog tuff and J-13 ground water. While samples have been obtained for the tuff/ground water experiment, sample analyses are not yet available.

\section{Glass/Rock Interactions Tests}

Digestion-Autoclave Tests. The weathering products of most crystalline rocks are clay minerals, and clay minerals are also a dominant component of the alteration assemblage of minerals formed from hydrothermal reactions of rocks in the relatively low temperature regime $\left(<250^{\circ} \mathrm{C}\right)$ expected in repositories. Clay mineral based materials are considered prime candidates for backfills, and clays are also a major detrital component of bedded salt deposits. In waste 
TABLE 17. Solution Analyses from Basalt and Basalt Ground Water Autoclave Tests (a)

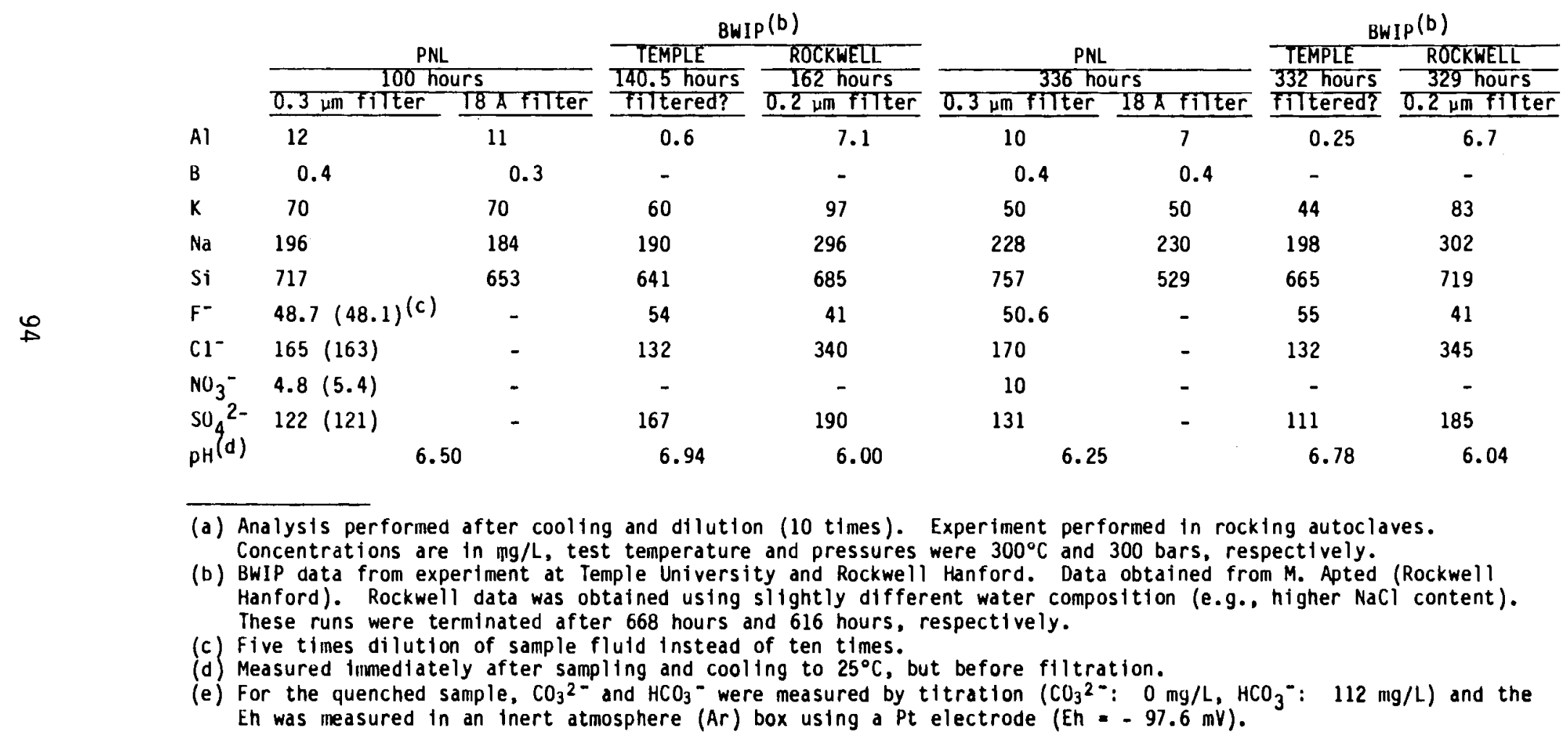


TABLE 17. (contd)

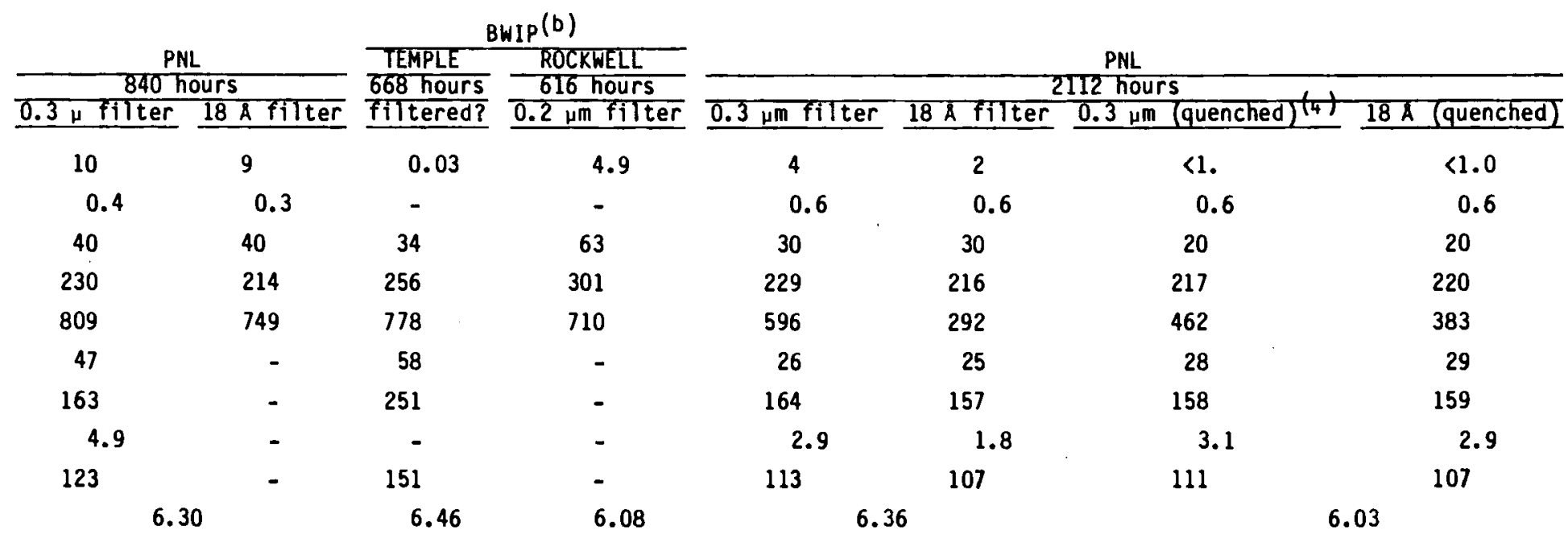

(a) Analysis performed after cooling and dilution (10 times). Experiment performed in rocking autoclaves. Concentrations are in $\mathrm{mg} / \mathrm{L}$, test temperature and pressures were $300^{\circ} \mathrm{C}$ and 300 bars, respectively.

(b) BWIP data from experinent at Temple University and Rockwell Hanford. Data obtalned from M. Apted (Rockwell Hanford). Rockwell data was obtained using slightly different water composition (e.g., higher NaCl content). These runs were terminated after 668 hours and 616 hours, respectively.

(c) Five times dilution of sample fluid instead of ten times.

(d) Measured immediately after sampling and cooling to $25^{\circ} \mathrm{C}$, but before filtration.

(e) For the quenched sample, $\mathrm{CO}_{3}{ }^{-}$and $\mathrm{HCO}_{3}{ }^{-}$were measured by titration $\left(\mathrm{CO}_{3}{ }^{-}: \mathrm{:} 0 \mathrm{mg} / \mathrm{L}^{-} \mathrm{HCO}_{3}{ }^{-}: 112 \mathrm{mg} / \mathrm{L}\right)$ and the Eh was measured in an inert atmosphere (Ar) box using a Pt electrode (Eh $=-97.6 \mathrm{mV}$ ). 


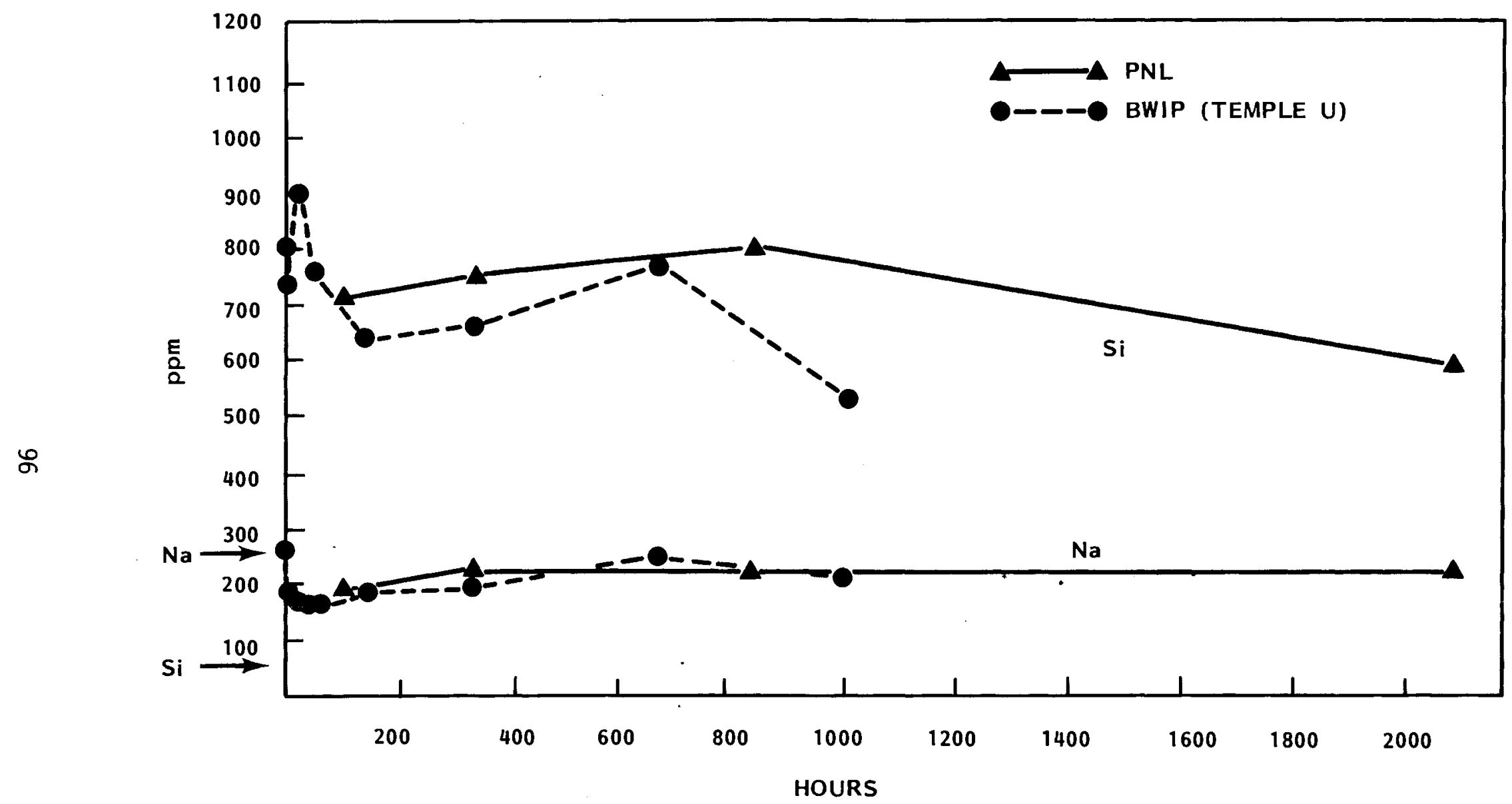

FIGURE 45. Concentration of Sodium and Silicon in Fluid Collected at $300^{\circ} \mathrm{C}$ and 300 Bars from Basalt Ground Water and Umtanum Basalt Autoclave Tests (Note: $\mathrm{Na}$ and $\mathrm{Si}$ arrows denote starting concentrations) 
package designs utilizing non-self shielded canisters, metallic components consist of a minor part of the waste package system on both a volume and weight basis. Consequently, the most reactive and accessible rock components available for interaction with the waste form are clay minerals. Some scouting experiments were thus initiated to examine the interactions of waste glass with both quartz and clay minerals as a function of temperature.

Powdered mixtures (1:1 by wt) of 76-68 or a simplified composition of 76-68 glass (STG) and either kaolin, bentonite, quartz, or tuff were reacted at 90,150 , and $250^{\circ} \mathrm{C}$ for 3 weeks in Teflon ${ }^{\circ}$ lined containers. The pH values of these solutions after the reaction period are shown in Figure 46. It is apparent from Figure 46 that $\mathrm{pH}$ values can vary from 12 (for glass-water systems alone) to 4 (for kaolin alone). These can be considered the range of pH variations expected in repositories, excluding secondary effects such as $\mathrm{Mg}$ silicate brine reactions or radiolysis effects. (Bentonite, not shown in Figure 46, yields $\mathrm{pH}$ values of about 8 to 8.5 , about $1 \mathrm{pH}$ unit less than glass alone.) Figure 46 also shows that a reactive clay, such as kaolin, can produce solutions of near neutral $\mathrm{pH}$, while less reactive minerals, such as quartz, do not yield beneficial reaction products with waste glass at short time periods.

Figure 47 shows the effect of kaolin-glass interactions on specific elements as a function of temperature. It is apparent in all cases that clayglass interactions yield reaction products that contribute to a reduction of waste-glass elements in solution. Consequently, this work suggests that an additional function of a backfill could be to produce stable waste-form/ backfill reaction products containing radionuclides.

Thermal Gradient Effects on Waste Package Interactions

One of the major criteria for repository siting is low hydrologic permeability. Consequently, during the thermal period, most fluid transport will probably be caused by convection, with convection cells gradually diminishing in size as thermal gradients decay. On the basis of models calculated for similar behavior during ore deposit emplacement, very little actual fluid transport is expected. Thus element transport away from the waste form would most probably be influenced strongly by thermal gradients in rock-water systems 


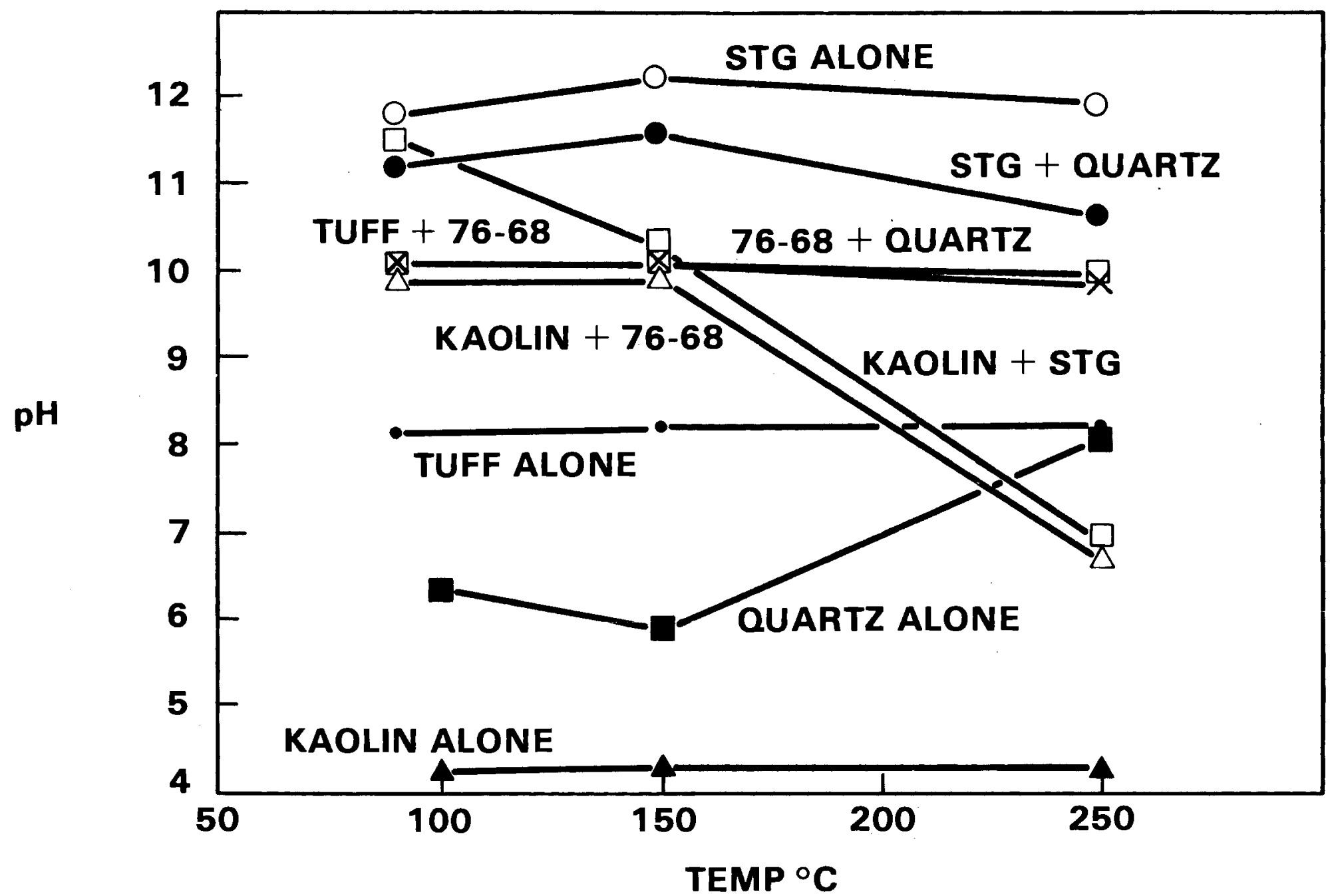

FIGURE 46. Solution pH As a Function of Temperature for Various Glass/Rock Interaction Tests Note: The composition of STG glass in weight percent is $\mathrm{SiO}_{2}=45 \%, \mathrm{Na}_{2} \mathrm{O}=20 \%, \mathrm{~B}_{2} \mathrm{O}_{3}=10 \%, \mathrm{Fe}_{2} \mathrm{O}_{3}=6 \%$, $\mathrm{ZrO}=5 \%, \mathrm{CeO}_{2}$ and $\mathrm{SrO}=4 \% ; \mathrm{M}_{0} \mathrm{O}_{3}, \mathrm{Nd}_{2} \mathrm{O}_{3}$, and $\mathrm{Cs}_{2} \mathrm{O}=2 \%$ 

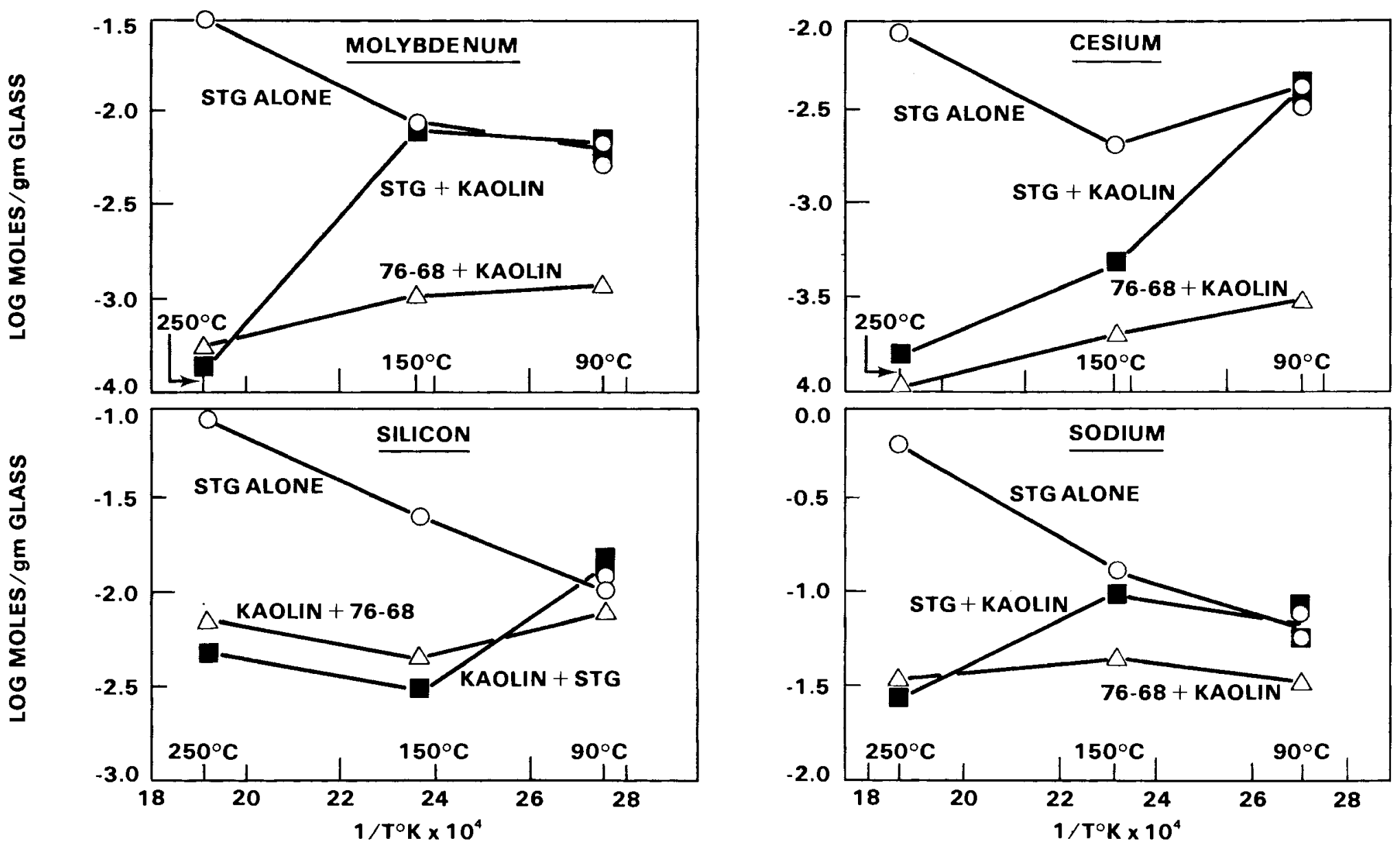

FIGURE 47. Evidence for Low Solubility Reaction Product Formation in the STG Glass-Kaolin System 
characterized by extremely high surface area to volume ratio. Figure 48 is an attempt to depict such a system in schematic form.

Several experiments were conducted to investigate the general effects of thermal gradients on nuclide transport. In these experiments, the waste-form powder was placed at one end of a gold tube and the remainder of the tube was packed with powdered rock or mineral material. A simplified ground water in an amount equal to $10 \%$ of the total solid material was also placed in the tube which was subsequently welded shut. The tube was placed in a cold seal pressure vessel and run under a thermal gradient of about $15^{\circ} \mathrm{C} / \mathrm{cm}$ for 60 days. The solid sample extracted from the tube was then mounted in polished sections and scanned qualitatively by EDX to determine the relative elemental distribution.

Figure 49 is an example of some of these results in terms of the relative peak to background ratios of selected elements. Some general trends similar to those expected from waste form leaching experiments are observed. Molybdenum exhibits very little interaction with the rock and migrates toward the cooler end of the tube, while neodynium (and by analogy, uranium) exhibits insignificant migration. Cesium, on the other hand, shows a bimodal concentration distribution, suggesting that at least two different: waste-rock interaction products can control cesium migration.

Single-Pass Continuous-Flow (SPCF) Leaching and Sorption

Studies in Basalt

In order to investigate the sorption of actinides from basalt ground water leachates of doped glass, the Lawrence Livermore National Laboratory's SPCF leaching technology was utilized in a complex and long-term study. Basalt ground water was continuously passed over doped ( $\mathrm{Np}$ and $\mathrm{Pu}$ ) 76-68 glass and $\mathrm{UO}_{2}$ pellets. The subsequent leachate was then passed through an adjacent basalt rock column where the leached actinides had the opportunity to immediately adsorb onto the rock. Also, the rock column was actually touching some beads of glass and $\mathrm{UO}_{2}$ pellets so that direct interactions could be studied upon termination and dismantling of the combined leaching cells and sorption columns. This test was run for about $1-1 / 4$ years, at 75 and $25^{\circ} \mathrm{C}$, and at three flow 


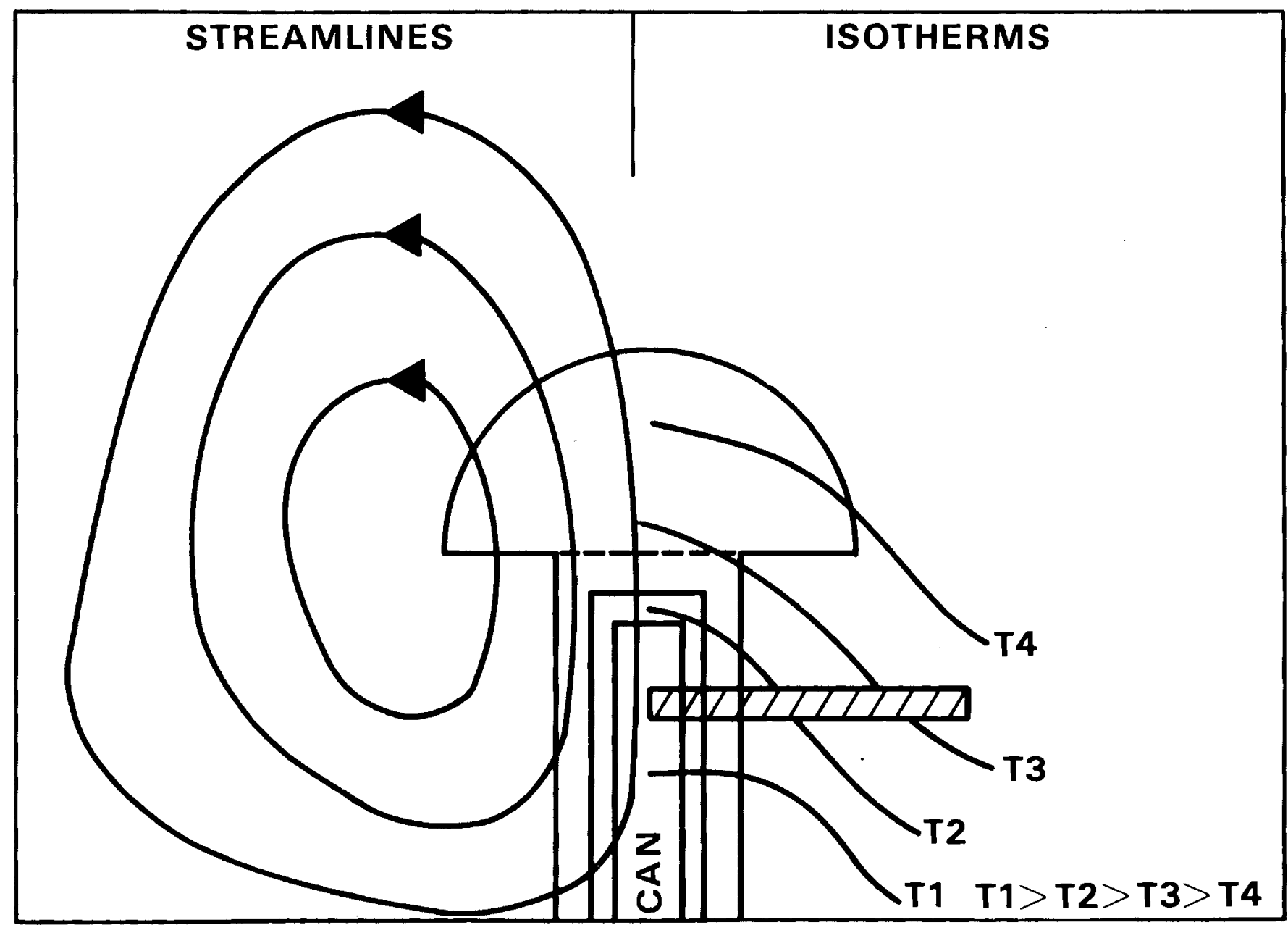

FIGURE 48. Thermal Gradients and Fluid Flow at Repository Conditions 


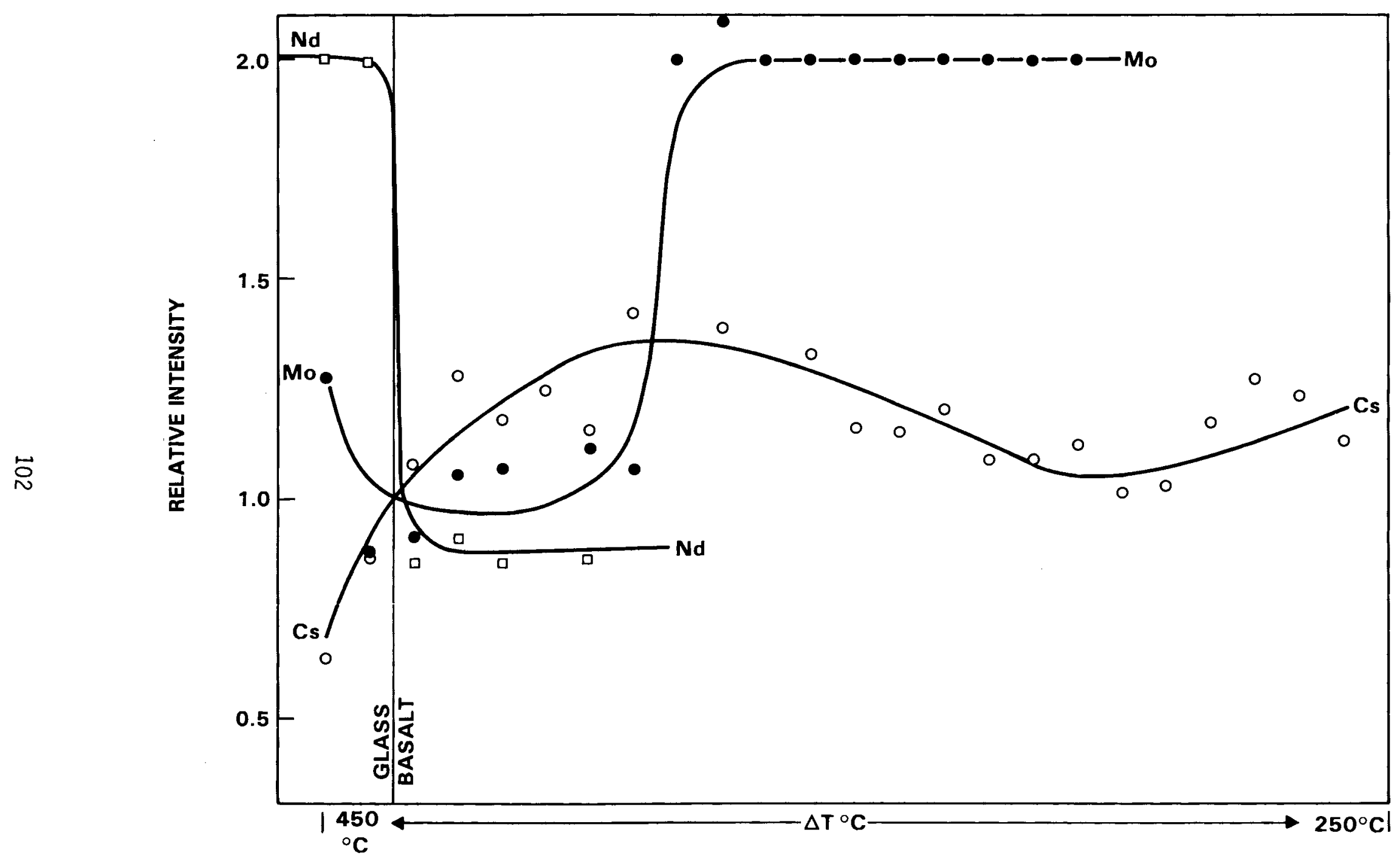

FIGURE 49. Relative Intensities of Elements After Migration in Basalt Under a Thermal Gradient 
rates ( $1 \mathrm{~mL} /$ day, $10 \mathrm{~mL} /$ day, and $300 \mathrm{~mL} /$ day). It was a partially replicated experiment that included about 35 separate flowing channels.

The purpose of this test was to provide a rock-sorption column with freshly leached actinides and compare the resultant sorption ratios with those obtained from tracer-sorption experiments. It was thought that the chemical species and conditions of tracer-sorption experiments may be significantly different than for this more realistic "combined" study. At the time the flow study was designed, the state-of-the-art tracer sorption experiments were obtaining sorption-ratio values for both $\mathrm{Np}$ and $\mathrm{Pu}$ in the range of several thousand. Analysis of leachates from both the glass and $\mathrm{UO}_{2}$ channels is nearing completion. These preliminary results indicate that for the high and medium flow-rate channels, both $\mathrm{Np}$ and $\mathrm{Pu}$ migration rates are retarded, with $\mathrm{Pu}$ showing the greater retardation. These data are entirely consistent with more recent results obtained using an improved technique for tracer-sorption studies (Salter et a1. 1981, Barney 1981). Those sorption results were 8 for $\mathrm{Np}$ and 65 for $\mathrm{Pu}$ under oxidizing conditions and freshly fractured basalt. Based on a calculation of expected retardation of our basalt columns using these sorption ratio values, we would predict breakthrough of $\mathrm{Pu}$ during the first day for the high flow-rate channel and after three days for the medium flow-rate channel. Results from the flow test indicated little sorption of $\mathrm{Np}$ at either flow-rate, retardation of about 1 day and 3 days for $\mathrm{Pu}$ at high and medium flow-rates, respectively.

For the low flow-rate channels, Np still has shown little retardation, but $\mathrm{Pu}$ has been adsorbed to the point where it has remained below the analytical detection limit for samples analyzed so far.

Since the column was designed for very highly sorbtive actinides, when in fact their sorption ratios are well below 100, the high and medium flow-rate channels are not optimum for obtaining more accurate dynamic sorption values since the column saturates too quickly. We expect to obtain better values with the low flow-rate channels, but results have been slower to obtain due to increased analytical problems.

Results to date are confirming that improved tracer-sorption studies can give meaningful sorption ratios. This is significant since they are cheaper to 
obtain than those which result from combined leaching-sorption studies. Further analysis and interpretation of the results from this experiment are currently in progress.

\section{Sensitivity Tests}

A series of basalt and tuff-relevant digestion autoclave tests are currently in progress utilizing a "roller" oven which keeps the vessels continually rolling in order to promote a mixing of the solid and fluid phases.

These tests are designed to study the effects of various ratios of rock, bentonite, and Fe powder on the nature and amounts of final reaction products. Table 18 presents the experimental matrix currently being followed. Also, for two of the tests, replicates are being done in Berghof and rocking autoclaves in order to compare the results of fluid sampling at temperature and pressure with the digestion autoclaves where only quenched samples of the fluid can be obtained. Also, higher temperature tests $\left(300^{\circ} \mathrm{C}\right)$ using the rocker vessels will be compared to the $150^{\circ} \mathrm{C}$ tests using digestion autoclaves.

TABLE 18. Basalt and Tuff Sensitivity Tests

$$
\begin{gathered}
\text { Temperature }=150^{\circ} \mathrm{C} \\
\text { Solution/Solid Ratio }=10 / 1 \text { (by weight) } \\
\text { Duration }=30 \text { and } 60 \text { Days }
\end{gathered}
$$

\begin{tabular}{|c|c|c|c|c|}
\hline Expt No. & Rocks & Fe Powder & Bentonite & Assoc. Tests \\
\hline 1 & $100 \%$ & -- & -- & (a) \\
\hline 2 & $95 \%$ & $5 \%$ & -- & \\
\hline 3 & $90 \%$ & $10 \%$ & -- & \\
\hline 4 & $85 \%$ & $15 \%$ & -- & \\
\hline 5 & $95 \%$ & -- & $5 \%$ & \\
\hline 6 & $90 \%$ & -- & $10 \%$ & \\
\hline 7 & $85 \%$ & -- & $15 \%$ & \\
\hline 8 & $90 \%$ & $5 \%$ & $5 \%$ & (a) \\
\hline
\end{tabular}

Note: There were 8 tests each for basalt system and tuff system.

(a) These tests are to be conducted at $300^{\circ} \mathrm{C}$ and $150^{\circ} \mathrm{C}$ in rocking autoclaves. 
These sensitivity tests are helping us to better utilize the hydrothermal equipment at our disposal by teaching us the limitations for comparing results between different testing methodologies. They are also helping us design more complex tests where we need to know the optimum ratios of various components required for a successful experiment.

Glass/Structural Barrier and Glass/Backfill Interactions Tests

The effects of waste package components on elemental release from PNL 76-68 glass have been investigated for ductile iron, Titanium Grade 12, and bentonite clay. Selected results, which were complete enough to discuss in a meaningful fashion, are presented.

The effect of various metals on elemental release from a borosilicate waste glass has been previously investigated as part of an evaluation of metal matrix encapsulated waste forms (Buckwalter and Pederson 1982). They determined the effects of aluminum, copper, lead, tin, and titanium on PNL 76-68 borosilicate waste glass leaching. Their findings showed that copper, tin, and titanium had an insignificant effect, while aluminum reduced leaching by an order of magnitude and lead essentially stopped glass leaching. Therefore, for the more reactive metals a strong synergistic effect was reported in which both metal and glass were affected. The presence of the metals evaluated either caused little effect or improved the glass leaching characteristics. However, the previous study did not include iron, which is a potentially important constituent of the waste package, and the experiments were conducted in deionized water rather than ground waters.

The present study was undertaken to evaluate the effects of iron on the leaching characteristics of borosilicate waste glass in realistic ground waters. Experiments were conducted with ductile iron in contact with deionized water, tuff, or basalt ground water leachants that contained PNL 76-68 glass. The iron and glass were not in contact with each other but were both in the same Teflon container. Both solution analysis of the leachates and surface analysis of the solids were conducted to determine the extent of the effects of iron on glass-water interactions. 
When the static leaching experiments conducted in ground waters, described earlier in this report, were repeated with the addition of a piece of ductile iron of the same approximate surface area as the glass sample, a totally different result occurs. The starting solution composition has little effect on the leaching characteristics of the glass samples. These results are illustrated by the cross-hatched region of Figure 50. The lines in this figure are identical to Figure 34 and represent leaching results with no iron present. The cross-hatched region includes the boron and cesium leaching results from deionized water, tuff, and basalt ground waters. Elemental removal rates in all of the leachates are initially similar to those observed for early leaching in deionized water without the presence of iron. However, in the presence of iron, the leach rates do not decrease as rapidly with time as they do in deionized water alone. Consequently, more elemental removal occurs from the glass samples.

The results presented in Figure 34 are from solution analyses. Solid state analyses of the glass samples from the same experiments show consistent behavior. Cross sections of glass samples that have been exposed to $90^{\circ} \mathrm{C}$ deionized water, basalt, and tuff ground waters for 28 days at an SA/V ratio of $10 \mathrm{~m}^{-1}$ are shown in Figure 51. The top row had glass and leachate only, while the bottom row included ductile iron. Reaction layer depths of glasses exposed only to the various leachates are quite different, as can be seen from the top row of Figure 51 .

The average depths of reaction are 9, 5, and $1 \mu \mathrm{m}$ for deionized water, tuff, and basalt ground water leachates, respectively. However, when iron is present during leaching, the reaction layer that develops on the glass is thicker and essentially the same in all three leachates. These results are shown in the bottom row of Figure 51, where the average layer thickness is 14, 13, and $13 \mu \mathrm{m}$ for deionized water, tuff, and basalt ground water, respectively. Elemental depth profiles of these depletion layers using EDAX and SIMS analyses show that although some differences exist in samples exposed only to the solutions, essentially no difference could be detected in the samples that had iron included in the leachate. 


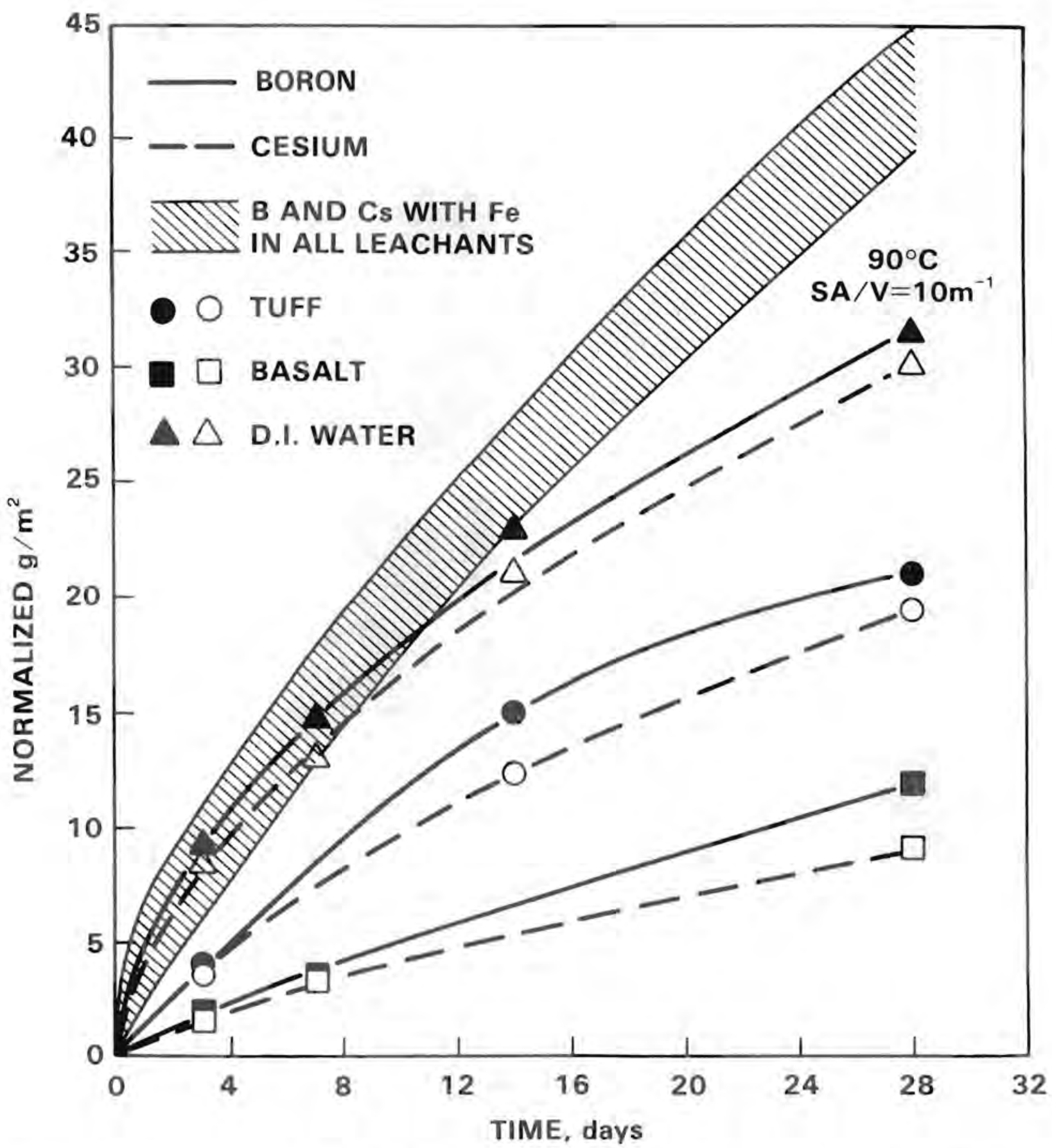

FIGURE 50. Leaching Characteristics of PNL 76-68 Glass: The Effect of Ground Water Composition without Iron Present and the Effect of Having Iron Present During Leaching 


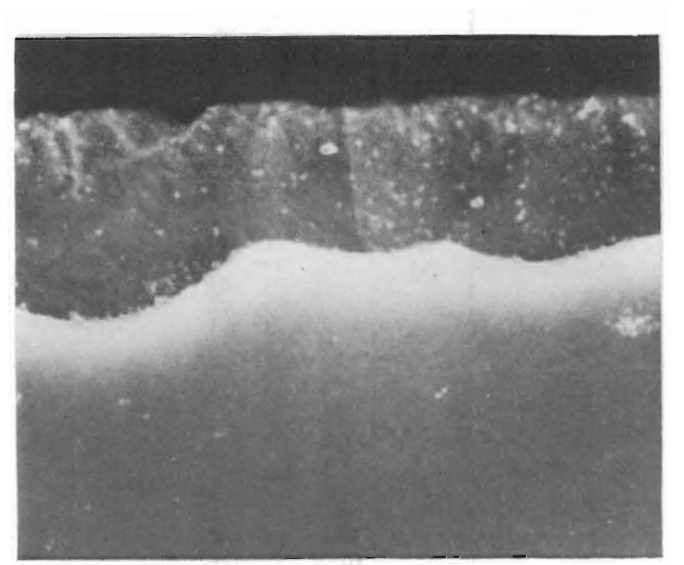

D.I. WATER

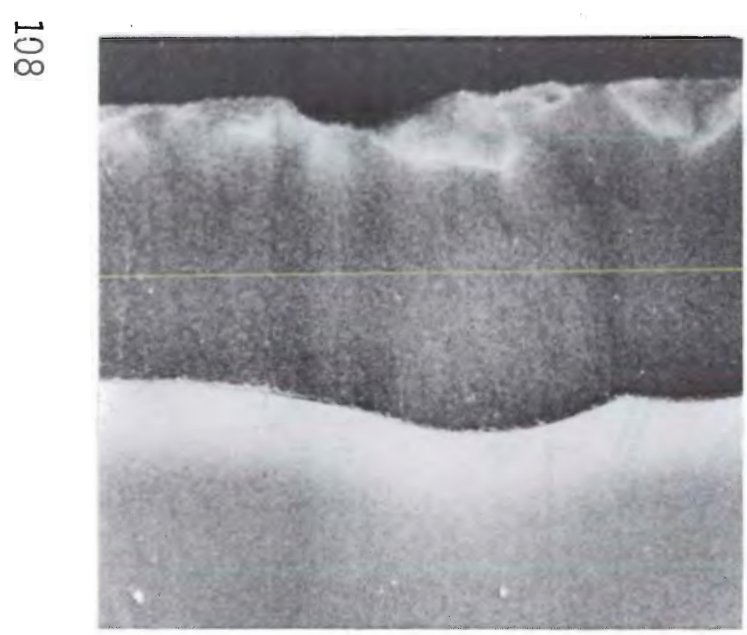

$\mathrm{Fe}$

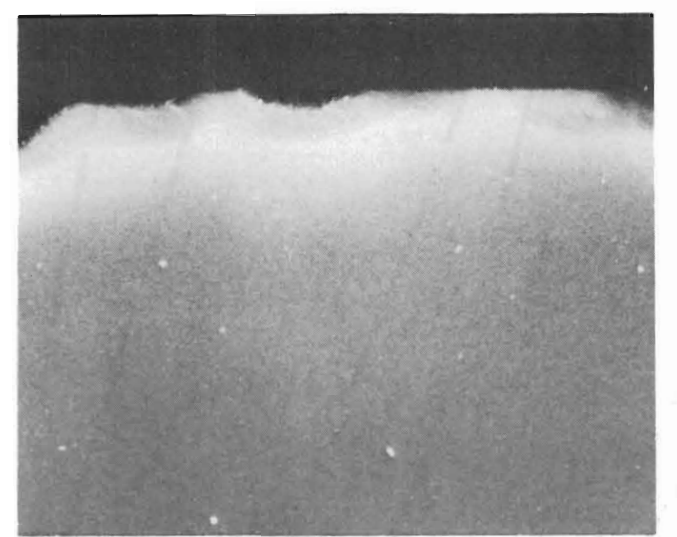

BASALT

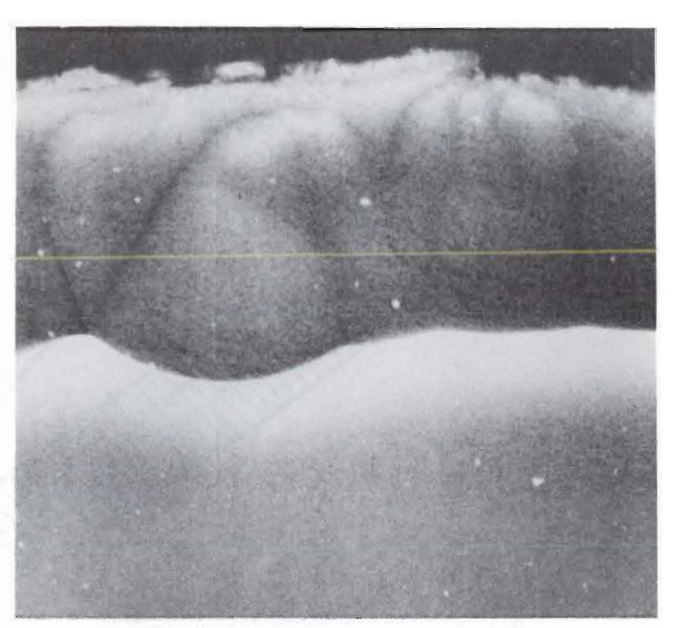

$\mathrm{Fe}$

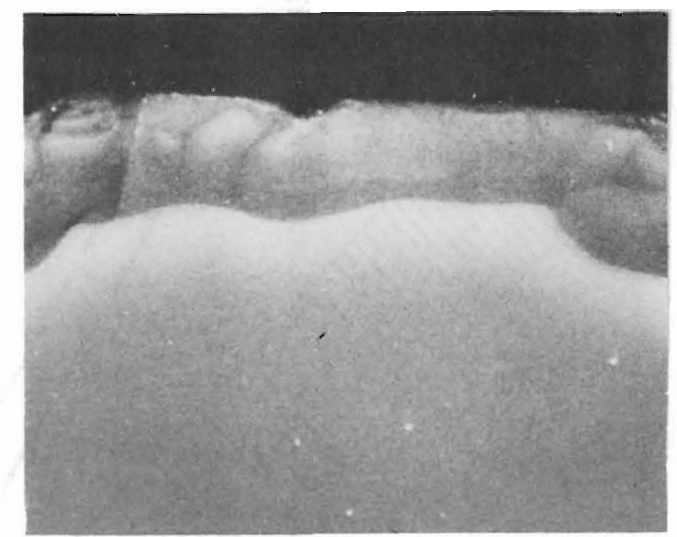

TUFF

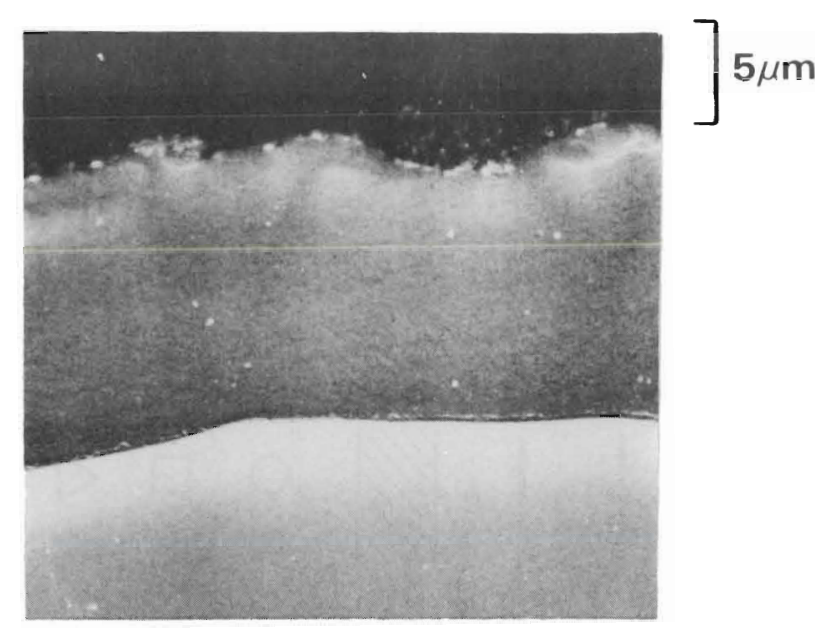

$\mathrm{Fe}$

FIGURE 51. PNL 76-68 Glass Reaction Layers After 28-Day Exposures to $90^{\circ} \mathrm{C}$ Deionized Water, Basalt, and Tuff Ground Waters with and without Ductile Iron Present 
In addition to a small pH increase, the presence of ductile iron also causes formation of precipitates--at least part of which are colloidal in nature. These precipitates are essentially X-ray amorphous. However, EDAX and XRF analyses of the filtered precipitates show that they contain primarily iron and silicon with many other elements present in lesser quantities. Furthermore, the surfaces of the iron coupon present during leaching form large quantities of loosely adherent iron silicate precipitates. Precipitates also form to a lesser degree on the glass sample. They are primarily on the "up" side surfaces, indicating a falling-out of precipitate from solution rather than a strong glass/iron interaction.

Placing ductile iron in basalt or tuff ground water without glass present tends to remove many of the elements and makes the two ground waters more nearly equal in composition, as shown in Figures 52 and 53 for $\mathrm{Si}$ and $\mathrm{Ca}$, respectively. In Figure 52 the time dependence of removal of silicon from both basalt and tuff ground waters by ductile iron at $90^{\circ} \mathrm{C}$ with an SA/V ration of $10 \mathrm{~m}^{-1}$ is illustrated. The results show a rapid removal of silicon from both ground waters by the iron. The total amount of silicon in solution, including colloids, is shown by the dashed lines. After filtration of the leachate through $200-n m$ filters, the amount of silicon in solution decreased, due to removal of the colloids, as shown by the solid lines. Further filtration through 100-nmr and 1.8-nm filters removed no additional silicon. Basalt and tuff ground waters have initial silicon concentrations of 56 and $30 \mathrm{ppm}$, respectively. Yet after a short time exposure to iron, the silicon concentrations are equal. Most of the silicon forms a precipitate on the iron coupon. However, some colloidal precipitates are also formed, as can be seen from Figure 52. Essentially identical results are found for calcium removal from basalt and tuff ground waters by iron, which are shown in Figure 53.

Tuff and basalt ground waters cause less elemental removal from glass samples than deionized water because their starting compositions contain many elements normally leached from the glass. Leach rates tend to decrease as the elemental concentrations increase in solution. However, as can be seen from Figures 52 and 53 the presence of iron causes the ground water compositions to lose many of their elements and to approach deionized water in effective 


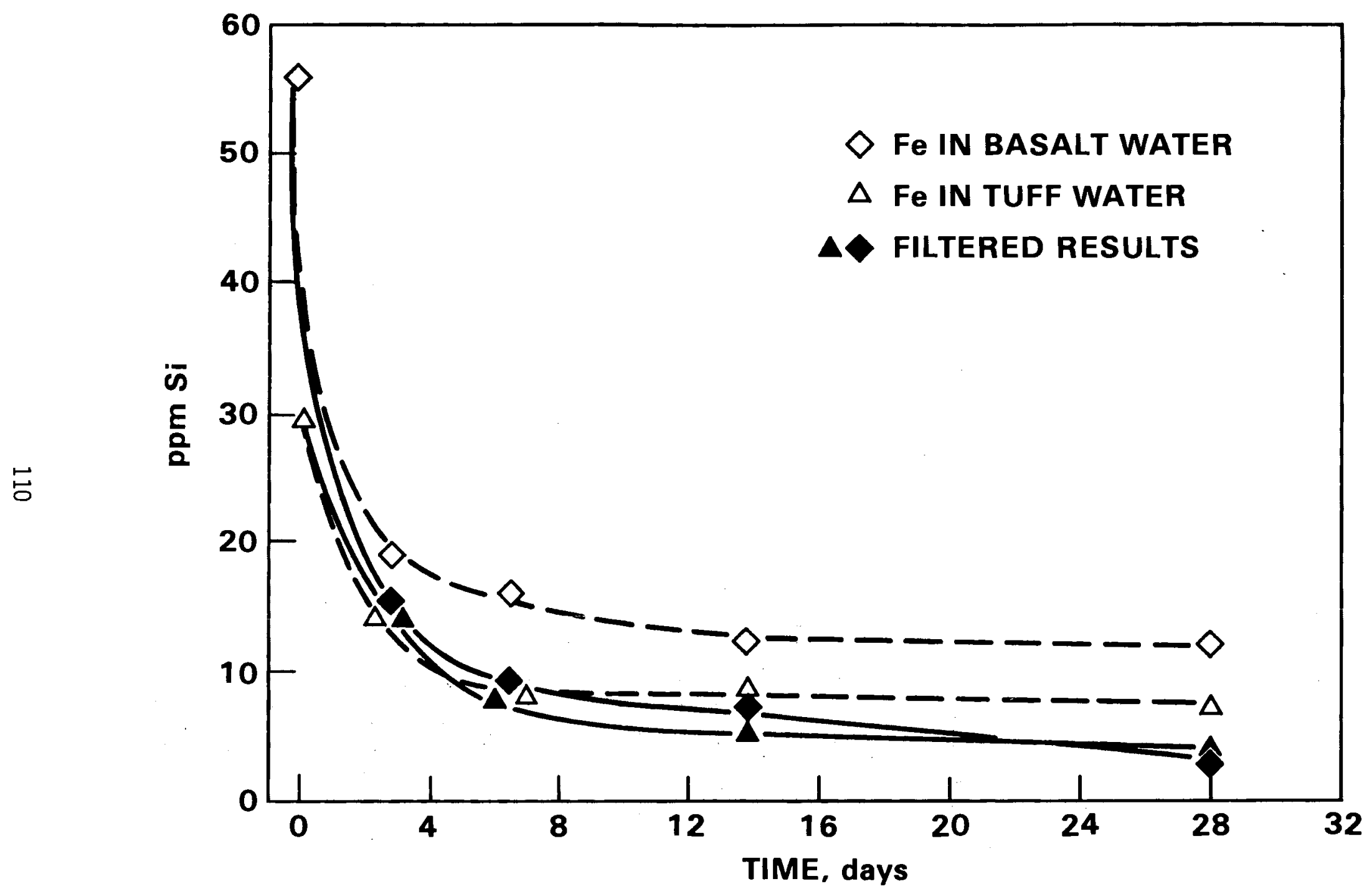

FIGURE 52. Time-Dependent Changes in the Silicon Concentrations of $90^{\circ} \mathrm{C}$ Basalt and Tuff Ground Waters When Exposed to Ductile Iron 


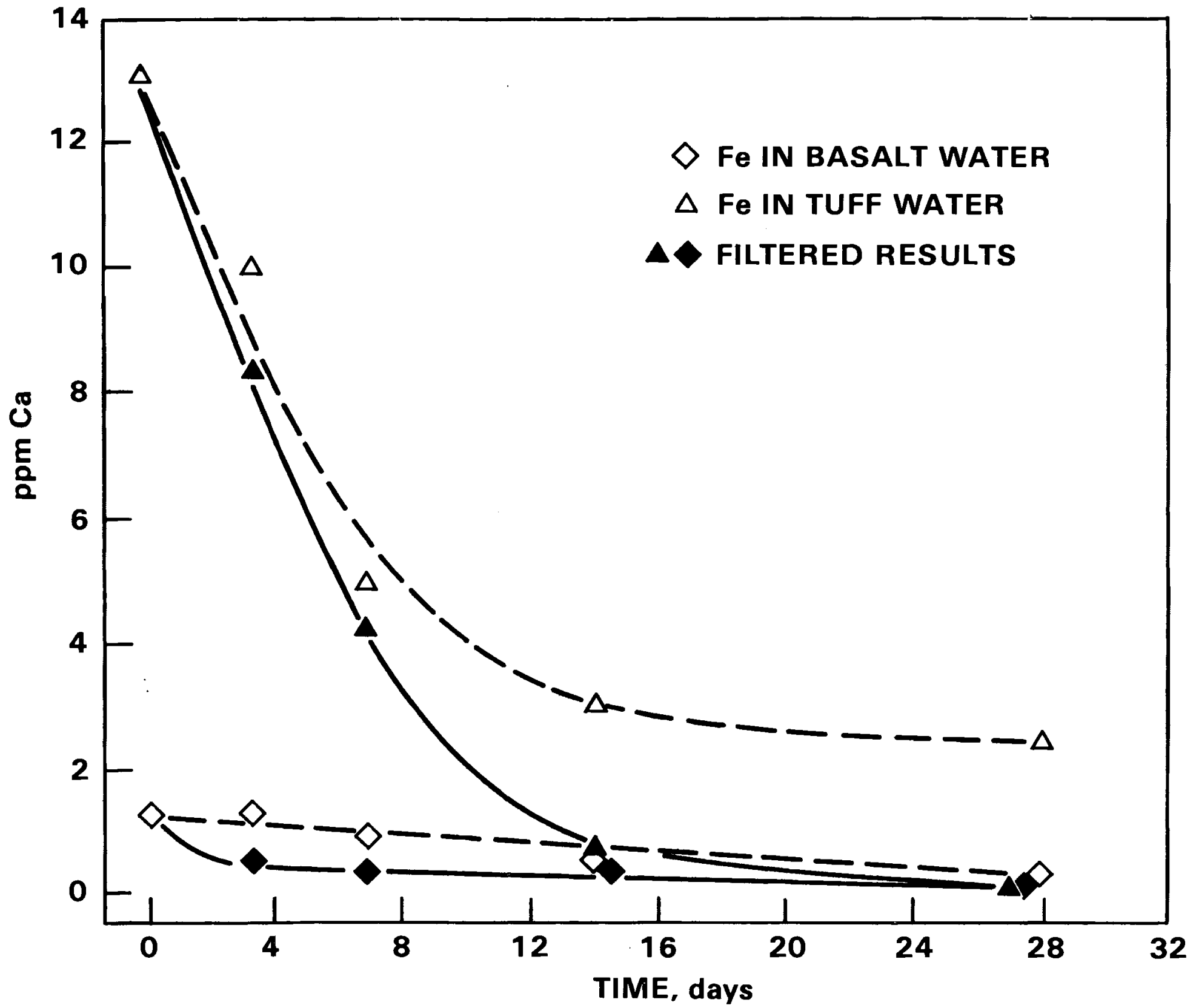

FIGURE 53. Time-Dependent Changes in the Calcium Concentrations of $90^{\circ} \mathrm{C}$ Basalt and Tuff Ground Waters When Exposed to Ductile Iron 
composition. Therefore, when ductile iron is placed in the leachates along with PNL 76-68 glass, the effect of ground water composition on leaching is essentially eliminated (see Figure 50). Furthermore, because iron silicate precipitates are formed as silicon is leached from the glass and these precipitates effectively remove many of the other leached elements from solution, the relatively high initial leach rates observed in deionized water are maintained for longer periods of time as illustrated by the cross-hatched region of Figure 50 . This results in enhanced leaching and larger depletion layer depths as shown in Figure 51 .

The formation of iron silicate colloids causes significant changes in the reactions of both PNL 76-68 glass and ductile iron with deionized water, and tuff and basalt ground waters. This is due primarily to effectively removing elements from solution by precipitate formation and thus reducing the saturation effects that normally occur in static leaching. In addition to the effects on elemental removal from waste glass, the presence of iron causes many of the removed elements to be incorporated into the precipitates. If iron is to be used in the repository, then the characteristics of the iron silicate precipitates should be evaluated. Furthermore, the potential for migration/ entrapment of colloids should be investigated as an alternative method of radionuclide transport or fixation within the repository.

Although only a few investigations have been conducted on the interactive effects of Titanium Grade 12 on elemental release from PNL 76-68 glass, some conclusions can be drawn. Titanium Grade 12 has no apparent effect on elemental release from PNL 76-68 glass in deionized water out to 28 days. However, in basalt ground water an increase in leach rates of up to $50 \%$ as observed when Titanium Grade 12 samples were placed in the leach container. Analysis of the metallic samples shows a silicate precipitate on the surface. The Titanium Grade 12 is removing silicon from solution, thus enhancing leach rates. This effect is small compared to iron and apparently requires a threshold amount of silicon in solution before an effect occurs. Perhaps longer time tests in deionized water would eventually show enhancement if silicon solution concentrations reached high enough levels. 
Preliminary results of the effect of bentonite clay on glass leaching (Figure 54) show a small enhancement in the reaction layer growth for both deionized water and basalt water. In these experiments the clays were not in physical contact with the glass sample. Surface analyses are about the only meaningful way to evaluate the effect of clay, since solution analyses are complicated by the elements released into the leachate by the clay and by the colloidal clay particles that clog filter paper. This area of research needs further investigation if bentonite clays are to be used in a repository environment.

\section{Systems Tests}

Tests of miniature waste glass canisters in a basalt, granite, or tuff matrix were the first "systems" tests conducted at PNL. These are reported by Shade and Bradley (1980) and Shade (1982), and a summary follows.

Waste package interaction tests were initiated in FY- 80 as part of the Waste Rock Interaction Technology (WRIT) program. These package tests represent a natural extension of previous and concurrent waste-solution interaction studies. This section describes the results of some initial investigations of the effects of rock media on the release of simulated fission products from a single waste form, PNL reference glass 76-68. The tests are intended to serve as a guide for the design of future experiments with the objective of supporting the development of a source-term release model, and to gain some insight into expected behavior in scaled-up, fully radioactive, large volume system tests.

All test assemblies contained a minicanister prepared by pouring molten, uranium-doped PNL 76-68 glass into a $2 \mathrm{~cm}$ diameter stainless steel tube closed at one end. The tubes were cut to 2.5 to $7.5 \mathrm{~cm}$ in length to expose a flat glass surface rimmed by the canister wall. A cylindrical rock pellet, cut from one of the rock materials used, was placed on the glass surface, and then, to complete the package, both the canister and rock pellet were packed in the same type of rock media ground to about $75 \mu \mathrm{m}$. Rock materials used were a quartz monzonite from the Climax Stock at the Nevada Test Site, basalt from the Umtanum flow at Hanford, and bedded salt from southeastern New Mexico. These packages were run from 4 to 6 weeks in either $125 \mathrm{~mL}$ digestion autoclaves or 


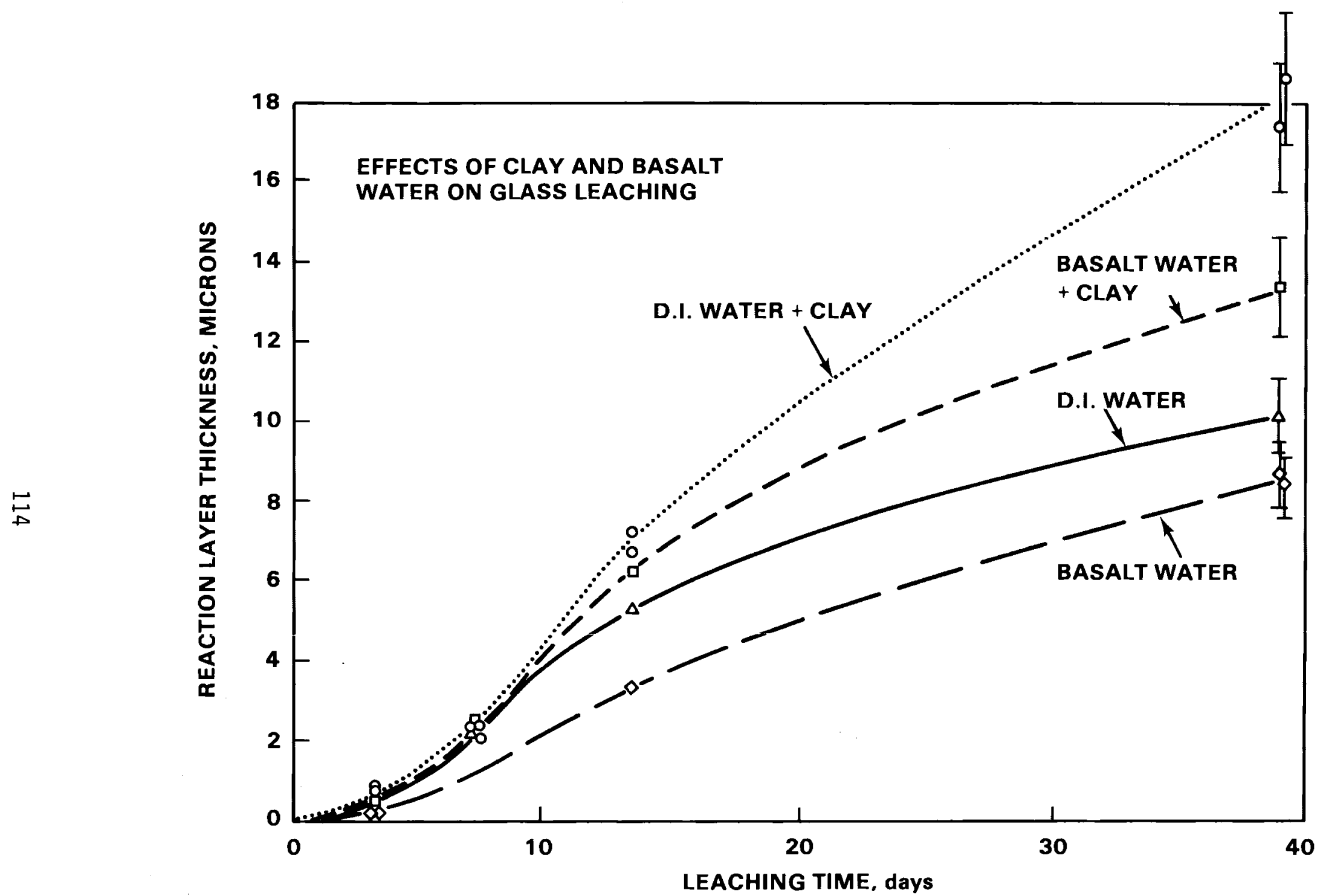

FIGURE 54. The Effect of Bentonite $\mathrm{Cl}$ ay on the Time Dependent Reaction Layer Thickness of PNL 76-68 Glass in $90^{\circ} \mathrm{C}$ Deionized Water and Basalt Ground Water 
$850 \mathrm{~mL}$ autoclaves capable of direct solution sampling, at either 150 or $250^{\circ} \mathrm{C}$. Digestion autoclave pressures were the vapor pressure of water, 600 psig at $250^{\circ} \mathrm{C}$. The direct sampling autoclaves were pressurized to 2000 psig with argon. The solution to package mass ratio was 0.5 in the digestion autoclaves and about 3.0 in the direct sampling autoclaves.

Differences between pre- and post-test brine compositions in salt package tests suggest that salt recrystallization during the test leads to a redistribution of elements between salt and brine, along with the removal of some elements from the glass and canister. In general, magnesium and cesium are enriched in the brine, while calcium and strontium are concentrated in recystallized salt. Nickel and chromium, probably from the canister, and zinc, from the glass, become enriched in the liquid. These effects were not as pronounced in the large volume autoclave tests as in digestion autoclave tests, but solution $\mathrm{pH}$ values in both tests were lowered to about 3.0 from the initial value of 5.5. Solution compositions determined from granite and basalt package posttest fluids suggest that dissolved $\mathrm{SiO}_{2}$ is derived from quartz in the granite packages, and from interstitial volcanic glass in basalt. It is also apparent from $\mathrm{SiO}_{2}$ concentrations that steady-state conditions had not been achieved. Soluble cesium concentrations in the granite and basalt tests were reduced relative to the salt package tests and previous glass-water hydrothermal tests, but basalt and granite appear to have little effect on molybdenum and boron release.

Examination of glass surfaces by scanning electron microscopy (SEM) revealed a variety of alteration products, some of which have been tentatively identified on the basis of their characteristic X-ray spectra. Uranium-bearing spheres and zinc silicate crystals were observed in packages that had been exposed to a vapor phase, but were not found in packages that remained submerged in a liquid phase during the run. X-ray photoelectron spectroscopy (XPS) of the rock pellet surfaces also revealed that uranium was present in rocks which contacted the vapor phase, but uranium was not found on rock surfaces which contacted only the liquid phase. Other phases present on rock surfaces in contact with either vapor and liquid phases include calcium phosphate and calcium sulfate and on one occasion, a zirconium silicate. 
In general, the solution chemistry of these initial package tests suggests that the rock media is the dominant controlling factor and that rock-water interaction may be similar to that observed in some geothermal areas. In no case was uranium observed in solution above $15 \mathrm{ppb}$. The observed leach rates of uranium doped glass not in contact with rock surfaces and alteration products have been observed to be considerably higher. Thus, the use of leach rates and uranium concentrations observed from binary leach experiments (waste-form water only) to ascertain long-term environmental consequences appear to be quite conservative compared to actual uranium release in the waste package experiments. Further evaluation, however, of fission product transport behavior and the role of alteration phases as fission product sinks is required.

Changes in solution composition as a function of time from these tests are shown in Figure 55. It is interesting to note that the concentration of elements such as sodium and silicon, present in both the waste-form and rock material, reach levels at $250^{\circ} \mathrm{C}$ that are similar to rock-only systems. Furthermore, at these temperatures, the initial water compositions (deionized water or a site-specific ground water) have a negligible influence on solution composition at pressure and temperature.

Figure 56 shows details of element segregation in the altered zone of PNL 76-68 glass after leaching in the minicanister tests. In general, this element distribution is similar to that observed across the gel layer of glass leached without other package components present, even at temperatures lower than $250^{\circ} \mathrm{C}$.

\section{Conclusions}

The conclusions from the work described in this section are summarized as follows:

- Fluid compositions for basalt reacted with basalt ground water at $300^{\circ} \mathrm{C}$ and 300 bars have been completed. Results are consistent with those of other labs. These results provide a fluid composition to react with the waste package. Similar tests are in progress for tuff. 

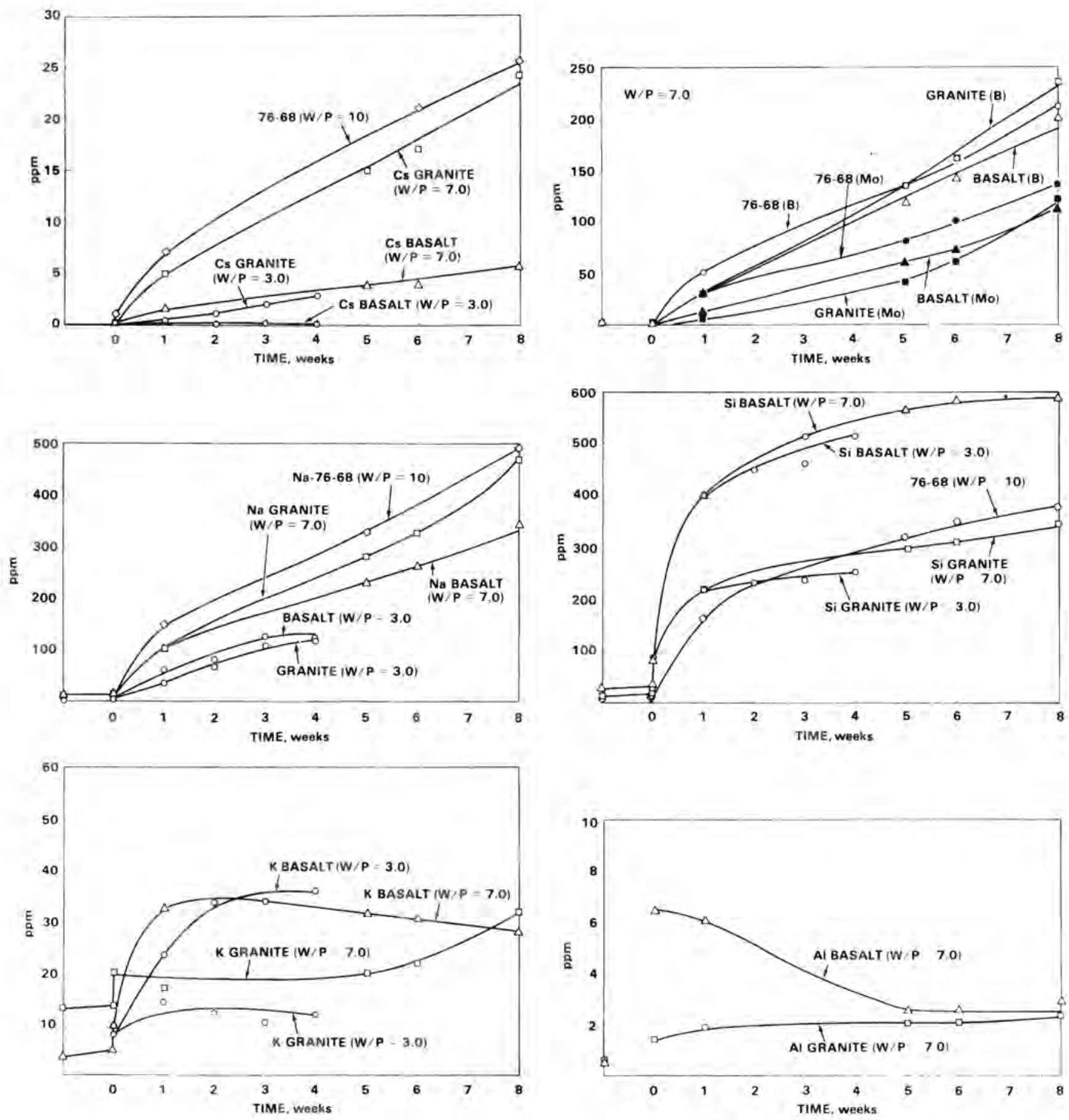

FIGURE 55. Changes in Solution Composition As a Function of Time from Basalt and Granite Minicanister Tests Note: W/P refers to the solution volume to total solids mass ratio. 

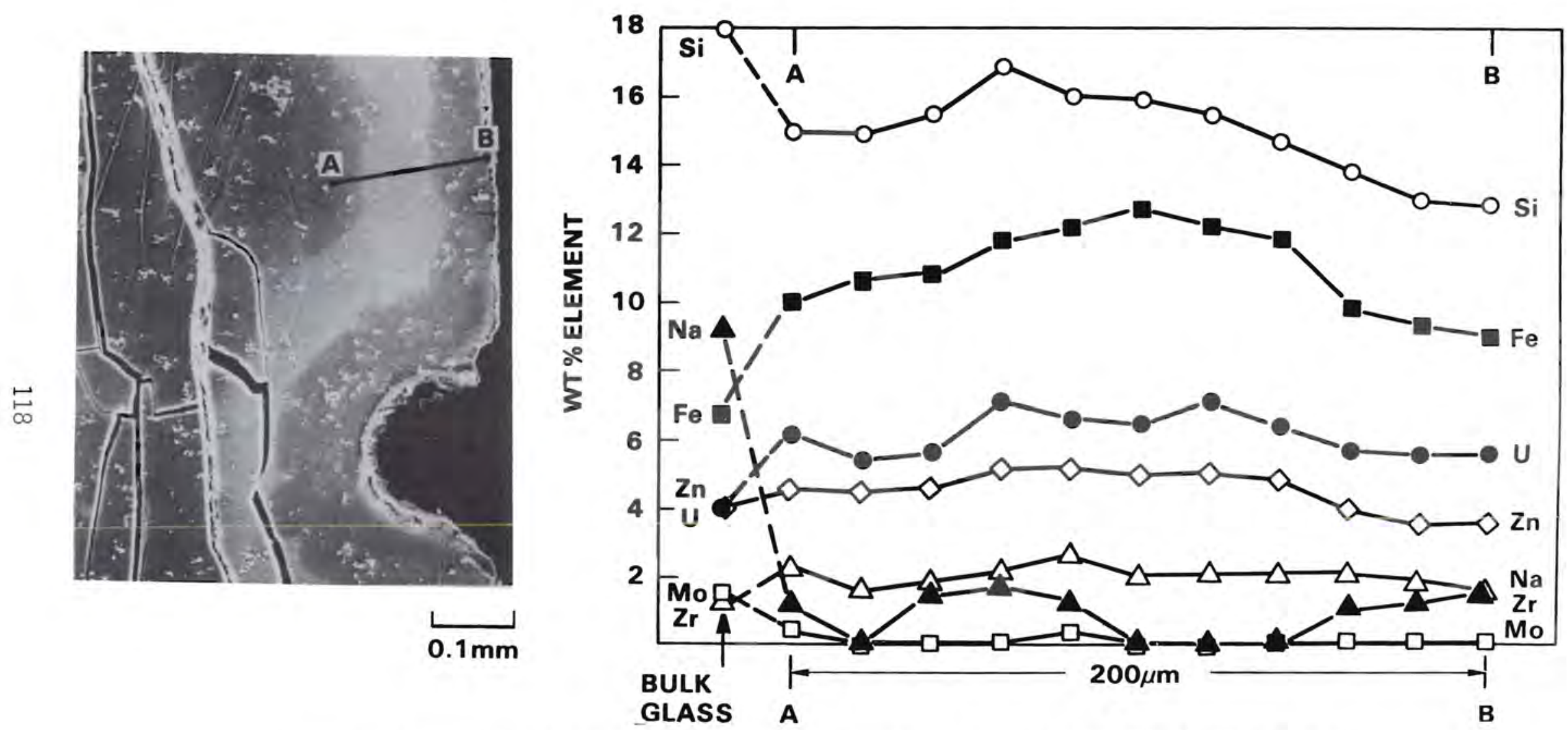

FIGURE 56. Element Segregation in the Reaction Layer of PNL 76-68 Glass During a Basalt Minicanister Test 
- Kaolin tends to lower the $\mathrm{pH}$ (to $\sim 4$ ) of reaction fluids when placed in a glass-ground water system compared to the high $\mathrm{pH}(\sim 12)$ values obtained when glass is reacted alone. Bentonite also produced a similar, although less pronounced, beneficial lowering of pH (to about 8 to 8.5$)$.

- Thermal gradient experiments have helped determine elemental mobility in a thermal field such as one would expect at a waste repository.

- Single-pass continuous flow experiments indicate that freshly leached actinides exhibit sorption behavior consistent with that predicted for batch sorption experiments using improved laboratory techniques. If further work confirms this preliminary observation, then the results from less expensive batch sorption experiments may be used with more confidence.

- Inclusion of ductile iron in leach tests with deionized basalt water or tuff ground water eliminates the compositional effect of the leachate, i.e., all of the leachates behave the same. The ductile iron enhances leaching from PNL 76-68 glass by removing elements from solution through precipitate formation; some of these precipitates are colloidal in nature.

- Inclusion of Titanium Grade 12 in leaching experiments in deionized water shows no effects, but in basalt water it shows enhanced leaching due to silicate precipitation on the Titanium Grade 12 surface.

- Bentonite clay causes some enhancement of elemental removal from PNL 6-68 glass in deionized water and reference basalt ground waters.

- The minicanister tests indicated that dissolved $\mathrm{Si0}_{2}$ was derived from interstitial volcanic glass in basalt and that steady-state conditions had not been achieved over the experimental run time. In general, the rock medium tends to dominate the fluid composition rather than the waste package. 


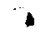

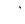

.

.

.

4

7

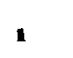




\section{ACKNOWLEDGMENTS}

The authors wish to acknowledge the dedicated effort and attention to detail shown by $D$. Getchell and R. Britton in the operation of the test autoclaves and the handling of test specimens; the careful and responsive surface experimental analysis work provided by J. Shade, H. Kissinger, and L. Pedersen; and the experimental assistance provided by D. Squier, S. Faber, L. Bray, J. Westsik, Jr., R. Peters, J. Shade, C. Buckwalter, S. Pitman, and J. Nelson. 
4

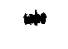

$r$

1

$\checkmark$

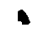




\section{REFERENCES}

Anbar, M. 1968. Fundamental Processes in Radiation Chemistry. ed. P. Ausloos, Interscience, New York.

Appleby, A. and H. A. Schwarz. 1969. Journal of Physical Chemistry 73:1937.

Barney, G. S. 1981. "Radionuclide Reactions with Ground Water and Basalts from Columbia River Basalt Formations." Presented at the Northwest Regional ACS Meeting, Bozeman, Montana, June 1981. RHO-SA-217, Rockwell Hanford Operations, Richland, Washington.

Buckwalter, C. Q., L. R. Pederson and G. L. McVay. 1982. "The Effects of Surface Area to Solution Volume Ratio and Surface Roughness on Glass Leaching." PNL-SA-9488, Pacific Northwest Laboratory, Richland, Washington. (Accepted for publication in Journal of Noncrystalline Solids.)

Buckwalter, C. Q. and L. R. Pederson. 1982. "Inhibition of Nuclear Waste Glass Leaching by Chemisorption. PNL-SA-9940, Pacific Northwest Laboratory, Richland, Washington. (Accepted for publication in Journal of the American Ceramic Society.)

Clark, D. E. and L. L. Hench. 1981. "An Overview of the Physical Characterization of Leached Surfaces." Nuclear and Chemical Waste Management 2:93.

Engineered Waste Package Conceptual Design Defense High-Level Waste (Form 1), Commercial High-Level Waste (Form 1), and Spent Fuel (Form 2) Disposal in Salt. 1981. Technical Report No. AESD-TME-3131, Westinghouse Electric Corporation, Advanced Energy Systems Division, Pittsburgh, Pennsylvania.

Ethridge, E. C., D. E. Clark and L. L. Hench. 1979. "Effects of Glass Surface Area to Solution Volume Ratio on Glass Corrosion." J. Phys. and Chem. of Glasses 25(2):35.

Glass, R. S. 1981. Effects of Radiation on the Chemical Environment Surrounding Waste Canisters in Proposed Repository Sites and Possible Effects on the Corrosion Processes. SAND81-1677, Sandia National Laboratory, Albuquerque, New Mexico.

Grambow, B. and C. Q. Buckwalter. 1981. "Specific Ion Effects and Solubility Limits." In Workshop on the Leaching Mechanisms of Nuclear Waste Forms, October 27-28, 1981: Summary Report, pp.14-15, comp. J. E. Mendel. PNL-4228, Pacific Northwest Laboratory, Richland, Washington.

Hench, L. L., D. E. Clark and E. Lue Yen-Bower. 1980. "Corrosion of Glass and Glass Ceramics." Nuclear and Chemical Waste Management 1:59.

Johnston R. G., and R. A. Palmer. 1981. Characteristics of Candidate Geologies for Nuclear Waste Isolation: A Review. DOE/ET/41900-6, Rockwell Hanford Operations, Richland, Washington. 
McVay, G. L. and C. Q. Buckwalter. 1980. "The Nature of Glass Leaching." Nuc. Tech. $51: 123$.

McVay, G. L. and C. Q. Buckwalter. 1982. The Effect of Iron on Waste Glass Leaching. PNL-SA-10474, Pacific Northwest Laboratory, Richland, Washington

Molecke, M. A., D. W. Schaefer, R. S. Glass, and J. A. Ruppen. 1981. Sandia HLW Canister/Overpack Studies Applicable for a Salt Repository. SAND81-1585, Sandia National Laboratory, Albuquerque, New Mexico.

Moss, M., and M. A. Molecke. 1982. Thermoconductivity of Bentonite/Quartz High Level Waste Package Backfills. SAND82-12745, Sandia National Laboratory, Albuquerque, New Mexico.

Salter, P. F., L. L. Ames, and J. E. McGarrah. 1981. The Sorption Behavior of Selected Radionuclides on Columbia River Basalts. RHO-BWI-LD-48, Rockwell Hanford Operations, Richland, Washington.

Shade, J. W., and D. J. Bradley. 1980. Initial Waste Package Interactions Tests: Status Report. PNL-3559, Pacific Northwest Laboratory, Richland, Washington.

Shade, J. W. 1982. "Release Kinetics and Alteration of Waste Glass in Crystalline Rock Systems." Chemical Geology 36:103-121

Strachan, D. M. and B. 0. Barnes. 1980. "Results From a One-Year Leach Test: Long-Term Use of MCC-1." PNL-SA-10036, Pacific Northwest Laboratory, Richland, Washington.

Weber, W. J., R. P. Turcotte, L. R. Bunnell, F. P. Roberts and J. H. Westsik, $\mathrm{Jr}$. 1979. In Proceedings of the International Symposium on Ceramics in Nuclear Waste Management. DOE CONF-790420, National Technical Information Service, Springfield, Virginia.

Westerman, R. E. 1980. Investigation of Metallic, Ceramic, and Polymeric Materials for Engineered Barrier Applications in Nuclear Waste Packages. PNL-3484, Pacific Northwest Laboratory, Richland, Washington.

Winograd, I. J. 1971. "Hydrogeology of Ash-Flow Tuff: A Preliminary Statement." Water Resources Research I (4):994-1006.

Wolfsberg, K., et al. 1981. Research and Development Related to Nevada Nuclear Waste Storage Invest igations, October-December, 1980. LA-8739-PR, Los Alamos Scientific Laboratory, Los Alamos, New Mexico.

Wood, M. I. 1980. BWIP Data Package for Reference Data of Ground Water Chemistry. RSD-BWI-DP-007, Rockwell Hanford Operations, Richland, Washington. 


\section{DISTRIBUTION}

No. of

Copies

\section{OFFSITE}

27 DOE Technical Information Center

Don Alexander

Nuclear Regulatory Commission

Mail Stop 1130-SS

Washington, D.C. 20555

Allied Chemical

Corporation

File Copy

505 2nd Street

Idaho Falls, ID 83401

Argonne National

Laboratory

Reference Library

9800 South Cass Avenue

Argonne, IL 60439

W. W. Ballard

DOE Division of Waste

Repository Deployment

Washington, DC 20545

S. J. Basham

Office of Nuclear Waste

I solation

Battelle Memorial

Institute

505 King Avenue

Columbus, $\mathrm{OH} \quad 43201$

10 Battelle Memorial

Institute

Office of Nuclear Waste

Isolation

505 King Avenue

Columbus, $\mathrm{OH} \quad 43201$

Attn: Beverly Rawles
No. of

Copies

F. Bazan

Lawrence Livermore Laboratory

P.0. Box 808

Livermore, CA 94550

J. 0. Blomeke

Union Carbide Corporation (ORNL)

Chemical Technology Div.

P.0. Box $Y$

Oak Ridge, TN 37830

Ernest Bondietti

Environmental Sciences Division

Oak Ridge National Laboratory

Bldg. 1505

Oak Ridge, TN 37830

A. Brandstetter

Office of Nuclear Waste Isolation

Battelle Memorial

Institute

505 King Avenue

Columbus, $\mathrm{OH} \quad 43201$

A. Brecher

Arthur D. Little, Inc.

Acorn Park

Cambridge, MA 02104

Brookhaven National

Laboratory

Reference Section

Info. Division, Upton

Long Island, NY 11973 
No. of

Copies

Wayne Carbiener

Office of NWTS Integration

Battelle Memorial Institute

505 King Avenue

Columbus, $\mathrm{OH} 43201$

J. A. Carr

Office of Nuclear Waste Isolation

Battelle Memorial Institute

505 King Avenue

Columbus, $\mathrm{OH} 43201$

H. Clyde Claiborne

Oak Ridge National Laboratory

P.0. Box $X$

Oak Ridge, TN 37830

F. E. Coffman

DOE Office of Terminal Waste Disposal and Remedial Action

Washington, DC 20545

P. Colombo

Brookhaven National Laboratory

Nuclear Waste Mgt. Group

Upton, NY 11973

C. R. Cooley

DOE Division of Waste Repository Deployment Washington, DC 20545

R. W. Cote

Office of Nuclear Waste Isolation

505 King Avenue

Columbus, $\mathrm{OH} 43201$
No. of

Copies

J. L. Crandall

E. I. du Pont de Nemours and Company, Inc.

Savannah River Laboratory

Aiken, SC 29801

R. E. Cunningham

Deputy Director for Fuels and Materials

Nuclear Regulatory

Commission

Siliver Springs, MD 20910

Jared Davis

U.S. Nuclear Regulatory

Commission

Washington, DC 20555

J. 0. Duguid

Office of NWTS Integration

Battelle Memorial Institute

505 King Avenue

Columbus, $\mathrm{OH} \quad 43201$

Environmental Protection Agency

Office" of Radiation Programs

Technical Assessment

Division AW559

Washington, DC 20460

Bruce R. Erdal

Los Alamos Scientific Laboratory

CNC-11, MS-514

Los Alamos, NM 87545

A. Gancarz

Los Alamos Scientific Laboratory

CNC-11, Mailstop 514

Los Alamos, NM 87545 
No. of

Copies

R. G. Garvin

E. I. du Pont de Nemours and Company, Inc.

Aiken, SC 29801

H. W. Godbee

Union Carbide Corporation (ORNL)

Chemical Technology

Division

P.0. Box Y

Oak Ridge, TN 37830

R. J. Hall

Office of NWTS Integration

Battelle Memorial Institute

505 King Avenue

Columbus, $\mathrm{OH} \quad 43201$

L. L. Hench

Dept. of Materials Science and Engineering

University of Florida

Gainesville, FL 32611

W. M. Hewitt

Office of Nuclear Waste Isolation

Battelle Memorial Institute

505 King Avenue

Columbus, $\mathrm{OH} 43201$

P. Hofmann

Office of NWTS Integration

Battelle Memorial

Institute

505 King Avenue

Columbus, $\mathrm{OH} \quad 43201$

J. Holloway

Dept. of Chemistry

Arizona State University

Tempe, AZ 85281
No. of

Copies

\author{
N. Hubbard \\ Office of Nuclear Waste \\ Isolation \\ Battelle Memorial \\ Institute \\ 505 King Avenue \\ Columbus, $\mathrm{OH} 43201$ \\ D. Isherwood \\ Lawrence Livermore \\ National Laboratory \\ P.0. Box 808, L-205 \\ Livermore, CA 94550 \\ J. K. Johnstone \\ Sandia Laboratories \\ Albuquerque, NM 87185 \\ L. H. Johnson \\ Fuel Waste Technology Branch \\ Atomic Energy of Canada, Ltd. \\ W.N.R.E. Pinawa, Manitoba \\ Canada ROE 1LO \\ I. A. Kilinic \\ Dept. of Geology \\ University of Cincinnati \\ Cincinnati, $\mathrm{OH} \quad 45221$ \\ J. F. Kircher \\ Office of Nuclear Waste \\ Isolation \\ Battelle Memorial \\ Institute \\ 505 King Avenue \\ Columbus, $\mathrm{OH} 43201$ \\ D. A. Knecht \\ Exxon Nuclear \\ P.0. Box 2800 \\ Idaho Falls, ID 83401 \\ E. H. Kobish \\ Solid State Division \\ Oak Ridge National \\ Laboratory \\ 0ak Ridge, TN 37830
}


No. of

Copies

Lawrence Berkeley

$$
\text { Laboratory }
$$

Reference Library

University of California

Berkeley, CA 94720

Lawrence Livermore

National Laboratory

Reference Library

P.0. Box 808

Livermore, CA 94550

A. Lerman

Dept. of Geological

Sciences

Northwestern University

Evanston, IL 60201

W. L. Lindsay

Centennial Professor

Colorado State University

Fort Collins, CO 80523

$T$. Longo

DOE Division of Waste

Repository Deployment

Washington, DC 20545

Los Alamos Scientific.

Laboratory

Reference Library

P.0. Box 1663

Los Alamos, NM 87544

R. Y. Lowrey

DOE Albuquerque Operations Office

Albuquerque, NM 87115

R. W. Lynch, Manager

Department 4530

Sandia Laboratories

P.0. Box 5800

Albuquerque, NM 87185
No. of

Copies

S. A. Mann

DOE Chicago Operations and Regional office

Argonne, IL 60439

J. B. Martin

Asst. Director for

Radioactive Waste Mgmt. Branch

NRC Division of Materials and Fuel Cycle Facility Licensing

Washington, DC 20555

R. D. McCright

Lawrence Livermore National Laboratory

P.0. Box 808

Livermore, CA 94550

Don Moak

Office of Nuclear Waste Isolation

Battelle Memorial

Institute.

505 King Avenue

Columbus, $\mathrm{OH} \quad 43201$

M. A. Molecke

Nuclear Waste Experimental Programs

Division 4512

Sandia Laboratories

Albuquerque, NM 87185

J. Moody

Office of Nuclear Waste

I solation

Battel le Memorial

Institute

505 King Avenue

Columbus, $\mathrm{OH} \quad 43201$ 
No. of

Copies

J. P. Murray

Harvard University

Pierce Hall

Cambridge, MA 02138

J. 0. Neff

DOE Columbus Program office

505 King Avenue

Columbus, $\mathrm{OH} \quad 43201$

D. Newby

Advanced Energy Systems Division

Westinghouse Electric Corporation

P.0. Box 10864

Pittsburgh, PA 15236

E. J. Nowak

Sandia Laboratory

Division 5824

Albuquerque, NM 87131

Oak Ridge National Laboratory

Central Research Library Document Reference Section Oak Ridge, TN 37830

G. K. Dertel

DOE Office of Defense and Byproducts

DP-12, GTN

Washington, DC 20545

J. D. Osnes

$\mathrm{RE} / \mathrm{SPEC}$

P.0. Box 725

One Concourse Drive

Rapid City, SD 57709

V. M. Oversby

Lawrence Livermore National Laboratory

P.0. Box 808

Livermore, CA 94550
No. of

Copies

W. M. Pardue

Office of Nuclear Waste Isolation

Battelle Memorial Institute

505 King Avenue

Columbus, $\mathrm{OH} 43201$

F. Parker

Dept. of Environmental Engineering

Vanderbilt University

Nashville, TN 37235

G. A. Parks

Department of Applied Earth Sciences

Stanford University

Stanford, CA 94305

A. F. Perge

DOE Office of Terminal Waste Disposal and Remedial Action Washington, DC 20545

T. H. Pigford Univ. of California Berkeley, CA 94720

G. F. Pinder

Dept. of Civil Engineering Princeton University

Princeton, $\mathrm{NJ} 08540$

M. S. Plodinec

E. I. du Pont de Nemours and Company, Inc.

Savannah River Laboratory

Aiken, SC 29801 
No. of

Copies

J. Pomeroy, Tech. Sec.

National Academy of

Sciences

Committee of Radioactive

Waste Mgmt.

National Research Council

2101 Constitution Avenue

Washington, DC 20418

R. G. Post

College of Engineering

University of Arizona

Tucson, AZ 85721

G. E. Raines

Office of Nuclear Waste

Isolation

Battelle Memorial

Institute

505 King Avenue

Columbus, $\mathrm{OH} \quad 43201$

L. D. Ramspott, $L-204$

Lawrence Livermore

National Laboratory

P.0. Box 808

Livermore, CA 94550

R. A. Robinson

Office of Nuclear Waste

Isolation

Battelle Memorial

Institute

505 King Avenue

Columbus, $\mathrm{OH} 43201$

A. J. Rothman, $\mathrm{L}-207$

Lawrence Livermore

National Laboratory

P.0. Box 808

Livermore, CA 94550

J. A. Ruppen

Sandia National Laboratory

P.0. Box 5800

Albuquerque, NM 87185
No. of

Copies

Savannah River Laboratory

Reference Library

Aiken, SC 29801

J. Schornhorst

Westinghouse Electric

Corp., AESD

P.0. Box 10864

Pittsburgh, PA 15326

M. Seitz

Argonne National

Laboratory

9700 South Cass Avenue

Argonne, IL 60439

R. Silva

Lawrence Berkeley

Laboratory

University of California

One Cyclotron Road

Building $70 \mathrm{~A} / 1160$

Berkeley, CA 94720

M. J. Steindler

Chemical Engineering

Division

Argonne National

Laboratory

9700 South Cass Avenue

Argonne, IL 60439

D. B. Stewart

National Center 959

U.S. Geological Survey

Reston, VA 22092

T. T. Vandergraaf

Atomic Energy of

Canada, LTD

W.N.R.E., Pinawa, Manitoba

Canada, ROE 1 LO 
No. of

Copies

J. W. Voss

Office of Nuclear Waste Isolation

Battelle Memorial

Institute

505 King Avenue

Columbus, $\mathrm{OH} \quad 43201$

R. D. Walton

DOE Nuclear Waste

Management and Fuel

Cycle Programs

$N-30$, GTN

Washington, DC 20545

W. B. White

Materials Research Laboratory

Penn. State University

University Park, PA 16802

J. B. Whitsett

DOE Operations office

550 2nd Street

Idaho Falls, ID 8340 I

R. E. Wilems

INTERA, Environmental

Consultants, Inc.

11999 Caty Freeway

Suite 610

Houston, TX 77079

R. F. Williams

Electric Power Research Institute

3412 Hillview Avenue

P.0. Box 104112

Palo, Alto, CA 94303

Wilste Library

U.S. Nuclear Regulatory Commission

Washington, DC 20555
No. of

Copies

T. J. Wolery, $L-202$

Lawrence Livermore National Laboratory

P.0. Box 808

Livermore, CA 94550

ONSITE

4 DOE Richland Operations Office

E. A. Brachen

H. E. Ransom

J. J. Schreiber

M. W. Shupe

13 Rockwell Hanford Operations

W. J. Anderson

M. J. Apted

R. A. Deju

L. R. Fitch

R. J. Gimera

R. N. Gurley

G. K. Jacobs

M. J. Kupfer

E. L. Moore

P. A. Salter

W. W. Schulz

M. J. Sinith

M. I. Wood

Exxon Nuclear Company

S. J. Beard

Joint Center for Graduate Study

J. Cooper

UNC Nuclear Industries, Inc.

F. H. Bouse 
No. of

Copies

5 Westinghouse Hanford Company

D. A. Cantley

L. A. James

R. L. Knecht

J. J. McCown

W. F. Sheeley

73 Pacific Northwest Laboratory

L. L. Ames

W. F. Bonner

D. J. Bradley (20)

L. A. Bray

H. C. Burkholder

D. B. Cearlock

T. D. Chikalla

M. O. Cloninger

D. G. Coles (3)

F. H. Cove

M. G. Foley

J. H. Jarrett

E. A. Jenne

C. 0. Harvey

F. N. Hodges (3)

Y. B. Katayama
No. of

Copies

M. R. Kreiter

K. M. Krupka

W. L. Kuhn

J. L. MCEl roy

J. L. Nelson

R. E. Nightingale

G. L. McVay (3)

J. E. Mendel

L. R. Pederson

R. D. Peters

S. G. Pitman

D. Rai

J. F. Relyea

W. A. Ross

R. J. Serne

J. W. Shade

J. A. Stottlemyre

R. G. Strickert

J. L. Swanson

R. P. Turcotte

H. H. Van Tuy 1

R. E. Westerman (3)

J. H. Westsik, Jr.

Technical Information (5)

Publishing Coordination (2) 